\title{
ESTUDO EPIDEMIOLÓGICO DA DENGUE EM MACEIÓ, ALAGOAS, NO PERÍODO DE 1997 A 2002
}

\section{OZINALDO OLIVEIRA DOS SANTOS}

Tese apresentada ao Departamento de Epidemiologia da Faculdade de Saúde Pública da Universidade de São Paulo para obtenção do Grau de Doutor.

Área de concentração:

Epidemiologia

ORIENTADOR:

PROF. ALMÉRIO DE CASTRO GOMES

SÃO PAULO

2003 
À Deus pela maravilhosa criação.

À memória dos meus pais, meus primeiros educadores, início efetivo da minha vida. "Saudades"

Aos meus irmãos, elo familiar determinante.

À Maria do Carmo(Cau), minha esposa:

Verdadeiro exemplo de amor, companheirismo, dedicação, compreensão, e ilimitado afeto. Simbolo maior de "Estrela Guia".

Obrigado pela capacidade de ter entendido e apoiado de forma irrestrita à minha longa ausência nesse periodo. Divido com voce os louros dessa vitória.

À minha filha Renata, acontecimento inesquecível e fundamental na nossa existencia; a nossa essência, a nossa perpetuação.

Te agradeço pelo carinho recebido nessa ausência. Juntos nesse momento externo a minha eterna gratidão. 
Cau, Re:

\section{"Esperança"}

$\mathcal{N a ̃ o ~ e ́ ~ f a z e r ~ d e ~ c o n t a ~ q u e ~ n u n c a ~ h a ́ ~ q u a l q u e r ~ d e s g o s t o ~}$

É o conhecimento de que os nossos problemas serão passado - amanfiã $\dot{E}$ a força interior que invocamos para nos manter, hoje e sempre Até que os nossos problemas fiquem para trás,

$\mathcal{E}$ já somos felizes - outra vez. 


\section{"VIVER"}

$\mathcal{N a}$ construção da tese, evoluiu o meu ser

$\mathcal{N}$ a construção do meu evoluir, aprendi a ver

$\mathcal{N a}$ reclusão desses dias tive saudades

Levo comigo para sempre a certeza dos amigos paulistanos

Livro escrito na rapidez desses dias marcantes

Me permitam a construção de outra tese: a tese de que ter amigos $e$ família, torna possivel a prova incontestável da superação de todas as dificuldades. 


\section{AGRADECIMENTOS}

-A Universidade Federal de Alagoas, em especial a Pró-Reitoria de Pesquisa e ao Departamento de Zoologia por ter viabilizado a realização desse doutorado.

-Ao CNPq pela concessão da bolsa que foi fundamental para que esse título fosse obtido fora do Estado de Alagoas.

-A Faculdade de Saúde Pública da USP por toda acolhida durante o meu doutorado.

-A todos aqueles que direta e indiretamente contribuíram à realização deste trabalho, em especial:

-Ao Professor Almério de Castro Gomes pela importante orientação, estímulo, apoio, compreensão nos momentos dificeis, e sobretudo pela construção de uma grande amizade e confiança, fruto do nosso convívio.

-A Professora Nilza Nunes da Silva, pela grande amizade, susgestões e inestimáauxilio na parte estatística do tabalho.

-Ao Secretário Estadual de Saúde de Alagoas Dr. Álvaro Antônio Machado pelo apoio recebido.

-Aos técnicos e funcionários da Secretaria de Estado da Saúde de Alagoas, especialmente a Cleide Maria Moreira, Isolda Maria Couto Lima e Celso Tavares, por acreditar no meu projeto de tese e receber apoio irrestrito em todas os momentos necessários.

-Ao Secretário Municipal de Saúde de Maceió Dr. Adeilton Loureiro, pela atenção e liberação de informações relativas a dengue.

-A Dra. Audinei Loureiro e Lúcia Barbosa da Secretaria Municpal de Saúde de Maceió pela apoio recebido no transcurso do meu trabalho.

-Aos funcionários e técnicos da Secretaria Municpal de Saúde pelo apoio recebido.

-A Secretaria Municipal de Controle e Convivio Urbano de Maceió pela liberação do mapa digital de Maceió que foi de grande utilidade na elaboração da minha tese.

- A Dra. Adelaide Reis pela amizade e incentivo ao meu doutorado.

-Aos professores, técnicos e funcionários do Departamento de Epidemiologia da Faculdade de Saúde Pùblica da USP, pelo apoio recebido. 
-Aos funcionários da Seção de Pós-Graduação da Faculdade de Saúde Pública da USP, especialmente a Ângela Maria Pereira Silva pelo apoio e gentileza sempre dedicados.

-Aos funcionários da Biblioteca da Faculdade de Saúde Pública da USP, particularmente as bibliotecárias Ângela Maria Belloni Cuenca e Maria Lúcia Ferraz pelo imprescindivel apoio e orientação bibliográfica.

-Aos amigos José Marcelo de Paula Alves e Lourani Oliveira dos Santos Correia pela amizade, apoio e auxílio relativo as informações sobre dengue.

-Ao grande amigo Professor José Maria Soares Barata, pela amizade construída ao longo desses anos de convivência.

-Ao amigo e incentivador Tarcisio Neves da Cunha por ter possibilitado o uso de análise espacial, confecção de mapas, tabelas e gráficos utilizados em minha tese.

-Ao técnico em informática do Departamento de Epidemiologia, Rodrigo Alexandre Sportello e Theodora de Paiva Pinheiro pela organização, formatação e digitação dos dados de minha tese.

-Ao amigo João Paulo Medeiros, que deu vida aos primeiros parágrafos da minha tese, ainda em terras caetés. 


\section{RESUMO}

Santos O.O. Estudo epidemiológico da dengue no município de Maceió, Alagoas, no período de 1997 a 2002. São Paulo; 2002. [Tese de Doutorado - Faculdade de Saúde Pública da USP].

Objetivos: Descrever a incidência, os fatores entomológicos e os ambientais para análise do perfil epidemiológico da dengue no município de Maceió. Métodos: $O$ estudo compreendeu o período de 1997 a 2002, utilizando-se dados secundários sobre casos da dengue, índice de infestação por Aedes aegypti, temperatura e chuva, obtidos na Fundação Nacional de Saúde e Secretaria de Estado da Saúde de Alagoas. Os coeficientes foram calculados para anos, meses e bairros. $O$ Índice Predial e a chuva foram obtidos mensalmente. Teste de correlação estatística foi empregado para observar associações entre as variáveis chuva, temperatura, incidência e índice de infestação vetorial. Resultados: Os coeficientes de incidência anuais no período de estudo variaram de 3,3 a 65,4 casos por 10.000 habitantes, enquanto que as incidências mensais variaram de 1,1 a 229,3 casos por 100.000 habitantes. Nos anos de 1999, 2000 e 2001, as incidências para dengue no município estiveram em torno de 3,9 casos por 10.000 habitantes. Verificou-se que o maior número de casos notificados ocorreu entre a $9^{\mathrm{a}}$ e $25^{\mathrm{a}}$ semanas epidemiológicas, período referente aos meses de março a junho. As faixas etárias menor de 14 anos; 15 a 49 anos e 50 e mais, mostraram valores diferentes segundo o ano examinado. Análise comparativa entre os anos epidêmicos de 1998 e 2002 mostrou que apenas os meses de março a junho apresentaram coeficientes entre 17,3 a 39,0 casos por 100.000 habitantes. $O$ coeficiente de incidência foi sempre maior no sexo feminino no período. Conclusões: $O$ padrão sazonal da dengue em Maceió revelou níveis de ocorrência mais elevada no primeiro semestre de cada ano. Ficou claro que as condições ambientais favoreceram a endemicidade dos três sorotipos da dengue. A medida da infestação pelo Índice Predial (IP) revelou uma distribuição não homogênea da presença de Ae. aegypti entre os bairros de Maceió.

Descritores: Dengue, Epidemiologia, Aedes aegypti, Coeficiente de Incidência, Densidade vetorial. 


\section{SUMMARY}

Santos O.O. An Epidemiological study concerning dengue in the municipality of Maceió, Alagoas during the period between 1997 and 2002. Sao Paulo; 2002 [ PhD thesis - School of Public Health].

Objectives: To describe the entomological and environmental factors which play a role in the incidence of dengue as well as its epidemiological profile in the municipality of Maceió. Methods: This study analyzes information concerning the notification of cases, the rate of infestation by Aedes aegypti, as well as data concerning temperature and rainfall available within the databank of the National Health Foundation and the Health Department of the State of Alagoas for the period between 1997 and 2002. The coeficientes were calculated according to year, month and neighborhoods. The House Index and pluviometric index were obtained every month. Statistical correlation tests were employed in order to observe the association between the variables rainfall, temperature, incidence and infestation by Aedes aegypti. Results: The coeficients of annual incidence during the study period varied between 3,3 and 65,4 cases per 10,000 inhabitants, while monthly incidence varied from 1,1 to 229,3 cases per 100,000 inhabitants. In the years 1999,2000 , and 2001, the incidence of dengue in the municipality was approximately 3,9 cases per 10,000 inhabitants. It was verified that a greater number of cases notified occurred between the $9^{\text {th }}$ and $25^{\text {th }}$ epidemiological weeks, which corresponds to the period from March to June. Variations occurred with respect to rates of incidence among age groups of people with less than 14 years of age; 15 to 49 years of age; and 50 years of age and older, depending upon the year being examined. Comparative analysis between the epidemic years of 1998 and 2002 demonstrated that only the months from March to June presented coeficients between 17,3 and 39,0 cases per 100,000 inhabitants. The rate of incidence was always higher among females, during the study period. Conclusions: The seasonal pattern of dengue infection in Maceió revealed higher levels of occurrence during the first semester of each year. It became clear that the environmental conditions favored endemic occurrence of the three serotypes of dengue. The rate of household infestation verified by means of the House Index (HI) 
revealed a non-homogeneous distribution of Ae. aegypti, among the neighborhoods of Maceió.

Key words: Dengue, Epidemiology, Aedes aegypti, Incidence Coeficient, Vectorial density. 


\section{INDICE}

1. INTRODUÇÃO 1

1.1. ETIOLOGIA E RELAÇÃO AGENTE-HOSPEDEIRO 2

1.2. O MODO DE TRANSMISSÃO DA DENGUE 3

1.3. FATORES ASSOCIADOS À TRANSMISSÃO DA DENGUE 9

1.4. HISTÓRIA DAS EPIDEMIAS 16

1.4.1. Dengue no Mundo 16

1.4.2. Dengue nas Américas $\quad 17$

1.4.3. Dengue no Brasil 22

$\begin{array}{ll}\text { 1.4.4. Dengue em Alagoas } & 29\end{array}$

2. OBJETIVOS 33

2.1. Objetivo Geral 33

2.2. Objetivos Específicos 33

3. MATERIAL E MÉTODOS 34

3.1. CARACTERIZAÇÃO DA ÁREA DE ESTUDO 34

3.2. REGISTRO DA DENGUE E DA INFESTAÇÃO

$\begin{array}{ll}\text { PELO AEDES AEGYPTI } & 39\end{array}$

- Caso Suspeito de Febre da Dengue 39

- Caso Suspeito de Febre Hemorrágica da Dengue 39

- Infestação Domiciliar pelo Aedes aegypti 40

3.3. ANÁLISE DOS RESULTADOS 41

3.3.1. Análise Estatística $\quad 41$

3.3.2. Análise Espacial 43 
4.1. DISTRIBUIÇÃO DA DENGUE SEGUNDO A IDADE E SEXO 51

4.2. DISTRIBUIÇÃO DA DENGUE POR BAIRRO EM MACEIÓ

4.3. MEDIDA DA INFESTAÇÃO DOMICILIAR POR AEDES AEGYPTI 58

4.4. FATORES CLIMÁTICOS 65

5. DISCUSSÃO 66

6. CONCLUSÕES 76

7. RECOMENDAÇÕES

8. REFERÊNCIAS 79

ANEXOS

Anexo 1 - Casos notificados da dengue segundo local de residência e ano de ocorrência. Brasil e Unidades Federadas, 1980 - 1998.

Anexo 2 - Distribuição dos casos notificados da dengue, segundo o ano de notificação, Unidade Federada e Macrorregião. Brasil - 1982 a 2000.

Anexo 3 - Dengue: Total de casos notificados da dengue por mês e por Unidade Federada. Brasil - 2000.

Anexo 4 -Dengue: Total de casos notificados da dengue por mês e por Unidade Federada. Brasil - 2001.

Anexo 5 - Ficha de notificação da dengue - SINAN - Sistema Nacional de Agravos de Notificação.

Anexo 6 - Ficha de investigação da dengue - SINAN - Sistema de Informação de Agravos de Notificação.

Anexo 7 - Coeficientes de incidência da dengue (Casos notificados / 100.000 habitantes) por semana epidemiológica. Maceió, 1997 - 2002. 
Anexo 8 - Número de casos da dengue por faixa etária, sexo e ano.

Maceió, 1997 - 2002. População por faixa etária, sexo e ano. Maceió, $1997-2002$.

Anexo 9 - Coeficientes de incidência da dengue (Casos por 10.000

habitantes), segundo os bairros. Maceió, 1997 - 2002.

Anexo 10 - Índice de infestação predial de Aedes aegypti, por bairro.

Maceió, $1997-2002$.

Anexo 11 - Coeficientes de incidência da dengue (por 10.000 habs.) por ano. Maceió, $1997-2002$.

Anexo 12 - Coeficientes de incidência da dengue (por 1.000 .000 habs.) por mês e ano. Maceió, 1997 -- 2002.

Anexo 13 - Índice de Infestação Predial (x100) de Aedes aegypti por mês e ano. Maceió, 1997 - 2002.

Anexo 14 - Temperatura por mês e ano. Maceió 1997 - 2002.

Anexo 15 - Precipitação por mês e ano. Maceió, 1997 - 2002. 
1 INTRODUÇÃO 


\section{INTRODUÇÃO}

A dengue é uma doença infecciosa aguda, de etiologia viral, transmitida pela picada de mosquitos vetores, pertencentes ao gênero Aedes e subgênero Stegomyia(Gomes 1986).

A expressão "dengue" que se refere a doença, é de origem hispano-caribenha, usada desde 1827, com o objetivo de identificar sindromes febris epidêmicas. Em suaile africano a doença é conhecida como "Ki denga pepo" que significa ataque doloroso tipo cãimbra, causado por mau espírito. Em português significa "melindre, manha, faceirice" (Figueiredo 1993;Donalisio 1995; Dal Fabbro 1997).

Dal Fabbro em 1997, afirmou que a dengue e sua forma hemorrágica tornaram-se um dos maiores problemas de saúde publica em nível global, é uma pandemia que teve início na Ásia após a segunda guerra mundial, se intensificando nos últimos 16 anos. Doença que já teve registro em mais de 100 países de todos os continentes exceto a Europa, mais de 2 bilhões de pessoas estão sob risco de contrair a doença, anualmente estima-se que ocorrem entre 50 e 100 milhões de casos e entre 250.000 e 500.000 casos da dengue hemorrágica em todo o mundo, com taxas de letalidade que variam entre as regiões (Chiaravalloti Neto 1999). No Sudeste Asiático todos os quatro sorotipos do vírus podem ser encontrados, onde são responsáveis por extensas epidemias. A introdução de um único sorotipo viral na América Central e Caribe, levou à ocorrência de grandes epidemias em 1952, 1963-64, 1977 e 1981. Múltiplos sorotipos do vírus da dengue têm se tornado endêmicos em muitos países da América Tropical e Subtropical, estando regularmente associados a surtos da doença (Medronho 1993; WHO 1998, 2000, 2002). 
Nas décadas mais recentes a dengue se constitui num dos mais importantes problemas para a maioria dos países tropicais pela freqüência de epidemias e endemias e também devido à emergência, expansão geográfica e aumento da incidência da dengue hemorrágica. A cada ano, milhões de pessoas contraem a infecção transmitida pelo virus da dengue em países da Ásia, África, Ilhas do Pacífico e as Américas. Por outro lado, todos os anos são notificados milhares de casos da forma mais grave da dengue. Durante as décadas de 80 e 90, ocorreu, um considerável aumento do problema da dengue nas Américas(PAHO 1994; Rawlins 1999).

\subsection{ETIOLOGIA E RELAÇÃO AGENTE-HOSPEDEIRO}

A etiologia da dengue descrita no início do século passado( Figueiredo 1993), estava associada a um agente infeccioso filtrável como causador da doença. Durante a segunda guerra mundial foram isolados os dois primeiros sorotipos dos vírus da dengue, sorotipos 1 e 2. Na epidemia de dengue hemorrágica ocorrida em Manilha no ano de 1956 foram isolados mais dois sorotipos denominados 3 e 4. Atualmente os agentes etiológicos da dengue são classificados em quatro sorotipos, conhecidos como: Dengue - 1 (DEN-1), Dengue - 2 (DEN-2), Dengue - 3 (DEN-3), Dengue - 4 (DEN-4), todos pertencentes a familia Flaviviridae, gênero Flavivirus (Pontes 1992).

Os quatro sorotipos da dengue formam um subgrupo no gênero Flavivirus. Dentro do critério epidemiológico, os Flavivirus são classificados como arbovirus (Arthropod borne viruses), os seja, vírus transmitidos por artrópodes. Esse gênero possui 68 representantes e tem como protótipo, o vírus da febre amarela. São esféricos, envelopados, medem aproximadamente $60 \mathrm{~nm}$ de diâmetro, possuem RNA e 
estão entre os mais importantes agentes etiológicos de arboviroses no Brasil. Estes vírus possuem capacidade de se multiplicar em diversos organismos, tais como o homem, mosquitos e macaco Rhesus(Gubler 1988; Guzmám e col. 1994; IbãnezBernal e col. 1997; Loroño-Picco e col. 199, Schatzmayr 2001) .

Observa-se que cada sorotipo possue cepas diferentes vistas na mesma região ou distribuídas em vários locais. Estudos realizados tentam identificar e classificar os sorotipos em variantes geográficas (topotipos), pois em função de mutações que ocorrem com o decorrer do tempo, a identificação da origem da cepa presente nas epidemias torna-se importante, além de se procurar verificar a possibilidade de relações entre a virulência e o desenho antigênico de uma cepa. A infecção da dengue causa imunidade completa nos humanos por toda a vida contra a reinfecção pelo mesmo sorotipo (imunidade sorotípica específica), contra os outros a proteção será apenas parcial e temporária (Pontes 1992; Miagostovich e col. 1993; Serufo e col. 1993; Figueiredo 1999; WHO 2001; Rodrigues e col. 2002).

Do ponto de vista clínico, a dengue se caracteriza por apresentar desde formas assintomáticas ou infecções inaparentes, até complicações hemorrágicas de maior gravidade e manifestações graves com choque que podem evoluir para óbito. Pode apresentar duas formas clínicas: Dengue Clássica (DC) e Febre Hemorrágica da Dengue ou Dengue Hemorrágica (FHD, DH) / Síndrome de Choque da Dengue (SCD). A febre indiferenciada da dengue pode se manifestar por uma síndrome viral inespecífica, indiferenciável de outras viroses. A dengue clássica caracteriza-se principalmente por febre abrupta e intermitente, dores osteomioarticulares, cefaléia frontal, artralgia, dor retro-orbital, náusea, vômitos, anorexia, adinamia, manchas na pele e erupções cutâneas, eventos que impedem o paciente de realizar suas atividades 
habituais. A febre pode durar de dois a sete dias, em média cinco dias. Os sintomas respiratórios não são comuns, geralmente apresenta hiperemia de orofaringe. Esta etapa é considerada a fase febril da doença, não sendo possível se diferenciar entre dengue clássica e dengue hemorrágica. A doença tem duração média de dez dias, a febre diminue a partir do quinto dia. É possível ocorrer manifestações hemorrágicas de pequena intensidade como gengivorragia, petéquias, epistaxe.

A febre hemorrágica da dengue caracteriza-se por quatro principais manifestações clínicas: febre alta, fenômeno hemorrágico e freqüentemente hepatomegalia e insuficiência circulatória. A principal alteração fisiopatológica que determina a gravidade na $\mathrm{FHD}$, que diferencia da dengue clássica, é o extravasamento de plasma, manifestado por um hematócrito elevado, uma efusão serosa ou hipoproteinemia. O fenômeno hemorrágico mais comum é a prova do laço positiva, a equimose fácil e o sangramento nos pontos de punção venosa. Presente na maioria dos casos estão petéquias finas e discretas. Ocorrem epistaxe, sangramento gengival, hemorragia gastro intestinal (Clark 1992; Prata e col. 1997; Cunha e col. 1999; WHO 2001).

A síndrome de choque da dengue ( $\mathrm{SCD}$ ), observada nos pacientes que vão a choque, após uma febre que dura de dois a sete dias, as condições orgânicas se deterioram rapidamente, apresentando sinais típicos de insuficiência circulatória: pele fria, manchada, congestionada, cianose perioral, freqüência do pulso torna-se mais rápida, e dor abdominal aguda freqüente. A SCD é geralmente caracterizada por: pulso rápido e fraco, ou hipotensão com a pele fria, úmida e agitação. Os pacientes em estado de choque correm risco de óbito, se o tratamento adequado não for aplicado imediatamente. 
A OMS, classifica a dengue hemorrágica em quatro graus de gravidade, onde os graus III e IV são considerados a sindrome de choque da dengue. Presença simultânea de trombocitopenia e hemoconcentração diferencia os graus I e II da forma hemorrágica do quadro da não hemorrágica.

A classificação em graus de gravidade da doença, foi considerada, no momento da alta, clínica e epidemiologicamente útil nas epidemias infantis de DH nas regiões das Américas, Sudeste da Ásia e Oeste do Pacifico, e as experiências em Cuba, Porto Rico e Venezuela sugerem que a gradação também é proveitosa nos casos de adultos (WHO 2001).

A dengue hemorrágica pode ser causada por todos os sorotipos da dengue, apesar de que tem se observado uma relação mais direta com o Dengue-2, em locais com presença anterior do Dengue-1(Figueiredo 1993; Putnam e Scott 1995).

Estudos realizados mostram que a $\mathrm{DH} / \mathrm{SCD}$, ocorre com maior freqüência em dois grupos susceptiveis na população: pessoas primo infectadas, e pessoas com infeç̧ão secundária ou seqüencial.

No primeiro grupo encontram-se pessoas com primeira infecção por qualquer sorotipo do vírus da dengue. Aqui acomete mais crianças com menos de um ano de idade em surtos da $\mathrm{DH}$; ou crianças e adultos em casos isolados em surtos da dengue clássica. Ainda observa-se em menor freqüência, epidemias de $\mathrm{DH} / \mathrm{SCD}$ em populações susceptiveis aos vírus da dengue.

No outro grupo, pessoas já acometidas por um tipo de vírus e desenvolve nova doença com outro sorotipo viral. O risco aqui se apresenta com maior intensidade, podendo apresentar caráter epidêmico ou endemo-epidêmico (Pontes 1992). 
Quando ocorre a infecção pela dengue, desenvolvem-se mecanismos fisiopatológicos determinando a evolução da doença na direção da dengue clássica ou hemorrágica(Freire e col. 2000). Os fatores envolvidos nesta fisiopatologia são explicados na literatura, através de hipóteses cientificas como:

A hipótese denominada Teoria da Infecção Seqüencial (Pontes e col. 1991; Figueiredo 1993; Pontes e Ruffino-Netto 1997), é aquela que em indivíduos submetidos a infecção por qualquer tipo de vírus da dengue, venham a ter nova infecção por estes vírus e desenvolvam quadro de DH/SCD. Outra situação de risco para $\mathrm{DH} / \mathrm{SCD}$, ocorre em menores de um ano com primo infecção pela dengue, e foram gerados a partir de mães que tiveram a doença e ocorreu a transferência de vírus através da placenta. Nestes casos, ocorre o processo denominado Antibody Dependent Enhacement - ADE, assim presença na circulação de anticorpos heterotípicos, leva a formação de complexos antígeno-anticorpo não neutralizantes, que se ligando a receptores $\mathrm{Fc}$ da membrana celular, facilitam para que os vírus penetrem no interior de vários fagócitos mononucleares, que são reconhecidos como importantes sítios de replicação dos vírus da dengue, os quais possuem tropismos por estas células. Portanto, a base fisiopatologica para a DH/SCD, seria uma resposta imune anômala, envolvendo leucócitos, citocinas, e imuno complexos (anticorpos antidengue e vírus), causando aumento da permeabilidade vascular, queda de pressão arterial e as hemorragias características.

A outra hipótese diz respeito a indivíduos primo infectados que apresentam quadros de DH/SCD, e são portadoras de cepas mais virulentas dos vírus da dengue, não sendo preciso infecções anteriores por outros sorotipos da dengue (Figueiredo 1993). 
As bases fisiopatológicas da DH/SCD mais moderna, englobam as hipóteses citadas anteriormente, além de fatores de risco associados as inter-relações entre hospedeiro, agente etiológico, vetor e ambiente antrópico (Pontes1992; Service 1992; Figueiredo 1993; Donalisio 1995).

\subsection{O MODO DE TRANSMISSÃO DA DENGUE}

Os elos que fazem parte da cadeia de transmissão incluem: homem infectado, agente etiológico (Dengue-1, 2, 3 ,4), mosquito vetor e o homem suscetível. A dengue é transmitida ao homem por algumas espécies de mosquitos do gênero Aedes, como: Aedes albopictus, Aedes polinesiensis, espécies do complexo Aedes scutellaris, dentre outros. A única espécie que transmite a dengue no Brasil é o Aedes aegypti. Além do homem, não se conhece nenhum outro hospedeiro de importância significativa que atue como reservatório e fonte de infecção. Já foram isolados virus da dengue em macacos naturalmente infectados, podendo atuar como reservatórios em zonas ocidentais da Malásia e África ( Milby e Reisen 1989; Medronho 1993; Thavara e col. 1996; Albuquerque e col. 2000).

Somente as fêmeas do mosquito se alimentam de sangue, necessário para o amadurecimento dos óvulos, e picam de preferência durante o dia. Sua antropofilia não é restrita, alimenta-se em outros animais na ausência do homem. Após cinco a seis dias em que o individuo foi picado por mosquito infectado (periodo de incubação intrínseco), desenvolve uma viremia, junto com os primeiros sintomas da doença. A viremia dura por quatro ou cinco dias, período no qual outro mosquito pode se contaminar alimentando-se do sangue. No mosquito ocorre o que se denomina período de incubação extrínseco, que dura de oito a dez dias, no qual o vírus se 
multiplica no interior dos tecidos, daí atingindo as glândulas salivares, o que torna o mosquito infectante para o homem, podendo assim permanecer pelo resto da vida (Gadelha e Toda 1985; Reisen 1989; Medronho 1993; O'meara e col. 1995; Trpis e col. 1995; Pereira 1997; Rawlins 1998; Augusto e col. 2000; Perich e col. 2000; Campos e Andrade 2001).

Observa-se que o período de incubação extrínseco e o comportamento do vetor, em relação a sua voracidade, são influenciados por condições climáticas (Glasser e Gomes 2002). O aumento da temperatura e umidade relativa do ar influenciam o ciclo reprodutivo do vetor, tornando-o mais rápido, sobretudo refletindo na abundância de fềmeas, bem como, na intensidade da hematofagia. Também, esta última atividade pode aumentar o número de mosquitos infectados favorecendo a disseminação do vírus. Os dois fatores fisicos conduzem para que a densidade do mosquito sofra variações sazonais, com maior concentração nas estações chuvosas e quentes, e diminuição em períodos secos e temperaturas mais baixas(Silveira 1998; Thu e col. 1998; Calado e Silva 2002).

A possibilidade de transmissão transovariana do vírus da dengue entre as gerações de mosquitos, permite manter os vírus no meio ambiente, mesmo na ausência ou dimiuição do número de susceptiveis, não se sabendo ainda, a duração deste período de manutenção do virus no ambiente; fato que amplia as possibilidades dos mecanismos de transmissão e dificulta as ações de controle da dengue (Medronho 1993). 


\subsection{FATORES ASSOCIADOS À TRANSMISSÃO DA DENGUE}

Dentre os fatores ligados à transmissão, temos: fatores relacionados aos vetores, ao vírus e ao homem. Dal Fabbro 1997, divide os determinantes do surgimento da doença em macrodeterminantes, que são os riscos ambientais e sociais, e microdeterminantes os associados ao hospedeiro, agente e vetor. Entre os fatores que contribuem para o desenvolvimento e manutenção do vetor numa região, bem como para a elevação dos níveis de densidade das populações de Aedes aegypti durante periodos do ano, estão incluídos os fatores climáticos, principalmente temperatura, umidade e índices pluviométricos. O clima representa fator importante na transmissão da dengue. Determinadas regiões possibilitam a endemização do vírus, ao passo que outras mostram, periodicamente, interrupções na circulação da doença. Variações climáticas devem também promover alterações genéticas nas populações dos vetores, alterando o comportamento e portanto, sua capacidade vetorial. A elevação da temperatura influi diretamente na velocidade de multiplicação viral, afetando a dinâmica de transmissão da dengue (Pereira 2001). A temperatura como fator ambiental, influencia a transmissão e a infestação vetorial. Estudos levados a efeito sobre a temperatura (Kuno 1995; Dal Fabbro 1997) sugerem que a dengue é transmitida em temperaturas acima de $20^{\circ} \mathrm{C}$ e nunca abaixo de $16^{\circ} \mathrm{C}$. Porém a temperatura ideal para transmissão seria entre 30 e $32^{\circ} \mathrm{C}$, o período de incubação extrínseco no vetor seria mínimo e a infectividade máxima, dados que poderiam explicar a variação sazonal da incidência da dengue, com diminuição nos meses frios, nos locais de climas tropicais onde observa-se variação de temperatura entre o verão e o inverno. A influência das chuvas no aumento dos indices vetoriais, é também observada em países tropicais; apesar de que em lugares onde ocorrem pouca chuva, 
tem-se epidemias de dengue, como na Tailândia e Cingapura (Hornby e col. 1994; LLoyd e col. 1994; Kuno 1995; Marquetti e col. 1995; Chadee e Beier 1997; Jetten e Focks 1997; Winch 1998; Teixeira e col. 1999; Honório e Oliveira 2001).

A análise da influência das chuvas sobre o vetor e transmissão da dengue, deve ser cautelosa, na medida em que a chuva atua diretamente sobre imaturos do vetor, permitindo maior sucesso nesse período de vida, e daí um aumento nos valores dos indices larvários. Portanto, não existe relação simultânea entre os índices e a população de fềmeas adultas, dos vetores envolvidos na transmissão, pois são as fêmeas que efetivamente transmitem a doença. A vigilância entomológica (Chiaravalloti Neto 1993; Pereira 1996; Dal Fabbro 1997; Edman e col. 1997; Gomes 1998), atua com o conceito estratificado de risco, assim assume papel importante no acompanhamento da ocorrência das epidemias da dengue, além de outras doenças virais. Esta vigilância orienta as intervenções nos ciclos de transmissão destas doenças, avalia as medidas de controle adotadas, monitora as populações de vetores quanto à presença, distribuição e abundância, além de auxiliar no desenvolvimento de métodos educativos e de participação comunitária. Para isto, depende do conhecimento de indicadores dos vetores, expresso através dos índices entomológicos, os quais medem os níveis de infestação destas populações e servem para avaliação de risco à transmissão da dengue(Perez Diaz e Fuentes Gonzalez 1990; Tun-Lin e col. 1996; Sherman e col. 1998; Yasumano e col. 1998; Freimuth e col 2000; Andrade e col. 2001).

Os índices entomológicos mais utilizados, tanto pela praticidade como reprodutividade, são os que utilizam procedimentos de amostragem de larvas e são denominados de: Índice Predial, Índice de Recipiente e Índice de Breteau (Alves e 
col. 1991; Winch e col. 1992; Montesano-Castellanos e Ruiz Matus 1995; Tun-Lin e col. 1995; Tun-Lin e Barnes 1995; Focks e Chadee 1997;Gomes 1998; Espinosa Gomez e col. 2000; Alves e Silva 2001).

No índice predial se calcula a percentagem de prédios infestados com larvas de Aedes aegypti e Aedes albopictus. Usado para medir os níveis populacionais dos vetores, nạo leva em conta o número de recipientes positivos por casa, nem a produtividade de cada recipiente, mas a sua utilidade é considerada pois fornece a percentagem de casas, prédios ou edificios positivos.

$\mathrm{O}$ índice de recipiente mede a percentagem de qualquer recipiente com água onde são encontradas larvas dos vetores citados.

Com este índice, obtém-se apenas o número e os tipos de recipientes positivos, sem considerar suas produtividades.

O Índice de Breteau, por sua vez, mede a percentagem de recipientes positivos com larvas por casa. Tem sido o mais usado, apesar de que também não leva em conta a produtividade dos habitats( Alves e Silva 2001).

A análise da literatura mostra que estes índices são recursos rotineiramente usados, apesar das limitações observadas e dúvidas existentes quanto ao momento adequado na utilização das ações preventivas. Além disto, são maus estimadores da densidade populacional de adultos, pois baseiam-se apenas na positividade dos recipientes para formas imaturas. Assim, duas regiões podem apresentar índices semelhantes, porém o risco potencial se diferencia em função dos tipos de criadouros, devido a capacidade de produção de adultos. Mesmo assim, os programas de controle da dengue continuam a fazer uso da informação obtida dos índices, acerca da 
distribuição e intensidade de infestação dos vetores(Chan e col. 1971; Nathan e Knudsen 1991; Sulaiman e col. 1996; Macoris e col. 1997; PAHO 1997; Tandon e Ray 2000).

A história da dengue, mostra uma doença originária da Ásia, endêmica, e de ambiente rural, transmitida pelo Aedes albopictus(Albuquerque e col. 2000). Com o processo de urbanização teria encontrado o mosquito Aedes aegypti, já domiciliado, e daí se dispersando neste ambiente(Kuno 1995). Com o processo de urbanização crescente que se observa nos nossos dias tem ocorrido o aumento da incidência da doença, dado a exposição de grandes contingentes populacionais, portanto população susceptível, ao contato com o principal vetor Aedes aegypti, e aos sorotipos virais da dengue. O tamanho populacional das cidades, expresso pela densidade demográfica, parece ser fator importante na dinâmica de transmissão da doença, pois em cidades pequenas, após epidemia da dengue, se observa tendência ao desaparecimento da transmissão, dado que a resposta imune (imunidade adquirida) populacional e a pouca circulação de pessoas, seriam pontos fundamentais para este evento. Fato oposto ocorre em cidades maiores, com mais de 150 mil habitantes, a doença tende a tornarse endêmica após período epidêmico (Kuno 1995).

Rodriguez-Figueroa e col. 1995, pesquisaram fatores de risco domiciliares como: pessoas por cômodo, proporção de cômodos com telas, tipo de material usado na construção, água estocada em tambores, frequêencia de uso de inseticidas no domicilio, entre outros, e verificaram que a relação entre o número de fềmeas de Aedes aegypti por morador, foi o único fator associado a dengue.

Trabalhos relativos à produção de conhecimentos sobre a dengue e seus mecanismos de transmissão (Tun-Lin e col. 1995; Chiaravalloti Neto 1997; Dal 
Fabbro 1997; Macoris e col. 1997; PAHO 1997), abordando as características culturais e comportamentais das populações envolvidas, mostram que tais conhecimentos levam a interpretações e atitudes diferentes em relação à doença. Observa-se que, apesar dos conhecimentos adquiridos nas campanhas educativas sobre a doença, além de medidas de proteção e controle; não se demonstrou ainda que o saber se transforme em procedimentos preventivos. Esta aparente contradição pode estar associada às campanhas que tem sido elaboradas e aplicadas, com pequena ou mesmo nenhuma participação da comunidade. Assim sendo, o entendimento da cadeia de transmissão por parte da população, torna-se secundário diante das atitudes dos Órgãos de Saúde que privilegiam medidas de caráter curativo do que preventivo.

Observa-se que, certas crenças e práticas da população, aliadas à condição sócioeconômica da mesma, influencia na transmissão da dengue, uma vez que hábitos domiciliares de se manter vasos de flores, plantas aquáticas, tendem a manter focos permanentes de Aedes aegypti no ambiente doméstico, tornando-se fatores de risco, principalmente para as pessoas que passam boa parte do dia nestes locais, como mulheres e crianças (Chadee 1990, 1997; Dal Fabbro 1997; Costa e Natal 1998; Santos 1999; Teixeira e col. 1999; Dégallier e col. 2000).

A larga produção industrial moderna, de recipientes descartáveis (pneus, latas, garrafas, artefatos de plásticos) e a incorreta disposição final, ao lado do destino inadequado dado aos resíduos sólidos nas grandes cidades, que são abandonados em quintais, ao longo das vias públicas, nas praias, terrenos baldios, em córregos poluidos e esgotos a céu aberto, têm contribuído para a proliferação do inseto transmissor da dengue( Moore 1990; Nobre e col. 1994; Focks e col. 1995; Tun-Lin e col. 1995; Costa 1996; Mazine e col. 1996; Donalisio 1999). 
O aumento expressivo do descarte de pneus usados no meio ambiente, sem uma solução que evite transformá-los em criadouros de vetores, têm contribuído para a proliferação e disseminação destes transmissores (Ko e col. 1992; Nobre e col. 1994; Chiaravalloti Neto 1996; Lopes e Lozovei 1996; Suleman e col. 1996;Cardoso e col. 1997; Forattini e col. 1997, 2001; Edman e col. 1998; Vezzani e col. 2001; Löwenberg e Navarro 2002 ).

Com relação ao vírus da dengue, em face do aumento numérico e da rapidez do tráfego aéreo, comercial e terrestre, tem sua distribuição facilitada amplamente pelo intercâmbio de pessoas virêmicas, entre cidades, países e continentes. Portanto, este fator associado a ineficácia dos programas de controle do vetor dificultam a obtenção de um nível de proteção adequado das comunidades (Gubler e Costa-Valez 1992; Dal Fabbro 1997; Kaul e col. 1998; Tauil 2001).

A dengue ocorre predominantemente no ambiente urbano, apesar de que não é incomum o seu registro em área rural, onde se encontra o vetor nas residências. A circulação de pessoas nos espaços geográficos auxilia a disseminação da doença tanto em áreas endêmicas quanto em áreas indenes, através de pessoas viremicas ou denominadas fontes de infecção. Observa-se que, na transmissão domiciliar, a dengue apresenta um padrão de aglomerado ("Cluster"), ou seja, familias com um caso inicial de dengue, apresentarão maior risco de ter a doença do que a população em geral. Fato que pode ser explicado pelo hábito hematofágico das fềmeas de Aedes aegypti sugarem várias pessoas até que complete sua alimentação sangüínea. Em localidades onde ocorre a transmissão da doença, a probalilidade de um indivíduo ser picado por mosquito infectado varia dentro desses ambientes. Em situações com altos índices vetoriais, predomina transmissão homogênea. Porém, quando os niveis de densidade 
vetorial são baixos e a imunidade exerce papel de proteção, verifica-se que a transmissão ocorre em focos, agregados ou "Clusters", determinada por uma complexa e dinâmica rede de contatos homem - vetor. Logo esses fatores modulam a transmissão explicando os padrões diferenciados segundo as realidades locais. Em localidades pequenas, a epidemia da dengue pode ter inicio por foco simples, enquanto que localidades maiores, a transmissão ocorre por vários focos, e daí alcançando toda a coletividade ( Dal Fabbro 1997).

A forma de organização social do espaço nos centros urbanos atuais, é de "inchaço populacional", resultante das mudanças demográficas ocorridas nos países subdesenvolvidos a partir da década de 60 , com intensos fluxos migratórios rurais urbanos. O modo de vida das populações, em locais onde as condições sanitárias são deficientes, ou seja, particularmente nas áreas mais pobres, onde os sistemas de abastecimento são inadequados, com fornecimento de água intermitente, insuficiente, ou mesmo inexistentes, as populações ai residentes, necessitam armazenar água para consumo, e o fazem em vários tipos de recipientes como vasilhames, tambores, latas, barris, dentre outros, tornando-se posteriormente criadouros para a proliferação de vetores. Os hábitos culturais dos indivíduos de classe soócio-econômica mais elevada também mantém no ambiente doméstico, ou perto deste, muitos criadouros que têm diferentes utilidades, pois em geral, são destinados à ornamentação (vasos de plantas com água) ou tanques para armazenamento de água tratada (Knudsen e Slooff 1992; Chiaravalloti Neto 1993, 1997; Barrera e col. 1995; Dal Fabbro 1997; Santos 1999; Teixeira e col. 1999; Tauil 2001). 


\subsection{HISTÓRIA DAS EPIDEMIAS}

\subsubsection{Dengue no Mundo}

Os primeiros relatos clínicos e epidemiológicos potencialmente compatíveis com dengue, são encontrados em enciclopédia chinesa datada de 610 d.C. Ao longo dos três últimos séculos (Osanai 1984; Pontes 1992; Medronho 1993; Gubler e Clark 1994; Dal Fabbro 1997; Teixeira e col. 1999; WHO 2001), tem-se registrado a ocorrência da dengue em várias partes do mundo, com pandemias e epidemias isoladas, atingindo as Américas, África, Ásia, Europa e Austrália. Relatos na literatura, de epidemias semelhantes a dengue, são do ano de 1779 em Jakarta, Cairo, Egito e Indonésia. Em 1780, Benjamin Rush, descreveu pela primeira vez clinicamente esta enfermidade, durante epidemia verificada na Filadélfia, EUA. Ocorreram no mundo oito pandemias com duração de três a sete anos, no periodo entre 1779 e 1916 (Serufo e col. 1993).

Ao longo do século XIX e início do século XX, registraram-se epidemias da dengue de grande magnitude em várias partes do mundo: Zanzibar $(1823,1870)$, Calcutá $(1824,1853,1871,1905)$, Índias Ocidentais (1827), Hong Kong (1901), Austrália (1925-1926), Grécia (1927-1928), Japão $(1942,1945)$.

Durante a maior parte do século XIX, as manifestações causadas tanto pelo vírus do gênero Chikungunya, como do gênero Flavivirus (vírus da dengue), foram generalizadas e denominadas de "febre da dengue". A luz dos conhecimentos atuais, não são consideradas como descrições de uma mesma nosologia. Ainda neste século, em 1827, epidemias ocorreram na região do Caribe, no Texas, Flórida, e Costa Attântica dos EUA, Cuba e Austrália. Em 1904, extensa epidemia no Panamá. Citam- 
se ainda, pandemias no Caribe e Golfo do México: 1827-28, 1850-51, 1879-80, 189799, 1905-07, 1922, 1934-38,1941-46, 1963-64, 1968-69(WHO 2001).

No início do século XX, ocorreu na Grécia (1928), epidemia de dengue de grande magnitude com aproximadamente 650.000 casos em Atenas e Piraeus, e cerca de 1.061 óbitos. Verificou-se um percentual de 13 e $27 \%$ de prevalência de indivíduos soropositivos para dengue 1 e 2 , sendo possivelmente a primeira epidemia da dengue hemorrágica registrada.

$\mathrm{Na}$ segunda metade do século $\mathrm{XX}$, após a segunda guerra mundial, começaram a surgir casos mais sérios da dengue, em nível endêmico, nas Filipinas, Tailândia e países do Sudeste Asiático, verificando-se que eram casos de uma nova forma da dengue, sendo denominadas de DH e SCD. Modifica-se o conceito de que a dengue era doença benigna e de baixa letalidade. Medronho 1993, sugeriu que a dengue hemorrágica não era doença nova, e que epidemias com sintomas semelhantes de hemorragia severa e choque já tinham sido descritas em Queensland, 1897, Durban, África do Sul, 1927 e Formosa, 1931.

Registros de epidemias por dengue hemorrágica se sucederam, deste período até os nossos dias, em vários países do Sudeste Asiático, Índia, Sri Lanka, Leste da China, Austrália, Nova Guiné, Havaí, Taiti, Ilhas Fiji, Vietnã do Sul, Cingapura, Malásia, Indonésia e Birmânia (Donalisio 1999).

\subsubsection{Dengue nas Ámericas}

A expansão geográfica das epidemias da dengue e dengue hemorrágica, e a distribuição dos vetores para este continente (Leontsini e col. 1993; Medronho 1993; Phillips e col. 1993; Serufo 1993; Gubler e Clark 1994,1996; Barrera 1995; Clark 
1995; Lifson 1996; OPS 1996; Dal Fabbro 1997; WHO 2001), praticamente livre da dengue hemorrágica antes da década de 1980, contribuíram para que ocorressem epidemias em Cuba (1981), Venezuela (1989-90, 1995), América Central (1995), Brasil (1990-91, 1994, 2001-02) e vários outros países das Américas. A hipótese que se coloca como ponto central é o fenômeno relacionado com a expansão do comércio mundial neste período, entre o Sudeste Asiático e o resto do mundo. Outras razões colocadas, para explicar o aumento da transmissão da doença, citam-se: aumento das viagens aéreas internacionais, propiciando maior e mais rápida circulação de indivíduos virêmicos de áreas com transmissão para áreas indenes; dificuldades operacionais nos grandes centros urbanos, nas atividades de combate ao vetor, permitindo a proliferação do mosquito e conseqüentemente condições para transmissão da doença; hábitos culturais modernos, com o aumento progressivo da utilização de descartáveis industrializados, que servem como criadouros potenciais para o vetor; reinfestação de grande parte da América Tropical pelo vetor; problemas relacionados com o sistema de abastecimento de água inadequados e intermitentes; dificuldades na disposição adequada do lixo nos grandes centros urbanos; crescente aumento populacional nas cidades, expondo esse contingente ao contato com os vírus da dengue; dificuldade de respostas rápidas para o controle de epidemias, em razão das precárias condições de funcionamento dos serviços públicos dos países em desenvolvimento.

A dengue como entidade clínica é conhecida há pelo menos 200 anos nas Américas. O primeiro relato da dengue ocorreu na Filadélfia, EUA em 1780, descrito como "febre quebra-osso", seguindo-se diversas epidemias registradas no Caribe desde 1827. A primeira pandemia tendo como referência critérios clínicos- 
epidemiológicos aconteceu nas Antilhas-Golfo do México - Atlântico, em 1827-28. A partir daí, até a década de 1950, aconteceram outras epidemias intercaladas por anos de silêncio (Pontes 1992; Medronho 1993; Serufo 1993; Gubler e Clark 1994, 1996; Dal Fabbro 1997).

O transporte de navios do Caribe e Sul dos EUA para diversas partes do mundo, contribuiu para ocorrência de varias epidemias. Ainda em 1827, epidemia iniciada nas Ilhas Virgens, se disseminou para Cuba, Jamaica, Venezuela, Estados Unidos da América e México. Nos anos de 1848-50, epidemias atingiram Havana, Nova Orleans e outras cidades; em 1879-80 a região do Caribe, Cuba, Panamá, Porto Rico, Ilhas Virgens e Venezuela (Dal Fabbro 1997).

Em 1885-86, extensa epidemia acometeu a cidade de Austin, Texas, em seguida outras epidemias ocorreram em Houston, Brownsville, Galveston, nos EUA. Países como Nassau, Bermudas, Cuba, Panamá, Porto Rico, Venezuela e Ilhas Virgens, também foram acometidos por epidemias da dengue. Do período que vai de 1921 até 1950 , nova epidemia de grande magnitude voltou a ocorrer no Texas, para em seguida chegar as cidades de Louisiana, Flórida e Geórgia nos EUA, e depois países do Caribe (Dal Fabbro 1997).

As epidemias referidas anteriormente, foram documentadas baseadas em critérios clínicos e epidemiológicos, denominado "período de diagnóstico prélaboratorial". Com a evolução dos conhecimentos científicos observada nas últimas décadas, tornou-se possível a utilização de técnicas laboratoriais para o diagnóstico dos diversos grupos de sorotipos virais existentes, particularmente os vírus da dengue. Desta forma, tal conhecimento, permitiu para que no início da década de 1950, fosse identificado pela primeira vez o sorotipo 2 em Trinidad, Caribe. Novamente em 1963- 
64 e 1968-69, duas novas epidemias acometem o Caribe, desta vez isolou-se o sorotipo 3 em Porto Rico, e ambos sorotipos passam a ser endêmicos na região. A introdução do sorotipo 1 na Jamaica em 1977, levou a ocorrência de grandes epidemias em vários países do Caribe. Pela primeira vez é identificado o sorotipo 4 em 1981, com epidemias no Caribe, América Central, México e Norte da América do Sul (Pontes 1992).

A década de 1980, é marcada por uma grande distribuição da dengue nas Américas, com a presença dos sorotipos 1, 2 e 4 envolvidos em várias epidemias nos seguintes paises: Bolívia, Equador, Peru, Brasil, Cuba, Paraguai e Venezuela (Dal Fabbro 1997).

O evento mais importante da epidemiologia da dengue nas Américas, foi a ocorrência do primeiro registro epidêmico da dengue hemorrágica e síndrome de choque da dengue, em maio de 1981 em Cuba, com extensa epidemia, onde foram registrados 344.203 casos, dos quais 10.312 foram classificados como forma grave da doença, segundo classificação da Organização Mundial de Saúde, com 116.143 internações hospitalares, 158 óbitos por dengue hemorrágica (sendo a principal faixa etária menores de 15 anos, com 101 óbitos e 57 óbitos na população adulta) (WHO 2001). O sorotipo 2 do vírus da dengue foi isolado do soro de indivíduos doentes, como também do vetor Aedes aegypti. Esta epidemia foi controlada em quatro meses, causando efeitos nefastos sobre a população humana na história das Américas. Este país já havia experimentado epidemia da dengue clássica pelo sorotipo 1 em 1977, quando $40 \%$ da população foi atingida pela doença. Em 1997, Cuba volta a sofrer epidemia da dengue pelo sorotipo 2 , com alguns casos de dengue hemorrágica, após vários anos em que se manteve a doença sob controle (Dal Fabbro 1997). 
Merece destacar o fato de que antes da epidemia de Cuba por DH/SCD só haviam registros esporádicos desta modalidade da dengue em Curaçao, 1968; Porto Rico, 1975; Jamaica, 1977; Honduras, 1978. A partir daí, observou-se importante mudança no comportamento epidemiológico da dengue nas Américas, acometendo cada vez um maior número de países (Pontes 1992).

Nos anos de 1989 e 1990, é a vez da Venezuela surgir nos registros de epidemia de DH/SCD, presença dos sorotipos 1, 2 e 4, um total de 8.619 casos e 117 óbitos, dois terços dos casos ocorreram em crianças menores de 14 anos, sendo considerado o segundo episódio mais grave nas Américas. Em 1994 aparece a Nicarágua com epidemia, onde foram notificados 20.469 casos, sendo 1.247 de dengue hemorrágica, presente sorotipo 3, que esteve ausente das Américas desde 1978. Neste mesmo ano, aparece o Panamá, também com tipo 3 do vírus da dengue (Dal fabbro 1997).

Na década de 1990, o quadro epidemiológico das Américas e Caribe agravouse, e epidemias da dengue clássica são freqüentemente observadas em vários centros urbanos, muitas delas junto com casos da dengue hemorrágica. Atualmente os quatro sorotipos estão presentes neste continente. Em 1998, 17 países notificaram casos da dengue nas Américas, com proporção variável de casos hemorrágicos, no total de aproximadamente 755.217 mil casos de DC/FHD/SCD. Os países que mais notificaram casos da dengue foram os seguintes: Brasil (559.285 casos da dengue; 105 casos de DH/SCD), Colômbia (63.182 casos da dengue, 5.171 casos de $\mathrm{DH} / \mathrm{SCD})$, Venezuela $(37.586 ; 5.723)$, México $(23.639 ; 372)$, Honduras $(22.218 ; 18)$, Porto Rico (17.241; 173), Nicarágua (13.592; 432), Republica Dominicana (3.049; 176), Trinidad $(3.120 ; 136)$, Jamaica $(1.551 ; 42)$, Guatemala $(4.655 ; 2)$, El Salvador 
$(1.688 ; 2)$, Panamá, Belice, Guiana Francesa, H. Lucia, Suriname $(4.411 ; 15)$ (Fouque e col. 1995; Mazzarri e col. 1998; Teixeira e col. 1999; Valdés e col. 1999).

As variações de casos hemorrágicos, podem ser devido a vários fatores, dentre eles: número de sorotipos e o tempo de circulação em cada espaço; magnitude das epidemias da dengue clássica anteriores e atuais, determinando o estado imunológico das populações expostas a novas infecções; diferenças genéticas entre as cepas; atributos individuais ligados a raça e idade dos indivíduos; e a qualidade e cobertura dos sistemas de saúde, associado a capacidade de funcionamento dos sistemas de Vigilância Epidemiológica de cada país.

O surgimento de epidemias da dengue hemorrágica / síndrome de choque da dengue nas Américas, a circulação simultânea de vários sorotipos virais, o aumento de infestação por Aedes aegypti e Aedes albopictus nas cidades, o registro endemoepidêmico da dengue clássica em inúmeros países, indicam que a doença esteja se desenvolvendo neste continente à semelhança do Sudeste Asiático nos anos cinqüenta (Gubler e Clark 1994, 1996; Donalisio 1999).

\subsubsection{Dengue no Brasil}

Os dados referentes à distribuição da dengue no Brasil, (Osanai 1984; Schatzmayr e col. 1986; Nogueira e col. 1990, 1993, 1995; OPS 1992; Pontes 1992; Figueiredo 1993; Leontsini e col. 1993; Medronho 1993; Gubler e Clark 1994; Zagne e col. 1994 ; Donalisio 1995; Dal Fabbro 1997; Teixeira e col. 1999; Santos 2000; Ministério da Saúde 2002; Anexos 1,2,3,4), datam de 1846 sobre epidemias no Rio de Janeiro, São Paulo, Salvador e outras cidades. A partir daí até 1923, registram-se epidemias em São Paulo e Niterói, e um período seguinte sem registro até a década de 
80. O registro para Niterói, Rio de Janeiro, em 1923, baseou-se em critérios clínicos para os casos observados da dengue. $O$ encontro de soros positivos para dengue (DEN-1, DEN-2), em inquérito na Amazônia em 1953-54, em indivíduos maiores de 25 anos, mostrou a presença de vírus da dengue na região, indicando talvez possível presença da dengue em épocas anteriores à 1930, quando o Aedes aegypti ainda se encontrava presente na região.

O Programa de Controle e posterior Erradicação da Febre Amarela no pais em curso no período, influenciou positivamente no desaparecimento da dengue, pois o combate ao Aedes aegypti, vetor da febre amarela como também da dengue, levou a sua erradicação em 1955, do território nacional juntamente com mais 18 países do continente. Reintroduções sucessivas deste vetor no Brasil, acabaram por influenciar a entrada definitiva no ano de 1976 pelo litoral paraense e em seguida pelos portos de Salvador (Bahia) e Rio de Janeiro, não seguindo o caminho de propagação pelas fronteiras imediatas do norte do país. Também em 1976, o vetor foi encontrado no porto de Santos (São Paulo), porém logo eliminado. A partir da década de 80, a sua expansão para outros estados foi progressiva e não controlada, passando a reinfestar o território nacional.

Considerando-se um risco a reurbanização da febre amarela no Brasil, a dengue acabou prevalecendo, e se instalando por todo pais. Após quase 60 anos ausente da literatura médica no Brasil, e seguindo a expansão da dengue nas Américas, surge com força em Boa Vista, Roraima, no ano de 1981.

A primeira epidemia com registro clínico e laboratorial da dengue clássica, ocorreu em 1981-82 em Boa Vista, com os sorotipos dengue-1 e 4, e ocorrência de 11.000 casos segundo estimativas, com taxa de incidência da doença de $22,6 \%$. A 
transmissão autóctone da doença teve grande impacto epidemiológico. Possivelmente foi reflexo da expansão da onda epidêmica que atingiu vários países do Caribe e Norte da América do Sul nos fins da década de 70. Medidas de controle realizadas pela antiga SUCAM - Superintendência de Campanhas de Saúde Publica - e o relativo isolamento geográfico-econômico da cidade, contribuíram para a não expansão da doença para regiões vizinhas. Além do mais, não se verificou processo de "endemização" da dengue em Roraima (Osanai 1984).

A continuidade da presença da dengue no Brasil, não se deu pelas fronteiras do estado de Roraima. No extremo Norte a doença não ocorreu. Até 1986 não houve notificação da doença no pais. A continuidade de expansão da dengue, seguiu caminhos próprios da realidade nacional, reaparecendo no Rio de Janeiro no ano de 1986, área de intensa movimentação do comércio e riqueza que ligam as regiões Sudeste e Nordeste do Brasil (Donalisio 1995).

No ano de 1986, foi então detectada epidemia da dengue no estado do Rio de Janeiro (Nova Iguaçu) de grande magnitude, pelo sorotipo 1 da dengue, onde foram notificados 93.910 casos da dengue, apesar de inquéritos epidemiológicos realizados, estimarem a sensibilização de mais de 1 milhão de pessoas na referida epidemia. Região de grande concentração populacional, com problemas de infra-estrutura urbana, densamente povoada e localizada no eixo de intenso comércio, e fluxo populacional por atividades econômicas e turísticas (Serufo e col. 1993).

As verdadeiras dimensões da epidemia não foram conhecidas. Um número significativo de casos passou sem ser detectado, contribuíram para isto possivelmente as características clínicas "benignas" da dengue clássica; o difícil diagnóstico diferencial de outras doenças febris, e dificuldades do sistema de notificação e 
vigilância epidemiológica do estado do Rio de Janeiro (Donalisio 1995). A partir deste evento, observou-se a propagação do processo epidêmico pelo mesmo sorotipo para outros estados do País, registrando-se ainda neste ano, transmissão autóctone em Alagoas e Ceará.

No estado do Ceará, a epidemia evoluiu até novembro de 1987, com notificação de 26.786 casos, com taxa de incidência de 138,1 casos por 100.000 habitantes. Neste ano, o vetor era encontrado em 82 cidades do interior cearense. A transmissão teve continuidade durante a década de 80 e início dos anos 90 , ainda com casos envolvendo o sorotipo 1. Ainda em 1987 registravam-se também, epidemias em Pernambuco, com 2.118 casos notificados, e taxa de incidência de 31,2 casos por 100.000 habitantes, com a maioria dos casos no interior do estado (60\%) e o restante em Recife; além de surtos localizados em pequenas cidades de São Paulo, Bahia, Minas Gerais, Maranhão, Piaui, Paraiba e Sergipe. A partir dai, torna-se endêmica em quase todos os estados, evidenciando tendência de propagação para estados sem registro da doença (Teixeira e col. 1999).

Na Bahia em 1987, a infestação domiciliar do vetor da dengue levou a notificação de 623 casos da dengue pelo sorotipo 1 no Município de Ipupiara. Inquéritos vetoriais neste estado, mostravam a presença do vetor em 108 municípios neste mesmo ano. Em Minas Gerais nesse mesmo ano, ocorreu epidemia na cidade de Pirapetinga (zona da mata), região da fronteira com os estados do Rio de Janeiro e Espírito Santo (já infestados), com 527 casos confirmados,e presença dos vetores Aedes aegypti e Aedes albopictus (Donalisio 1995; Vasconcelos e col. 2000; Anexos $1,2,3,4)$. 
Após as primeiras epidemias da dengue clássica, observa-se um período de baixa endemicidade que prolonga-se até o ano de 1990. Neste ano, com o aumento de circulação do dengue 1, e a introdução do dengue 2 no Rio de Janeiro, percebe-se um ressurgimento vertiginoso da doença, com 21.005 novas notificações. Para este estado no ano de 1991, foram notificados mais 78.702 casos, com os primeiros registros da dengue hemorrágica, num total de 1.306 notificações, 462 casos confirmados, 8 óbitos e taxas de incidência para os anos de $1990-91$ de 165,7 e 613,8 por 100.000 habitantes, respectivamente (Osanai 1984; Donalisio 1995; Anexos 1,2,3,4).

No início da década de 90 , a incidência da doença ficou quase que restrita aos estados já citados, somando-se ainda notificações de Alagoas, Mato Grosso, Mato Grosso do Sul, Tocantis, além do estado do Ceará que reaparece com 22.359 novos casos. Nos anos seguintes, a circulação viral (DEN-1 e DEN-2), alcança com grande rapidez, outras regiões do Brasil, evidenciando possibilidades de ocorrência de novas epidemias (Donalisio 1995; Figueiredo e col. 1995; Secretaria de Estado da Saúde de Alagoas 2001; Anexos 1,2,3,4).

Em junho de 1994, identifica-se a presença do sorotipo 2 da dengue, em Fortaleza, Ceará, com grave epidemia da dengue, onde foram notificados 47.221 casos, 185 casos suspeitos da dengue hemorrágica, com 25 casos confirmados e 12 óbitos, e taxa de incidência de 711,9 por 100.000 habitantes (Vasconcelos e col. 1995,1998).

Nos anos de 1995-2000, conforme previsão anunciada, a área de abrangência da dengue já atingia vários estados da federação, com graves epidemias, destacandose as regiões Nordeste: Ceará com 50.582 casos notificados neste período; Rio 
Grande do Norte: 55.218; Paraiba: 124.024; Pernambuco: 156.489; Alagoas: 22.817 e Bahia: 185.082; além das regiões Sudeste e Centro-Oeste (Donalisio 1995).

Tendo como referência as séries históricas de dados de notificação de 19802002 divulgados pelo Ministério da Saúde (Anexos: 1, 2, 3 e 4) observa-se que a dengue apresenta um caráter endemo-epidêmico em vários estados do Brasil: no Ceará, Alagoas, Rio de Janeiro e São Paulo houve notificações de casos em todos os anos do período 1986/87-2002. Em Pernambuco (1987/89, 1995-2002), e no restante dos estados brasileiros com transmissão, tem-se uma presença constante da doença desde o ano de 1995.

A transmissão da dengue jả atinge neste ano (2002), mais de 3.000 municípios brasileiros, com circulação do sorotipo DEN-1 em dois estados (Amapá e Rondônia); DEN-2 (Paraná); DEN-1,2 em oito estados (Amazonas, Acre, Maranhão, Tocantins, Distrito Federal, Piauí, Rio Grande do Norte e Sergipe); DEN-1,2,3 em 14 estados (Roraima, Pará, Mato Grosso, Mato Grosso do Sul, Goiás, Ceará, Paraiba, Pernambuco, Alagoas, Bahia, Minas Gerais, Espírito Santo, Rio de Janeiro e São Paulo). Apenas dois estados brasileiros não apresentam os sorotipos da dengue, Santa Catarina e Rio Grande do Sul (Ministério da Saúde 2002).

O número de notificações acumulados no período de 1981 a 2002 corresponde a mais de 3 milhões de pessoas. Atualmente no Brasil, todos os estados estão infestados pelo mosquito da dengue, com mais de 3.500 municípios nesta situação, com milhares deles apresentando altos índices de infestação predial por Aedes aegypti, e as epidemias de maior magnitude se concentram nas grandes cidades do país. 
Diante da tendência de aumento da incidência a partir de 1995 com um coeficiente de 87,7 por 100.000 habitantes, evoluindo até 2002 quando atinge um valor de 385,1 por 100.000 habitantes além da introdução do novo sorotipo DEN-3, isolado pela primeira vez no Brasil em dezembro de 2000 na cidade do Rio de Janeiro, observa-se cada vez mais, um risco crescente de novas e graves epidemias da dengue e febre hemorrágica da dengue, a exemplo do que mostram os registros para o período entre 1990 e 2001, onde foram notificados 1.634 casos da dengue hemorrágica, com 76 óbitos, e letalidade média de aproximadamente 4,25\%. Para o ano de 2002 (dados preliminares até julho), já foram notificados 2.090 casos, com 96 óbitos e uma letalidade média de 4,59\% (Ministério da Saúde 2002).

Com referência a Região Nordeste do Brasil, foram notificados 1.249.557 casos da dengue nos anos de 1982 até 2001, incluindo os casos clínicos hemorrágicos, com circulação simultânea dos sorotipos 1 e 2 e entrada recente do sorotipo 3 da dengue (Ministério da Saúde 2002).

A infestação por Aedes aegypti e o estado de transmissão da doença, já se comprovou em centenas de municípios da região, se destacando os estados do Ceará, Paraíba, Rio Grande do Norte, Pernambuco e Bahia. Ainda neste periodo, o ano de 1997 se destacou por apresentar a proporção de $81 \%$ de todos os casos do Brasil. No ano seguinte, esta proporção se reduziu para $32,5 \%$, sendo que os estados que mais notificaram dengue foram Pernambuco, Rio Grande do Norte, Ceará e Bahia. A explicação pode estar no possível esgotamento de suscetíveis para os sorotipos 1 e 2 , sendo mais provável que isto tenha ocorrido em função da maior circulação do primeiro sorotipo e as intensas transmissões ocorridas na região (Donalisio 1995). 
A introdução do sorotipo 3 , no Brasil e sua rápida disseminação para vários estados, incluíndo estados da região Nordeste, evidencia a facilidade de circulação de novos sorotipos ou cepas do vírus, com os intensos deslocamentos de pessoas para vários locais, expondo um contingente de milhões de brasileiros que já adoeceram por dengue, ao contato com mais este sorotipo, com grandes possibilidades de desenvolverem, formas mais graves da doença particularmente no Nordeste, o que poderá levar a uma situação de hiperendemicidade, com epidemias de febre hemorrágica da dengue.

Na região Nordeste, 1.146 municípios se encontravam infestados por Aedes aegypti, para os dados obtidos no período de 1982 a 1998. Deste total, 95 municípios eram do estado do Maranhão; 53 do Piauí; 92 do Ceará, 147 do Rio Grande do Norte; 174 da Paraíba; 130 de Pernambuco; 90 de Alagoas; 68 de Sergipe e 297 da Bahia. Isto significa que a infestação dos estados transcorreu independentemente das ações praticadas pelos serviços especializados de controle (Ministério da Saúde 2002).

\subsubsection{Dengue em Alagoas}

No estado de Alagoas (Secretaria de estado da Saúde de Alagoas SESAU/AL 1998a, 1998b, 1999, 2001,2002; Ministério da Saúde 96, 97; Secretaria Municipal de Saúde de Maceió - SMS/Mcz 2000, 2002), no ano de 1985 foi detectada a presença do mosquito Aedes aegypti no município de Maceió, com índice de infestação em torno de $80 \%$, distribuído por todos os bairros e periferia da capital. No ano seguinte, ocorreu a introdução do sorotipo DEN-1. A dispersão crescente do vetor observada nos anos seguintes, levou a ocupação de todos os municípios alagoanos até o final da década de 1990, fazendo com que a área de ocorrência da 
dengue chegasse ao ano de 2002 com $95 \%$ dos municípios registrando epidemias da dengue, e notificação de milhares de casos, determinando prejuízos para a população acometida, inclusive com redução de atividades laborais em fábricas, escritórios e o comércio em geral. Foi grande o número de municípios com transmissão da doença e as epidemias nas sedes municipais foram explosivas e de grande magnitude, principalmente no biênio 1986/87, com notificação de 12.625 casos pelo sorotipo 1, e concentração maior na capital do estado, o que correspondeu a uma taxa de 411,2 por 100.000 habitantes.

Em seguida, observou-se redução considerável dos índices de infestação, com diminuição do número de notificações da doença, nos anos seguintes. Com a persistência da transmissão no estado, se registrou a presença do sorotipo 2 em Maceió no ano de 1991, ocorrendo nova epidemia com registro de 1.317 casos e taxa de incidência de 52,6 por 100.000 habitantes(SESAU/AL 2001, 2002; SMS/Mcz 2000).

O quadro epidemiológico da dengue se delineia em nível endêmico, intercalado com período epidêmico, quando se observam as oscilações freqüentes para os dois períodos. Por outro lado, na medida que existem circulando os dois sorotipos, aumenta o risco para aparecimento de casos hemorrágicos. A partir de maio de 1994, se elevam os níveis de registros dos casos na capital e municípios maiores com importância econômica, desencadeando a elaboração de um plano emergencial de combate ao vetor, e dai se intensificam as operações de intervenção sobre o vetor.

Ainda que houvesse um esforço para redução da densidade de Aedes aegypti, em 1996 foram notificados 3.387 novos casos para os sorotipos 1 e 2 em todo o estado e taxa de incidência de 128,6 por 100.000 habitantes; progressão verificada 
para os anos de 1997/98, anos epidêmicos, totalizando 15.755 novos casos e taxas de incidência de 260,8 e 327,7 por 100.000 habitantes, respectivamente(SESAU/AL 2001, 2002).

No Estado de Alagoas a infestação pelo vetor no período de 1982 a 1998 registrava a proporção de $88,2 \%$. Ora, se a extensão da doença depende da interação vetor-hospedeiro-vírus, principalmente quando ocorre a introdução de sorotipo do vírus em populações sem contato prévio, subentende-se existir locais com grande densidade populacional de suscetível e altos índices de infestação pelo $A e$. aegypti (Seng e Jute 1994; Gubler e Clark 1996; Platt e col. 1997; Scott e col. 1997). Do ponto de vista epidemiológico, o complexo de sorotipos do vírus da dengue altera a forma de atuar quando se desloca entre as populações, variando as características endemo-epidêmicas das infecções e as apresentações clínicas da doença. Subseqüentemente, os diferentes perfis epidemiológicos podem se expressar de forma explosiva seguido de circulação endêmica, enquanto outros apresentam dois picos epidêmicos, para depois voltar aos niveis de baixa endemicidade (Leontsini e col. 1993; Savage e Smith 1995; Teixeira e col. 1999).

Em Maceió, verificou-se que houve dois picos epidêmicos intercalados com períodos de baixa endemicidade . Em 1996, 1997 e 1998, foram registrados 225, 475 e 1.197 casos do total de Alagoas, com incidências de 31,1, 63,6 e 156,2 por 100.000 habitantes, seguindo padrão semelhante ao Estado (SESAU/AL 1998a, 1998 2001, 2002; SMS/Mcz 2000).

Nos anos de 1999 e 2000, seguindo tendência nacional, observa-se redução do número de casos. A partir de 2001, tem-se novo crescimento dos registros da dengue no país, e Alagoas acompanhando tal tendência, aparece com 2.344 casos notificados, 
e incidência de 82,1; já em Maceió tem-se 389 casos e uma taxa de incidência de 47,5 por 100.000 habitantes.

Para o ano de 2002, acompanhando a entrada de novo sorotipo da dengue (DEN-3) no Brasil, confirma-se laboratorialmente a presença deste sorotipo em Alagoas, não só em Maceió, como em outros municípios alagoanos. Configura-se assim, nova epidemia, com notificação de 10.951 casos para o estado, e novamente Maceió concentra grande número de casos, com 5.469 registros, o que representa quase $50 \%$ de todas as notificações (dados referentes até semana epidemiológica 36).

A observação clínica, mesmo antes do encontro de novo sorotipo, já mostrava aumento da ocorrência de casos graves que necessitavam internação hospitalar, fugindo do padrão observado nos anos anteriores da endemia em Alagoas. Neste sentido no ano de 2002, surgem os primeiros casos de Febre Hemorrágica da Dengue no estado, com 33 casos notificados e 7 casos confirmados, sendo 5 casos confirmados em Maceió(SESAU/AL 2001, 2002; SMS/Mcz 2000).

Finalmente, o cenário da dengue no Brasil mostra perfil epidemiológico diferenciado por regiões, destacando-se a tendência do crescimento das notificações dos casos, inclusive no município de Maceió desde os anos de 1986/1987. Da mesma forma, se pode dizer para o crescimento dos índices de infestação de Ae. aegypti nesta localidade. Além disto, desconhece-se uma análise mais aprofundada das informações existentes em banco de dados da Secretaria de Estado da Saúde de Alagoas. Assim sendo, julga-se de elevada importância a contribuição de uma análise epidemiológica que possa atualizar os conhecimentos acerca dos determinantes da transmissão da dengue neste município, tendo como meta o aprimoramento das ações de controle. 
2 OBJETIVOS 


\section{OBJETIVOS}

\subsection{Objetivo Geral}

Descrever o perfil epidemiológico da dengue no município de Maceió, no período de 1997 a 2002, levando-se em conta a distribuição da incidência na população, no tempo e no espaço e da infestação vetorial, para contribuir ao controle da doença.

\subsection{Objetivos Específicos}

- Analisar os coeficientes de incidência da dengue no período estudado.

- Descrever atributos pessoais como idade e sexo na transmissão da doença.

- Descrever a distribuição da incidência segundo os bairros de Maceió.

- Analisar a infestação pelo vetor no plano temporal e espacial.

-Descrever os fatores climáticos e a relação destes com a infestação vetorial e a incidência da doença. 
3 MATERIAL E MÉTODOS 


\section{MATERIAL E MÉTOdOS}

O estudo foi realizado no município de Maceió, Estado de Alagoas, sendo composto de duas partes. Na parte inicial procurou-se fazer uma análise descritiva da ocorrência da dengue no período de 1997 a 2002, utilizando como indicador o coeficiente de incidência, e a sua distribuição ao longo do período do estudo, verificando seu comportamento nos seis anos. Procurou-se a distribuição da incidência segundo atributos pessoais, utilizando-se as variáveis demográficas sexo e idade.

Complementarmente, buscou-se relacionar a incidência da doença com as variáveis ambientais chuva e temperatura.

Como indicador entomológico foi utilizado o Índice de Infestação Predial(IP) para acompanhar a variação da infestação segundo os bairros do município. Verificou-se a possibilidade de existência de correlação entre a incidência da doença e o Índice Predial, com as variáveis chuva e temperatura.

Foi realizada uma análise espacial da distribuição da dengue na cidade estudada.

\subsection{CARACTERIZAÇÃo DA ÁREA DE ESTUdO}

O estudo foi realizado no município de Maceió(Figura 1), cidade fundada em 1815, situada na parte leste do Estado de Alagoas e apresenta as seguintes coordenadas geográficas: $9^{\circ} 39^{\prime} 57^{\prime \prime}$, latitude sul e $35^{\circ} 44^{\prime} 07^{\prime \prime}$ longitude oeste. Tem uma superficie de $512 \mathrm{~km}^{2}$, que corresponde aproximadamente a $1,84 \%$ do território deste Estado. Com uma altitude média de 16,6 metros acima do nível do Mar. Tem como limites ao norte os municípios de Paripueira, Barra de Santo Antonio e 
Flexeiras, ao sul os municípios de Coqueiro Seco e Marechal Deodoro, a oeste os municípios de Rio Largo e Satuba, e a leste é banhada pelo Oceano Atlântico (SMS/Mcz 2000; IBGE 2000).

A população é de 833.260 habitantes, sendo 393.329 homens e 439.931 mulheres, com taxa de urbanização de aproximadamente 99,8\%. Possui uma distribuição etária de 251.108 habitantes na faixa do zero a quatorze anos; 474.754 na faixa etária de 15 a 49 anos e 107.398 na faixa de 50 anos e mais (SMS/Mcz 2002).

Existem cerca de 319.250 imóveis na zona urbana, a cidade está dividida em 50 bairros e sete distritos sanitários. Em Maceió o abastecimento de água atende a $72,16 \%$ das residências, a coleta urbana de lixo cobre $80,76 \%$ dos domicilios, com destino posterior para aterro e apenas cerca de $24 \%$ da população é servida por rede de esgoto sanitário (SMS/Mcz 2000; IBGE 2000).

O clima da cidade é do tipo tropical, semi-quente e semi-úmido, com temperatura mínima de $18^{\circ}$ a $24^{\circ} \mathrm{C}$ e máxima de $27^{\circ}$ a $32^{\circ} \mathrm{C}$, e temperatura média anual de $28^{\circ} \mathrm{C}$.

Com uma privilegiada localização entre o Oceano Atlântico e o complexo estuarino lagunar Mundaú-Manguaba, a cidade tem em seu meio ambiente e suas paisagens naturais de lagunas costeiras, campos de dunas, cordões litorâneos com vegetação de restinga e tabuleiro dissecado com falésias vivas, enseadas com planícies costeiras estreitas, barreiras de recifes, estuários com manguezais e remanescentes de Mata Atlântica, as características mais marcantes.

Quanto a economia do município, a cana-de-açúcar e o coco da Bahia, são as culturas de maior representatividade dentre as atividades primárias desenvolvidas. A 
predominância da cana-de-açúcar denota claramente, a importância que tem a agroindústria açucareira em Alagoas.

No âmbito do setor secundário, o principal pólo industrial de Alagoas se localiza em Maceió, no bairro Tabuleiro dos Martins, formado por indústrias de pequeno e médio porte. Outro setor importante é o turismo, graças aos atrativos naturais que a cidade oferece, como, por exemplo, suas praias de águas mornas e cristalinas, lagoas e canais de rara beleza.

O aumento crescente do fluxo turístico foi um dos fatores que estimularam os investimentos nos ramos de hotelaria, artesanato, alimentação e serviços auxiliares, fornecendo a economia local no que se refere a geração de novos empregos e divisas para o município.

O mapa do município de Maceió pode ser visualizado na Figura 2. 
Figura 1 - Mapa evidenciando localização do Estado de Alagoas no Brasil e do município de Maceió no Estado.

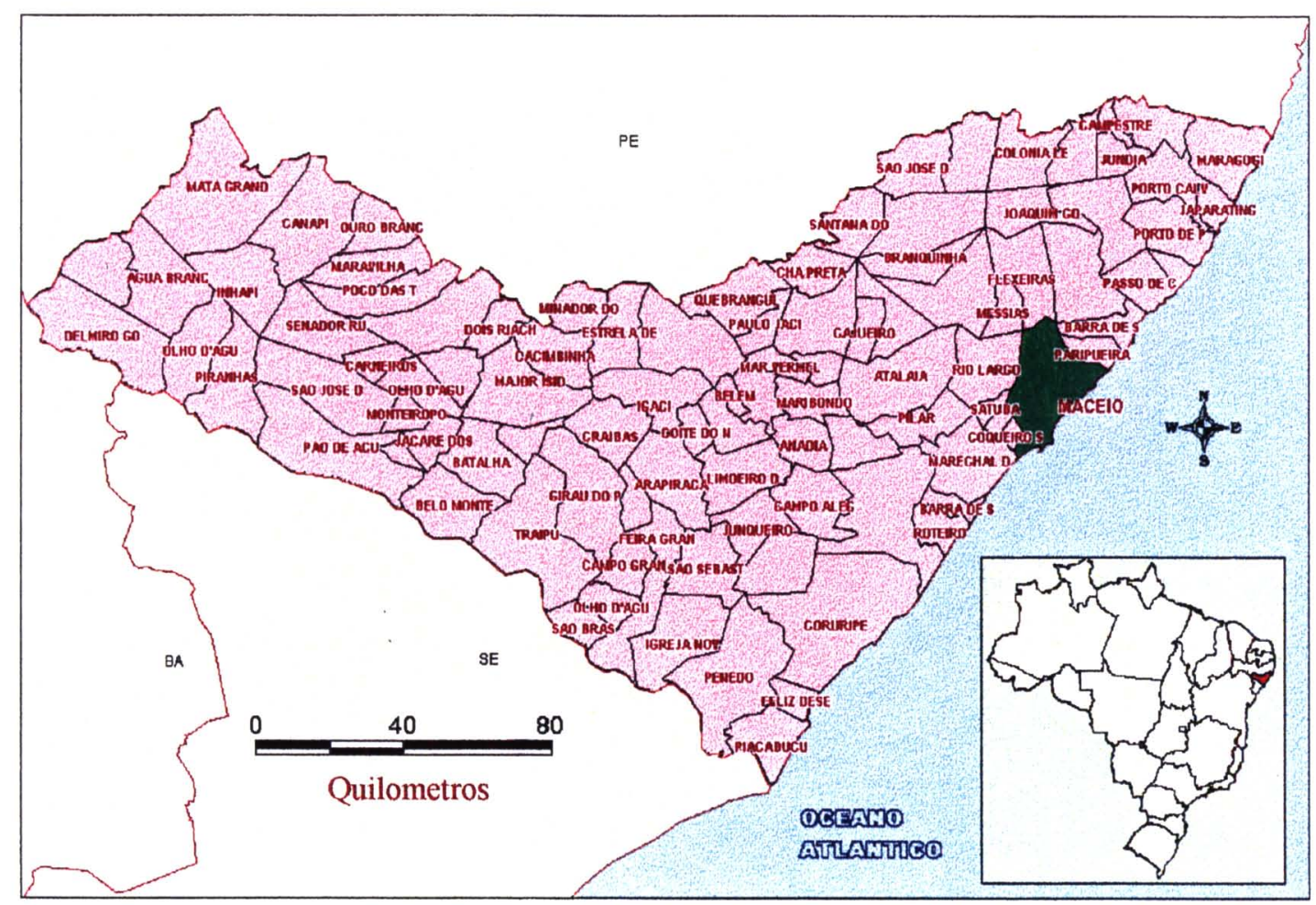

Fonte Fundação IBGE 2000. 
Figura 2 - Mapa do município de Maceió salientando as áreas rural, urbana e seus bairros.

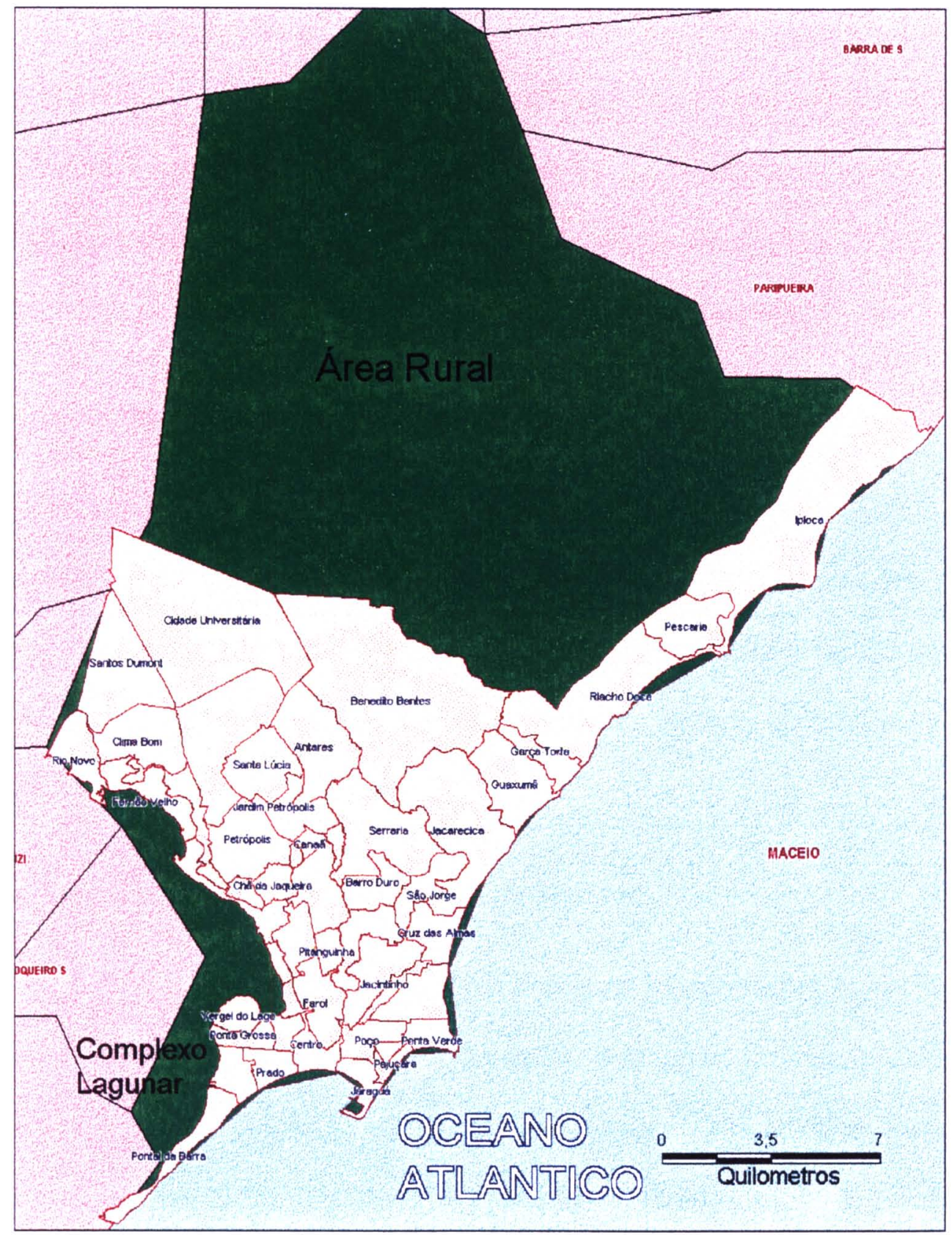

Fonte: SMCCU - AL 


\subsection{REgistro DA DENGUE E DA INFESTAÇÃo PELO AEDES} AEGYPTI.

A Vigilância Epidemiológica identifica e classifica clinicamente os casos da dengue(FD) e febre hemorrágica da dengue(FHD) que chegam aos serviços de saúde por demanda espontânea ou por encaminhamento. A fonte desses dados foi a Secretaria de Estado da Saúde e Secretaria Municipal de Saúde (SESAU/AL 2001; SMS/Mcz 2002). O registro da doença foi baseado nas seguintes definições:

\section{- Caso Suspeito de Febre da Dengue}

Paciente que apresenta doença febril aguda, com duração máxima de 7 dias, acompanhada de, pelo menos, dois dos seguintes sintomas: cefaléia, dor retroorbitária, mialgia, prostração e exantema. É importante considerar sempre os antecedentes epidemiológicos e as formas brandas da doença, principalmente em crianças.

\section{- Caso Suspeito de Febre Hemorrágica da Dengue}

É todo o caso suspeito de FD que apresenta manifestações hemorrágicas, segundo a OMS. Essas manifestações vão desde uma prova do laço positiva até hematêmese e outras. As mais freqüentes são as petéquias. Deve-se considerar como suspeito todos os indivíduos com doença febril acompanhada de sinais de instabilidade hemodinâmica.

Os casos são notificados ao Núcleo de Vigilância Epidemiológica do município por meio da Ficha de Notificação do Sinan Windows (Anexo 5). Após a notificação, inicia-se de imediato o trabalho de investigação epidemiológica, 
utilizando para isso a Ficha de Investigação da dengue do Sinan Windows (Anexo 6). Em seguida colhe-se material e solicita-se exames laboratoriais (isolamento viral e sorologia) ao Laboratório Central (LACEN).

Para o cálculo dos coeficientes de incidência, foram considerados os casos notificados à Vigilância Epidemiológica, e foram usadas as bases 10.000 e 100.000 (casos/10.000 e casos/100.000 habitantes). Na figura 11, foi usada a base casos/1.000.000 habitantes para compatibilizar a leitura gráfica das duas variáveis usadas. A população da cidade de Maceió para o período do estudo, foi obtida do banco de dados da Secretaria Municipal de Saúde (SMS/Mcz - Ministério da Saúde).

\section{- Infestação Domiciliar pelo Aedes aegypti}

A infestação pelo Aedes aegypti é medido periódicamente na cidade estudada, pelo Núcleo Municipal de Vigilância da Secretaria Municipal de Saúde, órgão responsável pelo controle da dengue.

As estratégias utilizadas para o controle do vetor constam no Plano Estadual de Controle da Dengue, do Núcleo de Vigilância Epidemiológica da Secretaria de Estado da Saúde de Alagoas (SESAU/AL 2001).

A metodologia utilizada nas operações de campo de combate ao vetor, advém do Manual de Normas Técnicas para dengue e do Plano Nacional de Controle da dengue do Ministério da Saúde e da Fundação Nacional de Saúde - FUNASA (SESAU/AL 2001; Ministério da Saúde 1996, 1998, 2001). Os dados obtidos permitem o cálculo do Índice de Infestação Predial (IP- \% de prédios com larvas do vetor/número de prédios examinados). 
Utilizou-se as informações referentes ao vetor, que se originaram do banco de dados denominado Sistema Febre Amarela e Dengue - FAD, mantido pelo atual Plano Estadual de Controle da dengue do Ministério da Saúde, Secretaria de Estado da Saúde de Alagoas e Secretaria Municipal de Saúde, referente à distribuição e ao nível de infestação do vetor em Maceió, no período de 1997 a 2002.

As variáveis climáticas temperatura e chuva foram obtidas do Banco de Dados do Instituto Nacional de Meteorologia- INMET, $3^{\circ}$ DISME, da Seção de Observação e Meteorologia Aplicada - SEOMA, Recife, Pernambuco. A Estação Meteorológica de Maceió, situa-se a uma distância de aproximadamente $22 \mathrm{Km}$ do centro da cidade, com coordenadas geográficas: $09^{0} 40 \mathrm{~S} \mathrm{~N} / \mathrm{S}$ (latitude); $35^{\circ} 42^{\prime} \mathrm{W}$ (longitude); 64,50 $\mathrm{HP}(\mathrm{m})$ de altitude com relação ao nível do mar; $65,10 \mathrm{HZ}(\mathrm{m})$ altura da cuba do barômetro. Os dados de temperatura foram: média mensal para os meses dos anos estudados; para os dados de precipitação foram: precipitação total mensal para os meses dos anos estudados.

\section{3. ÁNALISE DOS RESULTADOS}

\subsubsection{Análise estatística}

A análise dos dados foi orientada segundo o método epidemiológico descritivo (Pereira 1995; Rouquayrol 1999), cujo modelo geral toma a presença da doença e a infestação de larvas do Aedes aegypti como variáveis respostas, avaliadas segundo as distribuições das demais características demográficas (sexo e idade) ou ambientais(chuva e temperatura), ao longo da série anual construída no período estudado.

Coeficientes gerais de incidências anuais foram calculados pela expressão: 
$C I_{i}=\frac{N C_{i}}{P_{i}} x 10.000 ;(\mathrm{i}=1997$ a 2002$)$, onde $\mathrm{NC}_{\mathrm{i}}$ representa o número de casos notificados, e $\mathrm{P}_{\mathrm{i}}$ a população residente no município de Maceió no ano ( i ).

A expressão anterior, aplicada aos dados dos seis estratos definidos (menor de 14,15 a 49 e 50 anos e mais para os sexos masculino e feminino) em cada ano, resultou em séries de incidências específicas que foram comparadas por gráficos lineares, representados ao longo do período estudado.

A influencia dos fatores climáticos foi analisada também pela comparação de gráficos lineares, elaborados para a incidência mensal da dengue e do índice de infestação predial, segundo temperatura(em graus centigrados) e indice de pluviosidade.

Possiveis associações entre essas características foram exploradas pelo coeficiente de correlação de Pearson (r), cuja expressão abaixo apresentada calcula as covariâncias entre pares de variáveis $(\mathrm{X}, \mathrm{Y})$ observados separadamente ao longo dos doze meses de cada ano.

$$
(\mathrm{r})=\frac{\sum_{i=1}^{12}\left(x_{i}-\bar{x}\right)\left(y_{i}-\bar{y}\right)}{\sqrt{\sum_{i=1}^{12}\left(x_{i}-\bar{x}\right)^{2} \cdot \sum_{i=1}^{12}\left(y_{i}-\bar{y}\right)^{2}}}
$$

Os cálculos efetuados no software STATISTICA(Statsoft 1995), incluem os valores estimados para os níveis de significância, que foram comparados ao critério $(p<0,05)$ para confirmação das possíveis correlações detectadas. 


\subsubsection{Análise espacial}

Os dados utilizados são secundários, provenientes de fontes oficiais da administração pública de Maceió, do IBGE ou do Ministério da Saúde( Gesler 1986; Morrison e col. 1998). O período de observação compreende os anos de 1997-2002. Cópias das tabelas, com os dados organizados para processamento dos coeficientes e demais estatísticas calculadas para o desenvolvimento do trabalho, são apresentadas em anexos.

Os dados recebidos serviram de base primária de análise organizados da seguinte forma:

- Mapa digital de Maceió por bairros. Formato: ESRI shape (nativo de Arc View) sem nenhuma informação associada. Material obtido com autorização da Secretaria Municipal de Controle e Convívio Urbano de Maceió (SMCCU).

- População por bairro, em série temporal de 1997 a 2002 (SMS/Mcz).

- Ocorrências de casos da dengue (SESAU/AL).

- Formato original: EpiInfo

-Tabelas: uma tabela para cada ano do período. $\mathrm{O}$ ano de 2002 possui registros somente até a semana epidemiológica 36 .

-Registros: cada linha da tabela relatando uma ocorrência.

-Variáveis: campos segundo a descrição em arquivo enviado pela fonte.

-Vetores: arquivo Excel, uma pasta para cada ano, organizados por bairro, mês a mês, no periodo de 1997 a 2002(Funasa; SESAU/AL; SMS/Mcz.)

- Ambientais: dados de temperatura, chuva, obtidos do INMET - AL. 
Inicialmente, foram detectados registros com campos armazenando dados em codificação binária diferente da considerada padrão pelo Epilnfo. Estes registros estavam preenchidos de tal modo que não afetavam o Epilnfo, mas eram recusados pelos conversores do Excel e do Access.

Seguiu-se a importação para Excel e conseqüente conferencia para verificação da integriḍade com relação aos dados primários em Epilnfo. Estas planilhas serviram de base para os estudos exploratórios que se seguiram. Foi feita ainda a importação para o programa MapInfo e em seguida sua geocodificação. Com a informação dos bairros onde ocorreu cada caso, se pode associar a cada bairro o número de ocorrências segundo o ano da ocorrência.

Dentre os mapas digitais disponiveis, apenas se provou relevante para o projeto de pesquisa, um deles que representa os bairros de Maceió em número de 50, sendo um polígono para cada bairro. A associação entre os polígonos e seus nomes e códigos para posterior referencia e montagem do banco de dados geográfico, foi realizada e conferida manualmente.

A intenção foi associar as informações de casos da dengue ao bairro de residência pelo processo chamado de geocodificação, que consiste em vincular a cada ocorrência um ponto de referencia no polígono do bairro correspondente. A associação é feita usando um campo de conteúdo compatível presente nas duas tabelas. No caso foram usados campos contendo o nome do bairro, para os registros da dengue, e um campo código para os dados de índices de infestação. As tabelas de população por bairro e por ano foram importados para o Mapinfo, em seguida geocodificadas, permitindo a associação entre quantitativos populacionais por ano a cada bairro. 
Em cada ano da série foram gerados dois mapas temáticos para os coeficientes de incidência e os índices de infestação predial. Esses mapas foram apresentados em seqüência temporal para permitir comparação visual. Para facilitar comparações diretas entre os mapas ao longo do período, adotou-se o critério do "desvio padrão", indicado pelo MAPINFO (MapInfo 2000). A análise espacial seguiu a lógica de comparação entre grupos de bairros. Os bairros foram agrupados segundo os seguintes valores: zero ou ausência de casos (amarelo claro), um desvio padrão abaixo da média (azul claro), valores inferiores a este (azul escuro), um desvio padrão acima da média (amarelo escuro) e valores acima deste (vermelho).

Para os mapas de índices de infestação predial, o critério de agrupamento foi mantido, com a única diferença que os bairros sem informação receberam a cor amarelo claro. 


\section{RESULTADOS}

No ano de 1997 foram notificados 475 casos de dengue com uma incidência anual de 6,4 por 10.000 habitantes na cidade de Maceió (Tabela 1 e Anexo 11). O cálculo desta incidência por semana epidemiológica mostrou que os registros da doença ocorreram principalmente nas semanas 32 e 33 referentes ao mês de agosto; semanas 40, 41, 42 e 43, referentes ao mês de outubro. Os coeficientes mensais de incidência foram respectivamente 7,2 e 10,4 por 100.000 habitantes. A maior incidência individual foi registrada na semana 32 , com 3,2 casos por 100.000 habitantes, e a maior incidência mensal foi em outubro com 10,4 casos por 100.000 habitantes (Figuras 3 e 4; Tabela 2 e Anexo 7).

Durante todo o ano de 1998 foram registrados 1.197 casos de dengue cuja incidência foi de 15,6 por 10.000 habitantes. A maior incidência observada, ocorreu na semana 15 do mês de abril, atingindo o valor de 13,7 por 100.000 habitantes. A continuidade dos registros da doença demonstrou que a incidência em junho, correspondente a semana 22 , foi de 13,4 por 100.000 habitantes. Outros meses apresentaram queda da incidência(Tabela 1; Fig. 3 e Anexo 7).

Em 1999 foram notificados 307 casos da dengue, sendo o coeficiente de incidência anual de 3,9 por 10.000 habitantes. No geral, a incidência mensal foi reduzida a valores inferiores aos anos anteriores(Tabela 1, Fig. 3, Anexo 7).

No ano 2000 , foram notificados 266 casos com incidência anual de 3,3 por 10.000 habitantes. Os valores mensais registrados, apresentaram semelhança com o ano anterior. 
A partir de 2001 observou-se que houve um recrudescimento no número de casos notificados, o que resultou na elevação da incidência para 4,8 casos por 10.000 habitantes. Este crescimento continuou em 2002 de modo a atingir 5.453 notificações e uma incidência de 65,4 casos por 10.000 habitantes até a semana epidemiológica 36. Na distribuição mensal das incidências se destaca o mês de março (semana 11) com valores de 54,4 casos por 100.000 habitantes. Nos demais meses deste ano, os resultados das incidências que compõem a curva epidemiológica da dengue, revelaram que nos meses de abril a maio (semanas 14 a 21) as taxas de incidência mantiveram-se ainda elevadas.

Os coeficientes de incidência anuais no periodo de 1997 a 2002 variaram de 3,3 a 65,4 casos por 10.000 habitantes, enquanto que as incidências mensais variaram de 1,1 a 229,3 casos por 100.000 habitantes. Nos anos de 1999, 2000 e 2001, as incidências para dengue no município estiveram com valores próximos, ou seja, a taxa esteve em torno de 3,9 casos por 10.000 habitantes. Ao contrário, nos anos de 1998 e 2002 as taxas de incidência de dengue foram bem mais elevadas, o que caracterizou período epidêmico da doença. Ainda nestes dois anos, se verificou que o maior número de casos notificados ocorreu entre a oitava e a vigésima quinta semanas, periodo referente aos meses de março a junho (Tabelas 1,2 e Anexo 7). 
Tabela 1 - Número de casos de Dengue e incidência anual por 10.000 habitantes Maceió - AL: 1997-2002*

\begin{tabular}{rrrr}
\hline Ano & Casos & Pop & Coef \\
\hline 1997 & 475 & 746.709 & 6,3612 \\
1998 & 1197 & 766.498 & 15,6165 \\
1999 & 307 & 784.918 & 3,9112 \\
2000 & 266 & 796.842 & 3,3382 \\
2001 & 389 & 814.444 & 4,7763 \\
2002 & 5453 & 833.257 & 65,4420 \\
\hline
\end{tabular}

Fonte: SINAN/PROVEP/SESAU-AL

(*) Dados preliminares ate a semana 36

Figura 3 - Coeficientes de incidência da dengue (por 100.000 habs.) por semana epidemiológica. Maceió, 1997 - 2002*.
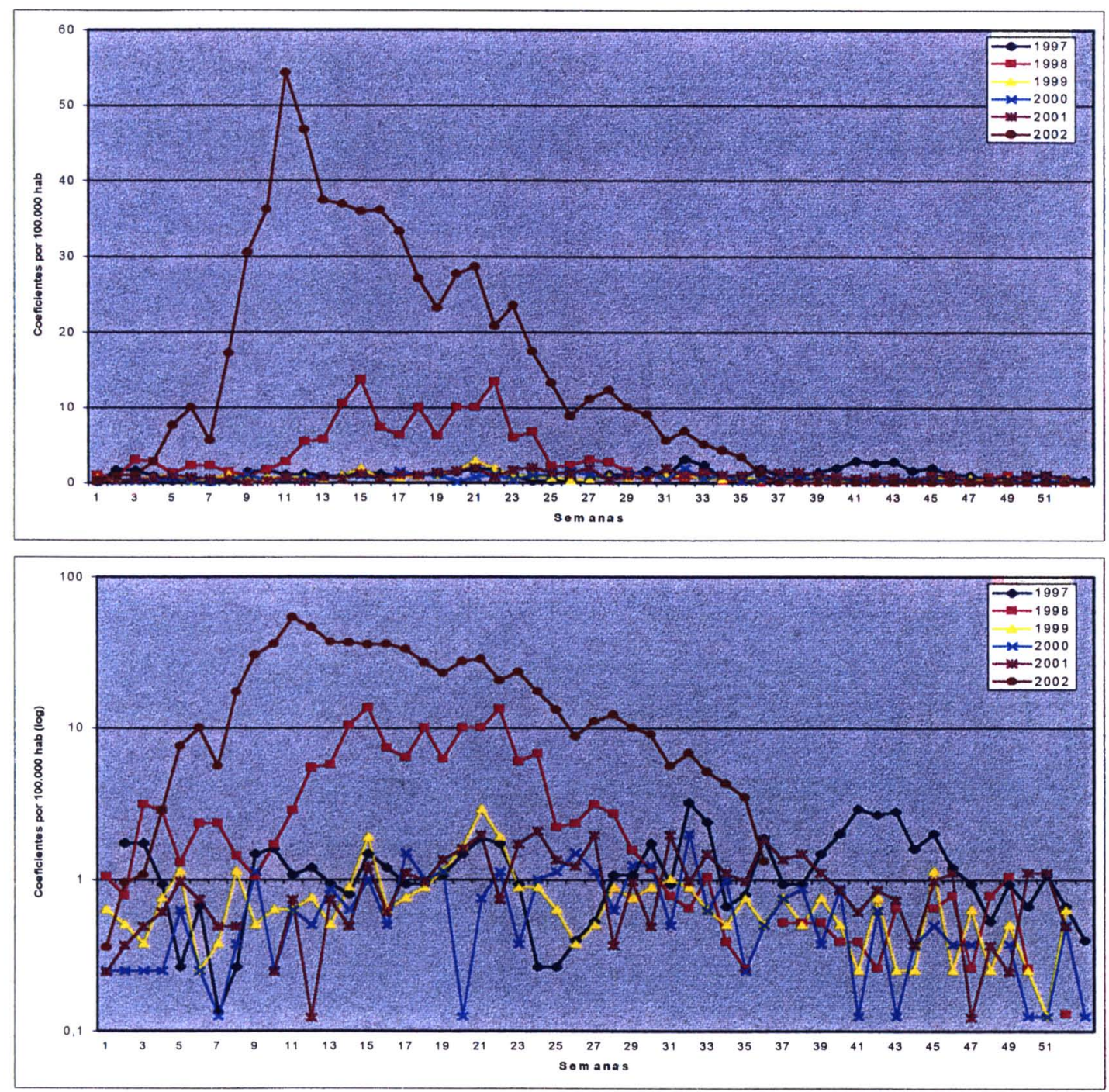

Fonte: SINAN/PROVEP/SESAU-AL

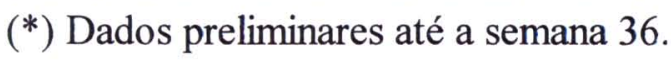


Tabela 2 - Coeficientes de incidência da dengue (por 100.000 habs.) por mês e ano. Maceió, 1997-2002*.

\begin{tabular}{rrrrrrr}
\hline Mês & 1997 & 1998 & 1999 & 2000 & 2001 & 2002 \\
\hline 1 & 4,419392293 & 8,0352587 & 2,4105776 & 1,0713678 & 1,8748937 & 5,8925231 \\
2 & 1,339209786 & 7,6334958 & 3,0801825 & 1,4731308 & 2,9462615 & 45,399212 \\
3 & 6,294285994 & 17,275806 & 3,2141035 & 3,6158664 & 2,0088147 & 229,27272 \\
4 & 4,419392293 & 38,971005 & 4,4193923 & 3,8837084 & 3,7497874 & 158,9642 \\
5 & 5,356839143 & 37,363953 & 6,9638909 & 3,2141035 & 6,428207 & 119,18967 \\
6 & 3,615866422 & 31,605351 & 4,9550762 & 5,4907601 & 7,7674168 & 94,012527 \\
7 & 4,419392293 & 8,8387846 & 3,2141035 & 4,5533133 & 4,1515503 & 47,675868 \\
8 & 7,231732844 & 2,9462615 & 3,2141035 & 4,4193923 & 6,026444 & 24,507539 \\
9 & 6,026444036 & 1,8748937 & 3,4819454 & 2,9462615 & 7,3656538 & 5,3568391 \\
10 & 10,44583633 & 1,7409727 & 1,8748937 & 1,8748937 & 3,3480245 & \\
11 & 5,758602079 & 1,7409727 & 2,4105776 & 1,7409727 & 2,8123406 & \\
12 & 3,883708379 & 2,2766566 & 1,8748937 & 1,2052888 & 3,6158664 & \\
\hline
\end{tabular}

Fonte: SINAN/PROVEP/SESAU-AL

(*) Dados preliminares até o mês de setembro.

Figura 4 - Distribuição dos coeficientes de incidência (casos por 100.000 habs.) por mês e ano. Maceió, 1997 - 2002*.

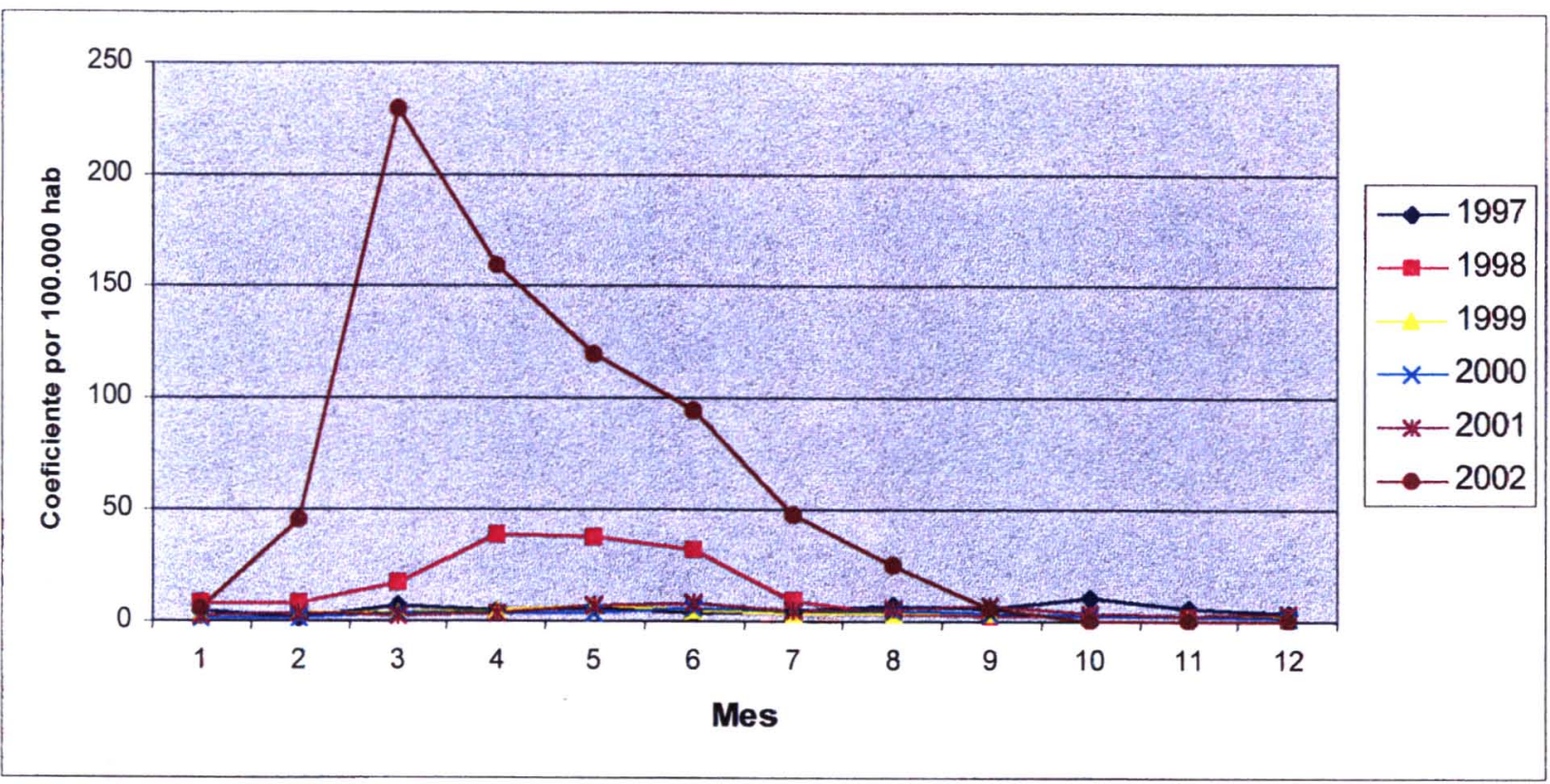

Fonte: SINAN/PROVEP/SESAU-AL

(*) Dados preliminares até o mês de setembro. 
Figura 4 - Distribuição dos coeficientes de incidência (casos por 100.000 habs.) por mês e ano. Maceió, 1997 - 2002*.

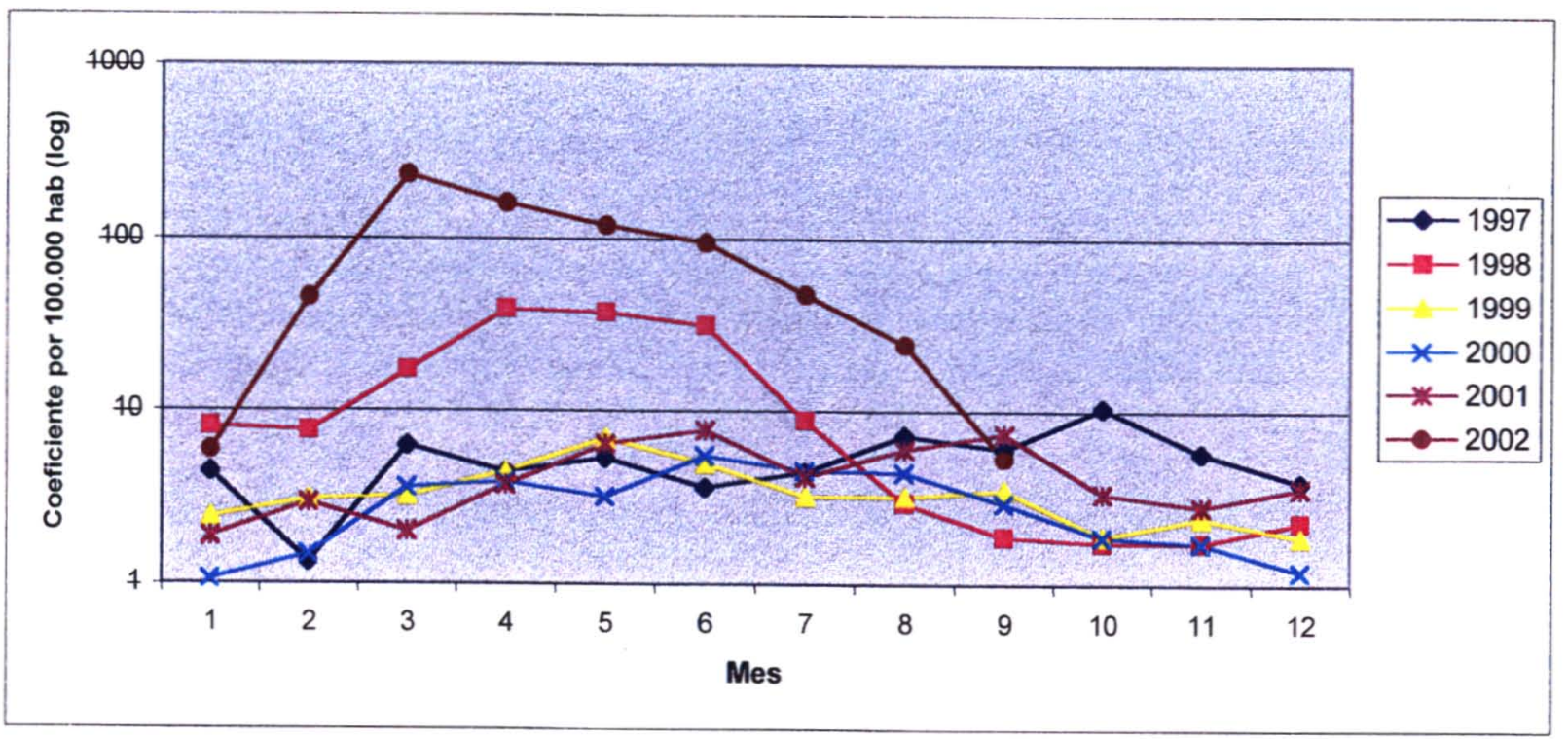

Fonte: SINAN/PROVEP/SESAU-AL

(*) Dados preliminares até o mês de setembro. 


\subsection{DISTRIBUIÇÃO DA DENGUE SEGUNDO A IDADE E SEXO}

A Tabela 3 mostra a incidência de dengue por 10.000 habitantes, por idade e sexo no período de 1997 a 2002. As faixas etárias: menor de 14 anos; 15 a 49 anos e 50 e mais, mostraram valores diferentes segundo o ano examinado. A última faixa etária se destacou ao longo do período; exceto para os anos de 1999 e 2000, onde a incidência foi um pouco superior nas idades entre 15 e 49 anos. Embora o menor registro tenha sido entre menores de 14 anos, as taxas de incidência para o grupo foram proporcionalmente próximas, independentemente do ano epidêmico. Na Figura 5 se demonstra o comportamento da incidência a cada ano do estudo. Em 1997, 1998, 2000, 2001 e 2002, as incidências se concentraram nas idades acima de 15 anos e no ano de 1999 na faixa etária de 15 a 49 anos(Figueiredo e col. 1991).

$\mathrm{Na}$ Tabela 3 se verifica que o sexo feminino teve incidência sempre superior em relação ao sexo masculino. Entretanto, nos anos com menor notificação de casos, os valores de incidência por 10.000 habitantes tenderam a uma proximidade visível. Os dados encontrados para o sexo masculino mostram no ano de 1997, concentração maior de casos na faixa etária de 15 a 49 anos. Nos demais anos pesquisados, observa-se deslocamento das maiores incidências para faixa etária acima de 50 anos.

A distribuição das incidências da dengue por faixa etária, mostra predomínio nas idades acima de 50 anos, nos anos de 1997, 1998, 2001 e 2002. Por outro lado, em 1999 e 2000 verificou-se concentração de casos nos indivíduos entre 15 a 49 anos de idade. Quanto aos menores coeficientes de incidência, o grupo que prevaleceu foi nas idades abaixo de 14 anos, e no sexo masculino nos anos pesquisados. As curvas de incidência por sexo e idade são apresentadas nas Figuras 5 e 6. 
Tabela 3 - Coeficientes de Incidência (por 10.000 habs.) segundo idade e sexo. Maceió, 1997 - 2002.

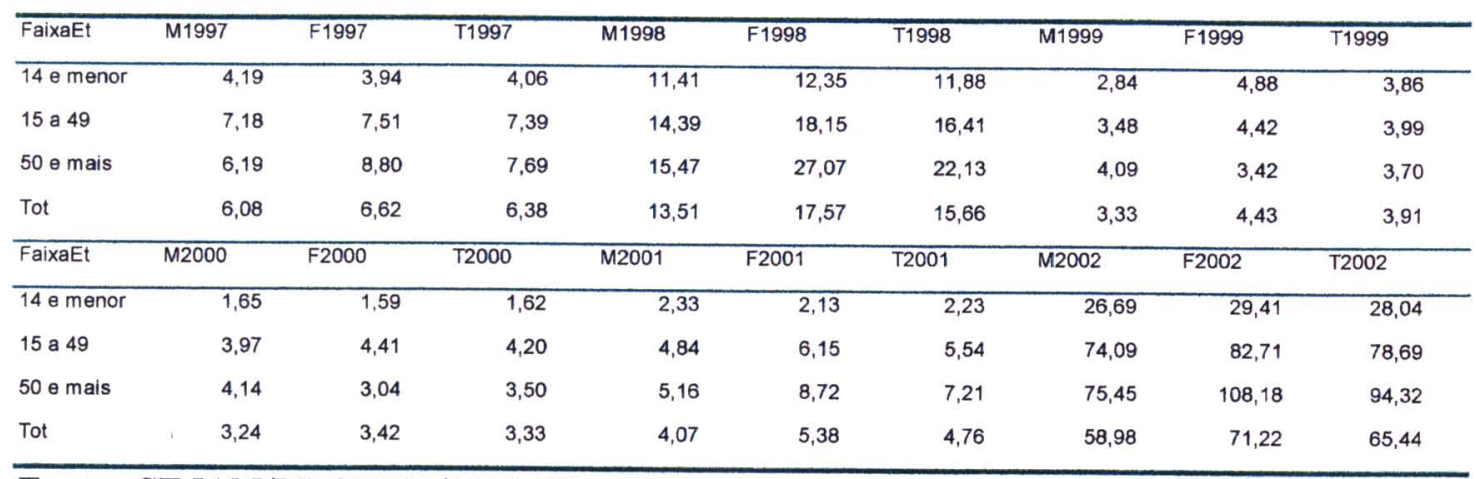

Fonte: SINAN/PROVEP/SESAU-AL

Figura 5 - Coeficientes de incidência da dengue (casos por 10.000 habs.) segundo faixa etária. Maceió, 1997 - 2002.

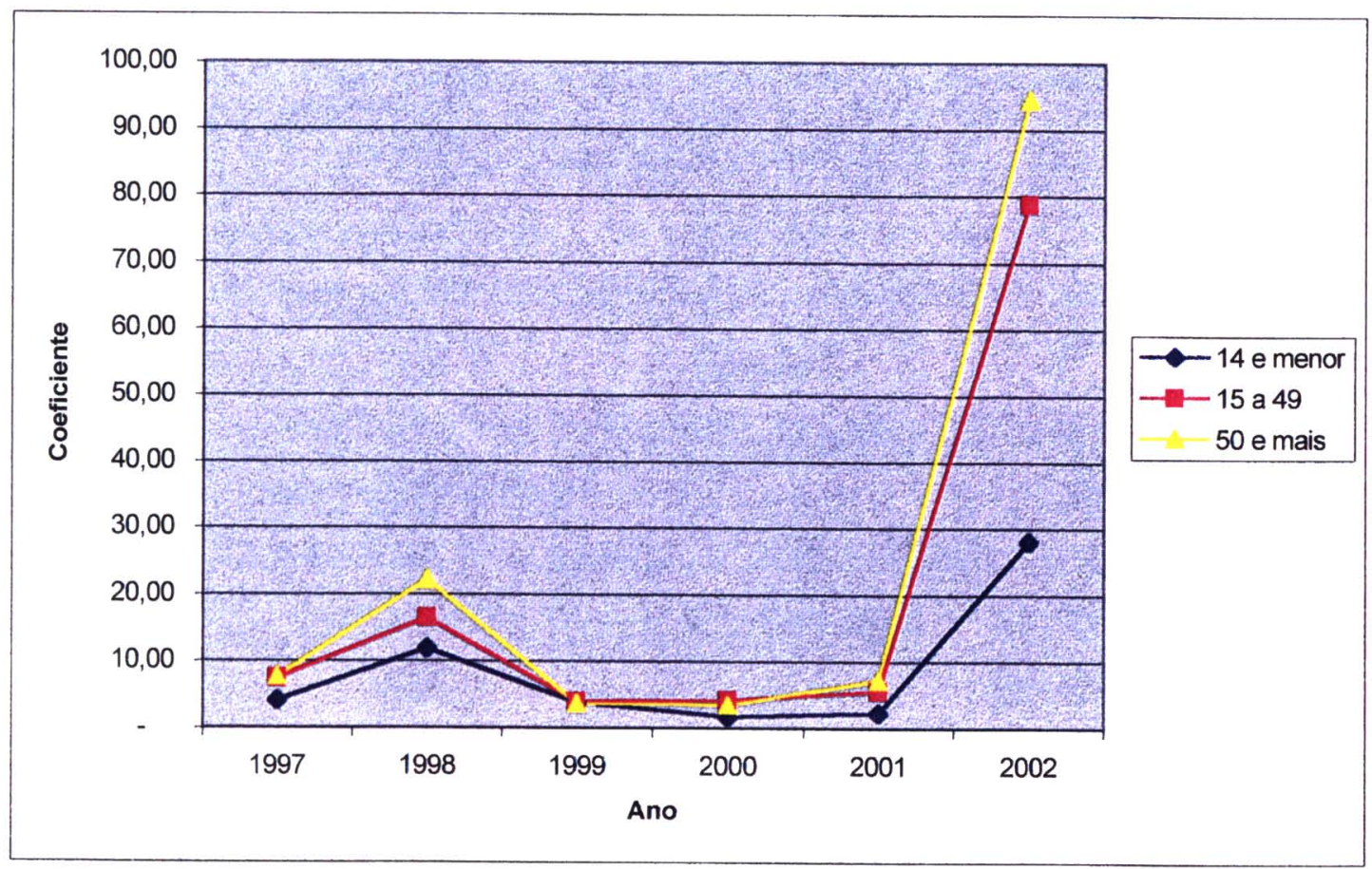

Fonte: SINAN/PROVEP/SESAU-AL 
Figura 6 - Coeficientes de incidência da dengue (casos por 10.000 habs.) segundo sexo. Maceió 1997 - 2002.

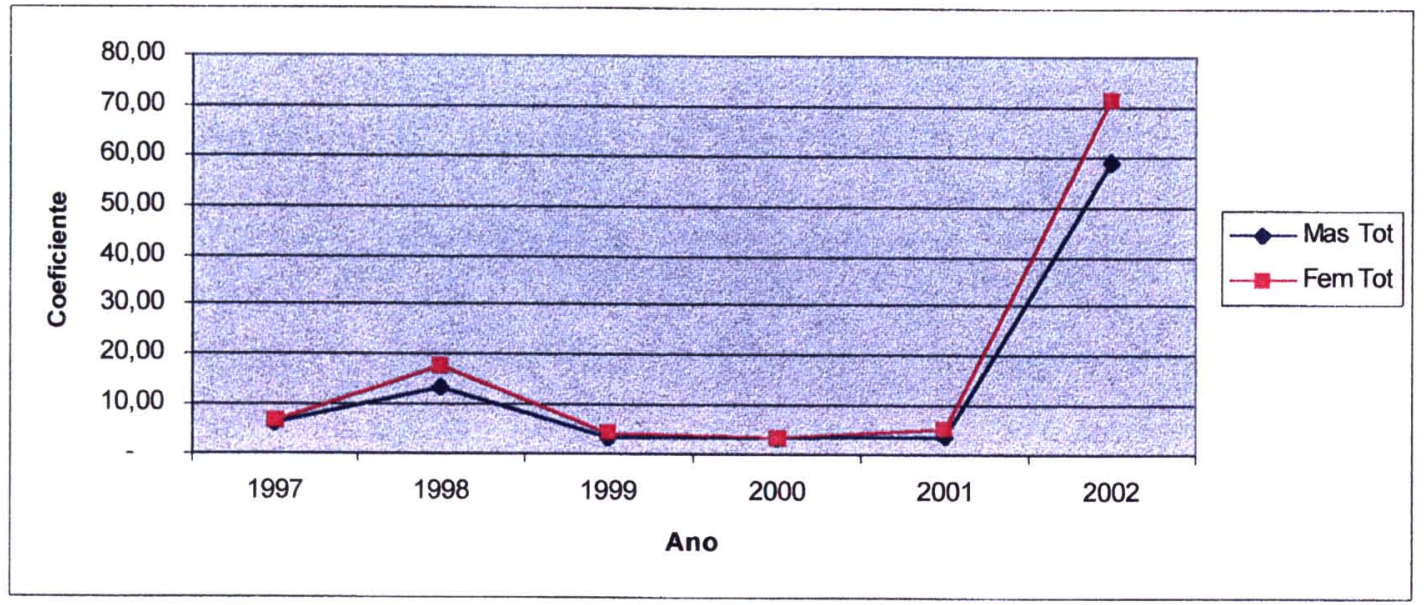

Fonte: SINAN/PROVEP/SESAU-AL 


\subsection{DISTRIBUIÇÃO DA DENGUE POR BAIRRO EM MACEIÓ}

$\mathrm{Na}$ Tabela 4 são apresentados os coeficientes de incidência por 10.000 habitantes nos cinqüenta bairros do município.

Os coeficientes de incidência de dengue nos anos de 1997 a 2002, variaram entre 0,0 a 249,3 casos por 10.000 habitantes. Os bairros com coeficientes de incidência mais elevados foram: Pajuçara (181 - código referente ao número do bairro); Farol (071); Centro (051); Chã da Jaqueira (331); Pontal da Barra (221); Guaxuma (541) e Cruz das Almas (061), com valores acima de 138,3 por 10 mil habitantes. Em 1998, os bairros com incidências maiores foram: Chã da Jaqueira (331), Pontal da Barra (221); Riacho Doce (271); Bebedouro (021); Mutange (171); Tabuleiro dos Martins (291) e Vergel do Lago (321), que apresentaram coeficientes acima de 30,4 casos por 10.000 habitantes.

Os bairros que apresentaram as menores taxas de incidência em 1998 e 2002 foram: Cidade Universitária (781) e Jardim Petrópolis (821), e aqueles que não registraram casos foram: São Jorge (831) e Antares (881).

Para os anos de 1997, 1999, 2000 e 2001, os maiores coeficientes de incidência foram encontrados no bairro Farol (071), enquanto que o bairro Pescaria (681) não apresentou registro de casos. Merece destaque o bairro Antares (881) por não ter registro de casos de dengue nos anos estudados. Os coeficientes por bairro podem ser vistos na Figura 7, 8 e Anexo 9. 
Tabela 4 - Coeficientes de incidência da dengue (casos notificados por 10.000 habs.) por bairros de Maceió, 1997 - 2002.

\begin{tabular}{|c|c|c|c|c|c|c|c|c|}
\hline Nome & $\begin{array}{l}\text { Codigo } \\
\text { SMS }\end{array}$ & $\begin{array}{l}\text { Reg } \\
\text { Adm }\end{array}$ & 1997 & 1998 & 1999 & 2000 & 2001 & 2002 \\
\hline Ipioca & 091 & 1 & 0,00 & 24,05 & 2,34 & 6,92 & 2,25 & 41,83 \\
\hline Pitanguinha & 201 & III & 6,45 & 0,00 & 3,06 & 1,51 & 1,48 & 72,09 \\
\hline Jacintinho & 121 & V & 3,78 & 12,41 & 2,76 & 1,54 & 2,42 & 30,23 \\
\hline Cruz das & 061 & I & 11,69 & 16,56 & 3,03 & 7,98 & 5,84 & 150,19 \\
\hline Jardim & 821 & III & 0,00 & 3,34 & 0,00 & 0,00 & 0,00 & 18,39 \\
\hline a & 471 & VII & 1,43 & 2,78 & 0,00 & 3,96 & 1,31 & 26,82 \\
\hline Benedito Bentes & 031 & VI & 5,26 & 10,89 & 6,99 & 1,04 & 3,87 & 13,29 \\
\hline Petrópolis & 501 & IV & 3,25 & 9,49 & 0,00 & 0,00 & 0,00 & 0,00 \\
\hline Chã da Jaqueira & 331 & IV & 11,09 & 55,54 & 8,10 & 0,53 & 13,54 & 192,31 \\
\hline Serraria & 361 & V & 3,27 & 18,49 & 2,49 & 7,36 & 9,58 & 84,85 \\
\hline Gua & 541 & 1 & 0,00 & 6,93 & 0,00 & 6,72 & 6,56 & 160,36 \\
\hline Tab & 291 & VII & 12,70 & 33,52 & 5,42 & 5,95 & 8,91 & 114,00 \\
\hline Cidad & 781 & VII & & 2,10 & 1,28 & 0,25 & 0,25 & 0,48 \\
\hline Garça & 101 & 1 & 5,22 & 10,17 & 0,00 & 0,00 & 4,77 & 28,01 \\
\hline Santa & 641 & IV & 2,86 & 6,96 & 0,97 & 0,00 & 0,94 & 6,41 \\
\hline Fernão Velho & 081 & IV & 2,56 & 29,88 & 0,00 & 3,44 & 6,72 & 134,38 \\
\hline lima $\mathrm{B}$ & 341 & VII & 1,83 & 13,64 & 3,77 & 0,84 & 1,67 & 20,69 \\
\hline it & 671 & VII & 2,57 & 7,52 & 0,00 & 0,00 & 0,00 & 23,06 \\
\hline$P$ & 681 & 1 & 10 & 0,00 & 0,00 & 0,00 & 0,00 & 19,21 \\
\hline Bebec & 021 & IV & 11,31 & 41,63 & 4,28 & 5,08 & 2,48 & 81,39 \\
\hline Rio $\mathrm{N}$ & 491 & IV & 11,10 & 12,36 & 1,08 & 1,07 & 0,00 & 28,48 \\
\hline de Lourdes & 111 & III & 1,34 & 2,61 & 1,28 & 2,52 & 7,38 & 34,17 \\
\hline Mut & 171 & IV & 31,89 & 37,97 & 9,67 & 0,00 & 0,00 & 79,53 \\
\hline & 391 & III & 0,00 & 9,63 & 0,00 & 3,72 & 1,81 & 53,07 \\
\hline & 401 & III & & 0,00 & 5,5 & 8,26 & 2,69 & 23,58 \\
\hline & & III & 0,00 & 11,75 & 0,0 & 67 & 5,53 & 80,91 \\
\hline Faro & 071 & III & 17,63 & 24,53 & 8,14 & 8,52 & 10,63 & 210,35 \\
\hline Verc & 321 & & 17,75 & 31,65 & 7,44 & 7,03 & 5,76 & 86,06 \\
\hline Bon & 041 & IV & 2,04 & 15,64 & 8,21 & 2,03 & 3,96 & 59,83 \\
\hline ossa & 231 & II & 3,39 & 9,18 & 6,1 & 3,87 & 4,13 & 61,01 \\
\hline & & | & & 11,53 & 3,7 & 6,45 & 0 & 59,07 \\
\hline Tra & 30 & II & & 15,80 & & 7,20 & ,24 & 121,84 \\
\hline & 05 & II & 0,00 & 24,75 & $0,($ & 5,26 & 2,56 & 201,21 \\
\hline & 13 & & 2,45 & 2,38 & 2,33 & 2,29 & 0,00 & 61,28 \\
\hline & 141 & & 2,37 & 8,10 & 3,39 & 3,61 & 7,33 & 62,40 \\
\hline Verde & 251 & 1 & 6,50 & 10,77 & 3,09 & 9,14 & 9,52 & 126,23 \\
\hline Ter & 241 & & & 11,05 & 2,9 & 0,97 & 0,94 & 58,02 \\
\hline & 18 & | & & & 10 & 84 & 4,18 & 249,28 \\
\hline Pon & 221 & II. & & 47 & 5 & 8,47 & 8,26 & 23 \\
\hline abeiras & 16 & I & 11,7 & & 1, & 6,30 & 24,58 & 129,19 \\
\hline Poç & 211 & I & 5,68 & 10,64 & 4,57 & 2,87 & 4,40 & 77,40 \\
\hline & 15 & II & 6,61 & 20,24 & 1,8 & 5,29 & 7,75 & 85,99 \\
\hline de Bebedo & 431 & IV & 0,00 & 3,13 & 0,73 & 1,44 & 2,11 & 35,02 \\
\hline & 19 & III & & 6,93 & 1, & 2,39 & 1,86 & 17,72 \\
\hline & 831 & V & 0,00 & 0,00 & 7,20 & 0,00 & 0,00 & 0,00 \\
\hline & 35 & V & 7,97 & 30,27 & 1,14 & 0,37 & 4,01 & 63,77 \\
\hline uro & 01 & V & 4,0 & 9,87 & 4,82 & 1,90 & 5,56 & 69,73 \\
\hline & 51 & 1 & 10,03 & 26,86 & 4,77 & 2,35 & 6,88 & 96,41 \\
\hline & 88 & VI & 0,0 & 0,00 & 0,0 & 0,00 & 0,00 & 0,00 \\
\hline Doce & 271 & I & 38,35 & 42,04 & 13,72 & 4,49 & 4,38 & 81,48 \\
\hline
\end{tabular}

Fonte: SINAN/PROVEP/SESAU-AL 
Figura 7 - Coeficientes de incidência da dengue (casos por 10.000 habs.) segundo bairros. Maceió, 1997 - 2002
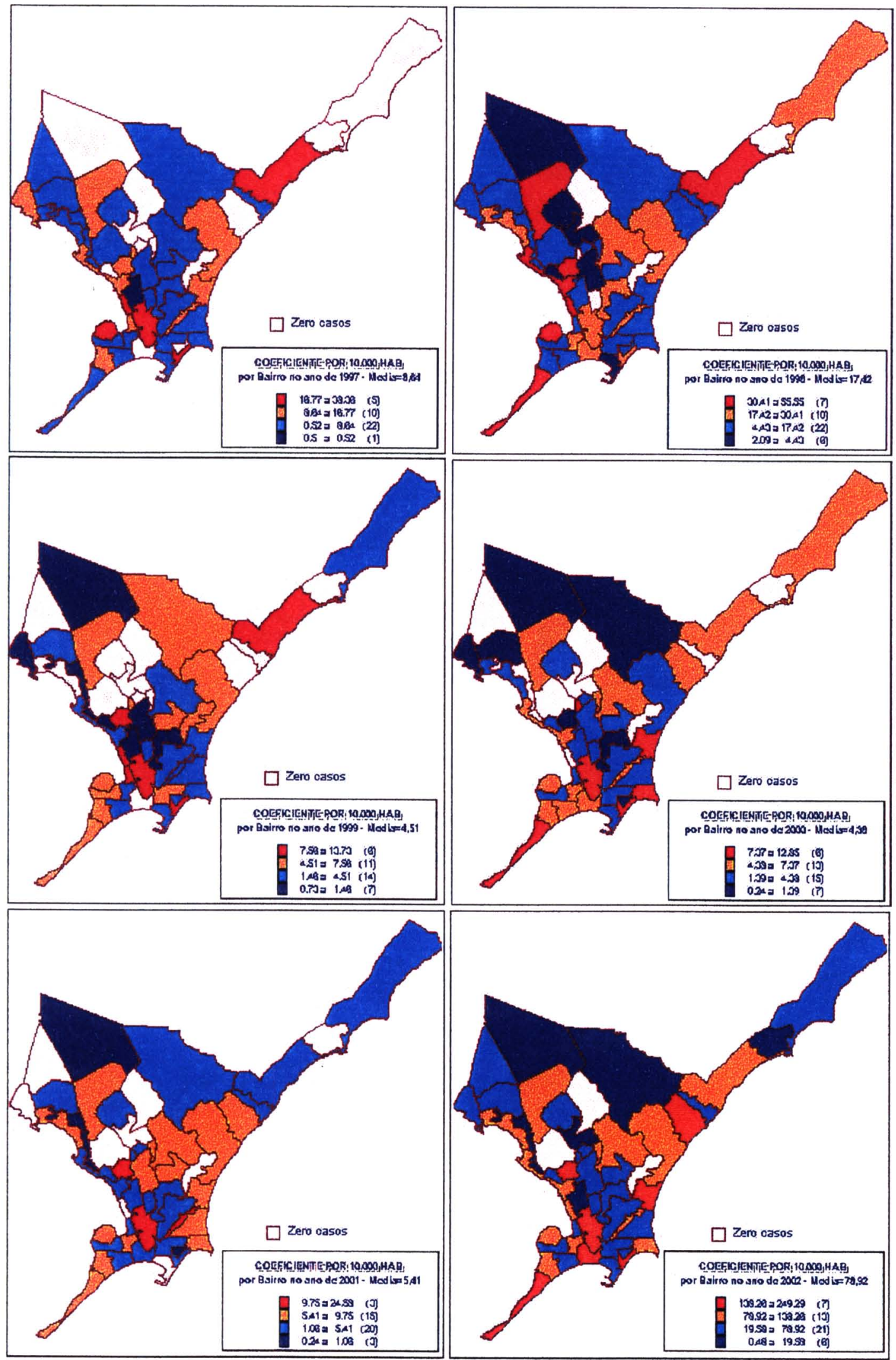

Fonte: SINAN/PROVEP/SESAU-AL 
Figura 8 - Município de Maceió. Divisão por bairros

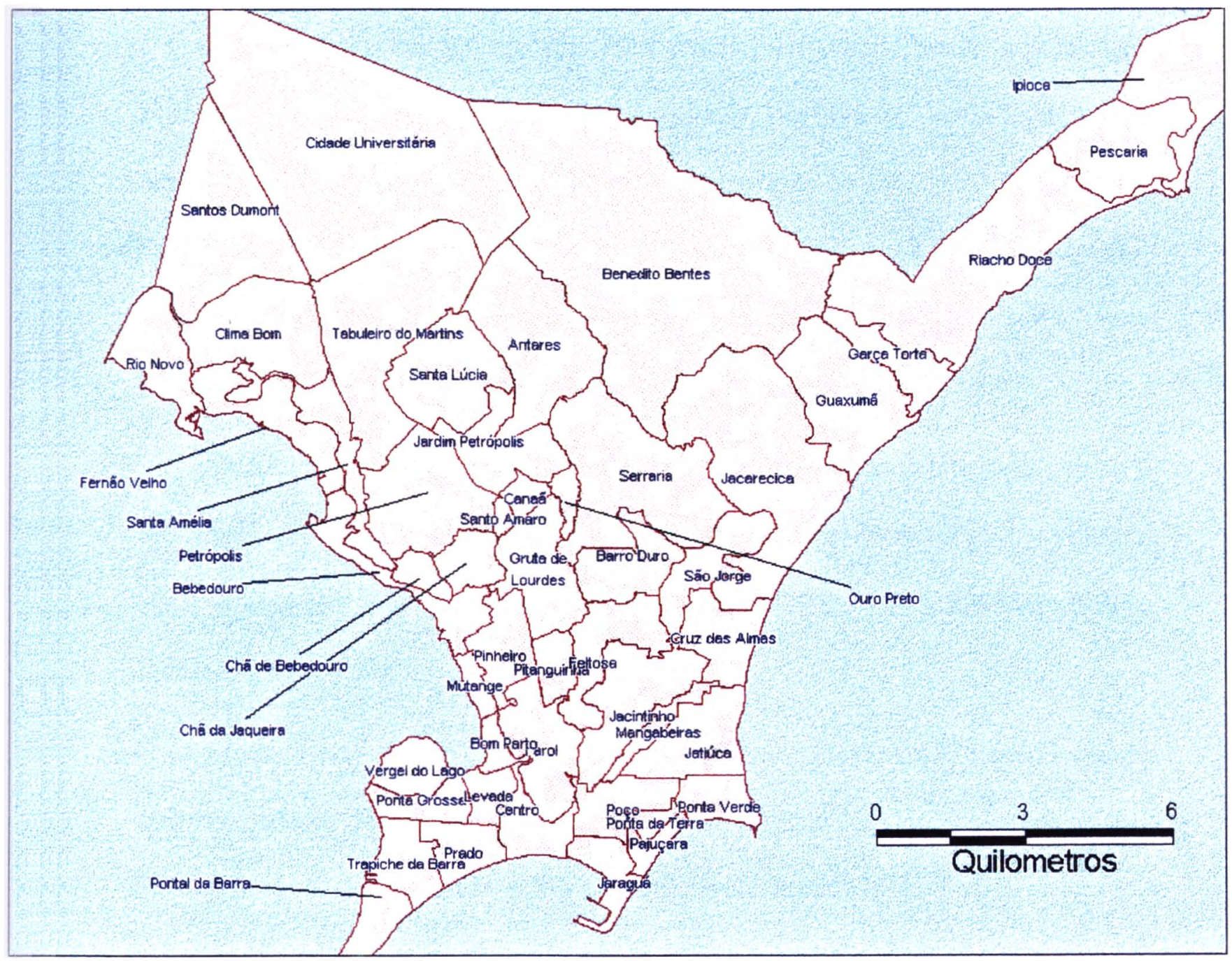

Fonte: SMCCU - AL 


\subsection{MEDIDA DE INFESTAÇÃO DOMICILIAR POR AEDES AEGYPTI}

O resultado do Índice Infestação Predial (IP) para medir a infestação domiciliar por Aedes aegypti e os bairros estudados, constam da Tabela 5, Figura $9 \mathrm{e}$ Anexo 10. Tal índice variou entre 0,0 a $8,3 \%$ no período de 1997 a 2002 . O IP mais elevado ocorreu durante o ano de 2000 , com valores entre 5,4 e $8.3 \%$, nos seguintes bairros: Ponta Grossa (231); Jacintinho (121); Chã de Bebedouro (431); Santo Amaro (401); Jardim Petrópolis (821) e Ouro Preto (371).

No ano de 1999 foram encontrados os menores índices de infestação, sendo o IP máximo de $0,6 \%$. Os bairros positivos foram Trapiche da Barra (301); Pajuçara (181); Riacho Doce (271); Santo Amaro (401); Fernão Velho (081); Rio Novo (491) e Santos Dumont (671).

Para o ano de 1998 o IP obtido variou entre $0,1 \%$ a $6,3 \%$ sendo que os maiores valores foram encontrados nos bairros Poço (211); Jacintinho (121); Petrópolis (501); Santo Amaro (401) e Cidade Universitária (781).

Em 2002, o IP encontrado variou entre $0,0 \%$ a $5,5 \%$ com os maiores índices nos bairros Pajuçara (181); Poço (211); Farol (071); Feitosa (351); Clima Bom (341) e Cidade Universitária (781).

No período de 1998 a 2001, o bairro Jacintinho (121) apresentou sempre os maiores índices de infestação.

Os resultados apresentados nas Figuras 10, 11, 12, 13 e Anexos 12, 13, 14 e 15, evidenciam instabilidade para as correlações entre incidência de dengue e IP, com temperatura e chuva. Na figura 13, multiplicou-se os valores do IP por 100 para ajuste na escala gráfica e leitura das variáveis utilizadas. Também pode ser notado que a 
maioria desses resultados não foram considerados estatisticamente significantes $(\mathrm{p}<0,05)$. Com exceção, registram-se entretanto correlações significantes para os anos 2000 e 2001 tanto para incidência como para o IP sendo as mesmas consideradas consistente para ambos os anos. Na Tabela 6 são apresentados os resultados dos cálculos das referidas correlações.

Tabela 5 - Índice de infestaçâo predial de Aedes aegypti, por mes e ano. Maceió 1997 - 2002*

\begin{tabular}{cccccccccccccc}
\hline ANO & IIP01 & IIP02 & IIP03 & IIP04 & IIP05 & IIP06 & IIP07 & IIP08 & IIP09 & IIP10 & IIP11 & IIP12 \\
\hline 1997 & 1,13 & 0,56 & 0,00 & 3,91 & 5,22 & 0,74 & 0,00 & 0,00 & 1,70 & 0,56 & 0,00 & 1,02 \\
1998 & 0,00 & 0,00 & 1,75 & 3,06 & 4,33 & 4,79 & 3,11 & 2,24 & 1,40 & 3,68 & 2,61 & 1,12 \\
1999 & 1,19 & 1,53 & 1,56 & 1,40 & 0,45 & 1,57 & 1,21 & 0,22 & 0,63 & 2,00 & 2,41 & 1,87 \\
2000 & 3,09 & 2,91 & 3,07 & 3,66 & 4,86 & 5,08 & 5,39 & 4,78 & 4,61 & 3,70 & 3,21 & 2,18 \\
2001 & 0,00 & 0,00 & 2,35 & 4,48 & 5,23 & 6,55 & 6,77 & 5,34 & 4,67 & 5,33 & 4,96 & 4,69 \\
$2002^{\star}$ & 5,07 & 2,02 & 1,29 & 2,32 & 2,48 & & & & & & & \\
\hline
\end{tabular}

(*) Dados preliminares até maio. Fonte FUNASA - SMS - AL. 
Figura 9 - Índice de Infestação Predial de Aedes aegypti, por bairro. Maceió 1997 2002.
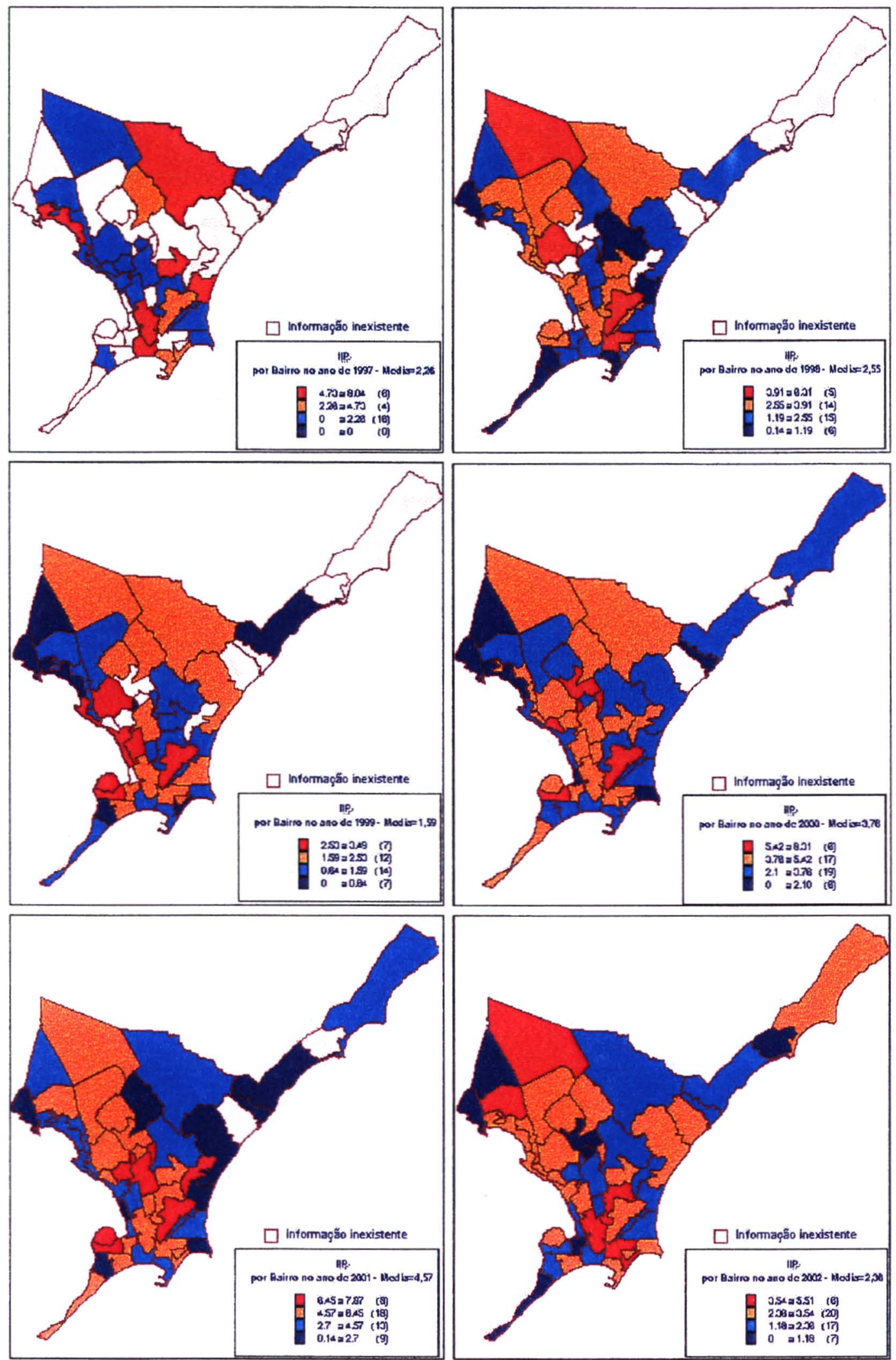

Fonte: FUNASA/SMS - AL 
Figura 10 - Temperatura e coeficientes de incidência da dengue por mês e ano (por 100.000 habs.). Maceió, 1997 - 2002*
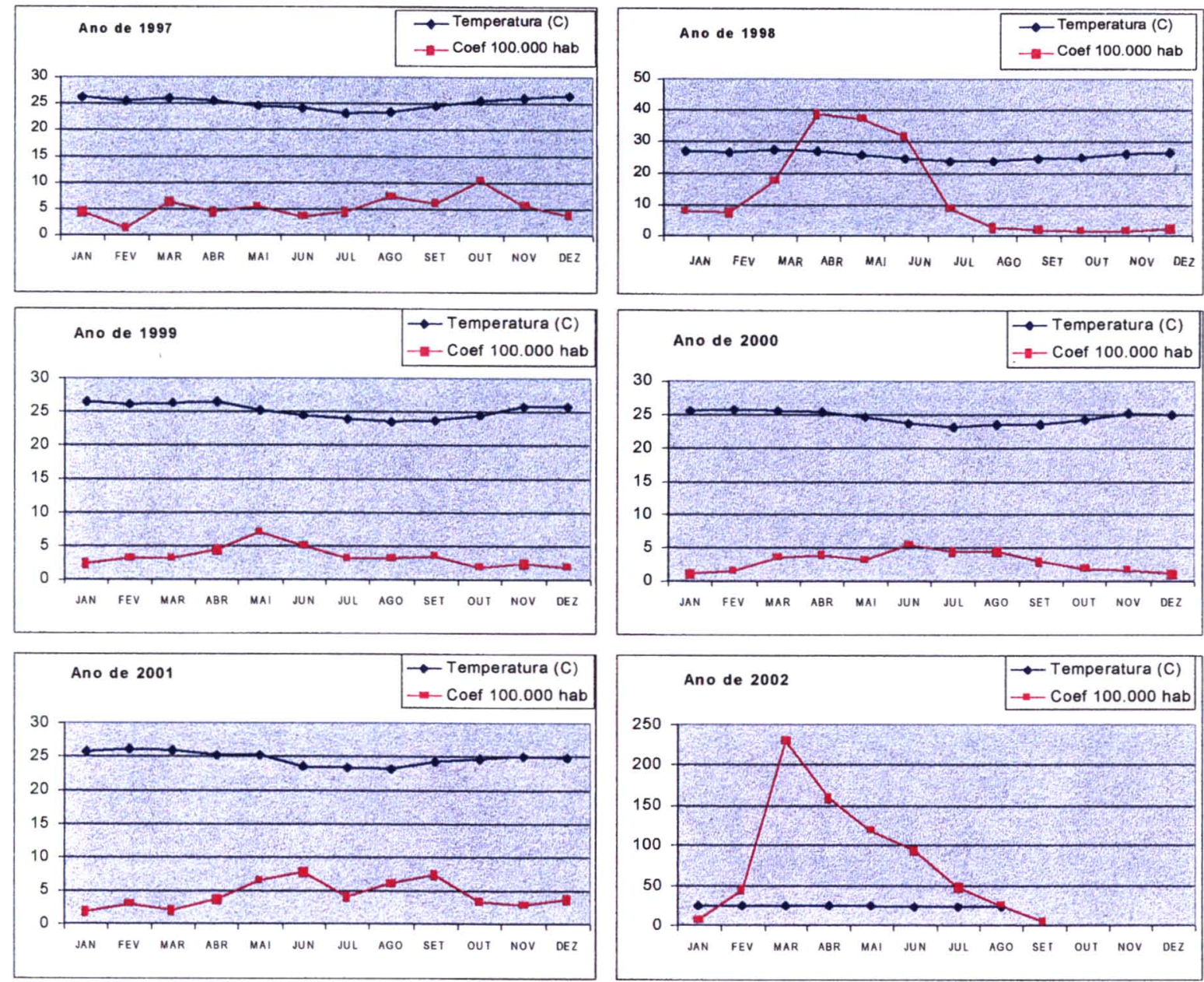

(*) Dados preliminares até o mes de agosto.

Fonte: INMET/SINAN/PROVEP/SESAU - AL 
Figura 11 - Precipitação e coeficientes de incidência da dengue por mês e ano (casos por 1.000.000 habs.). Maceió, 1997 - 2002*
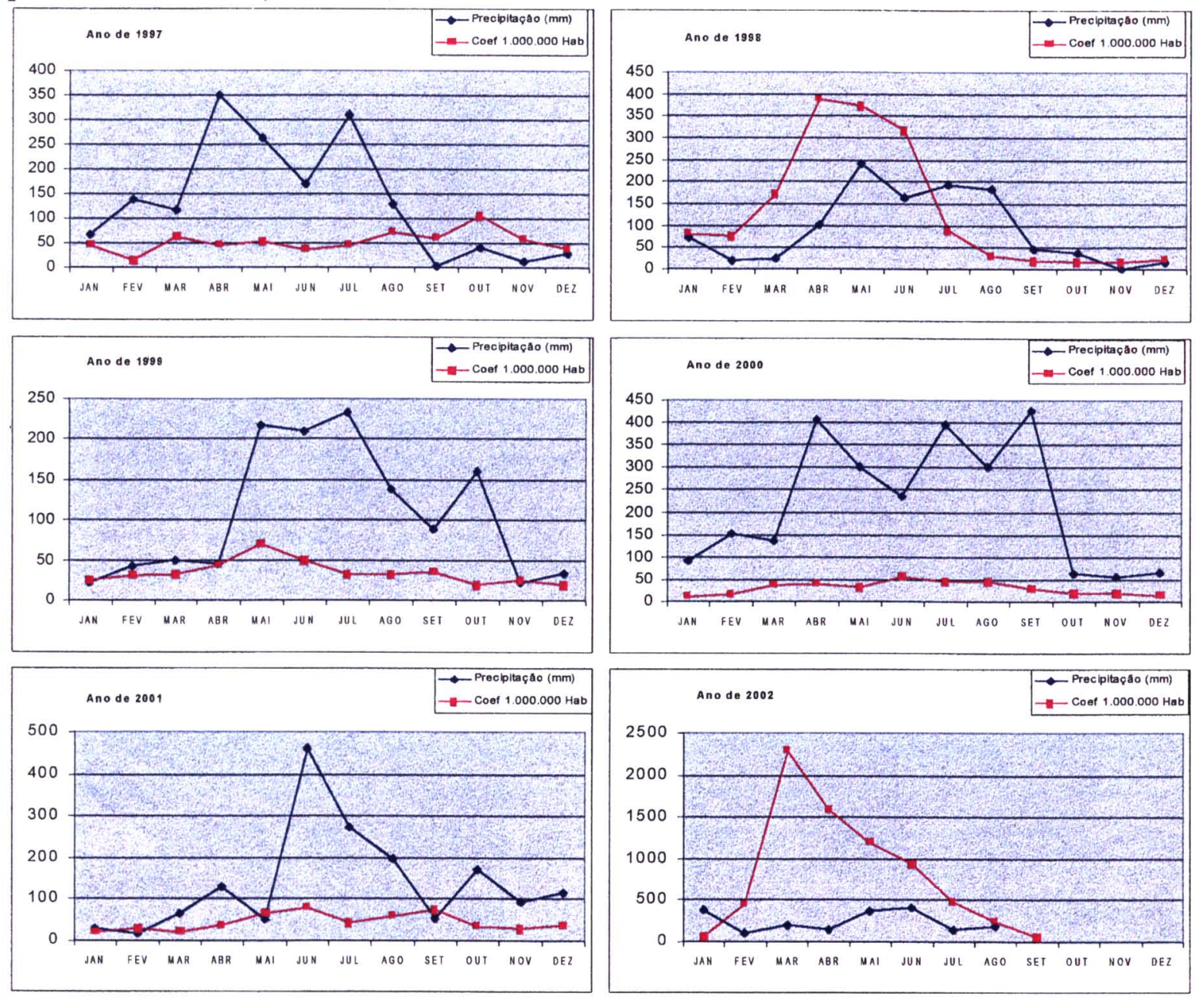

(*) Dados preliminares até o mes de agosto.

Fonte: INMET/SINAN/PROVEP/SESAU - AL 
Figura 12 - Temperatura e índice de infestação predial por mês e ano. Maceió, 1997 2002*
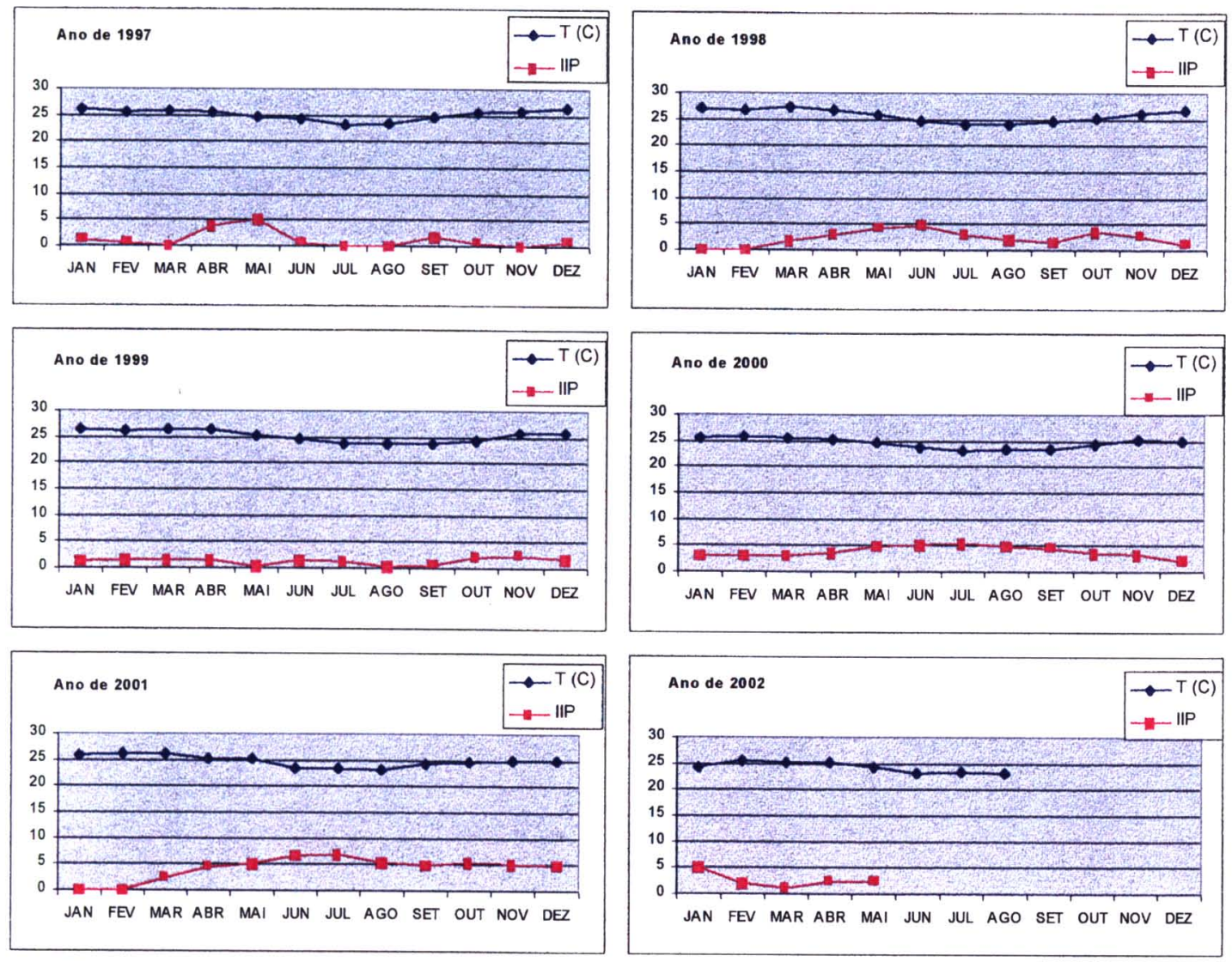

(*) Dados preliminares até maio.

Fonte: INMET - FUNASA - SMS - AL 
Figura 13 - Precipitação e índice predial. Maceió, 1997 - 2002*
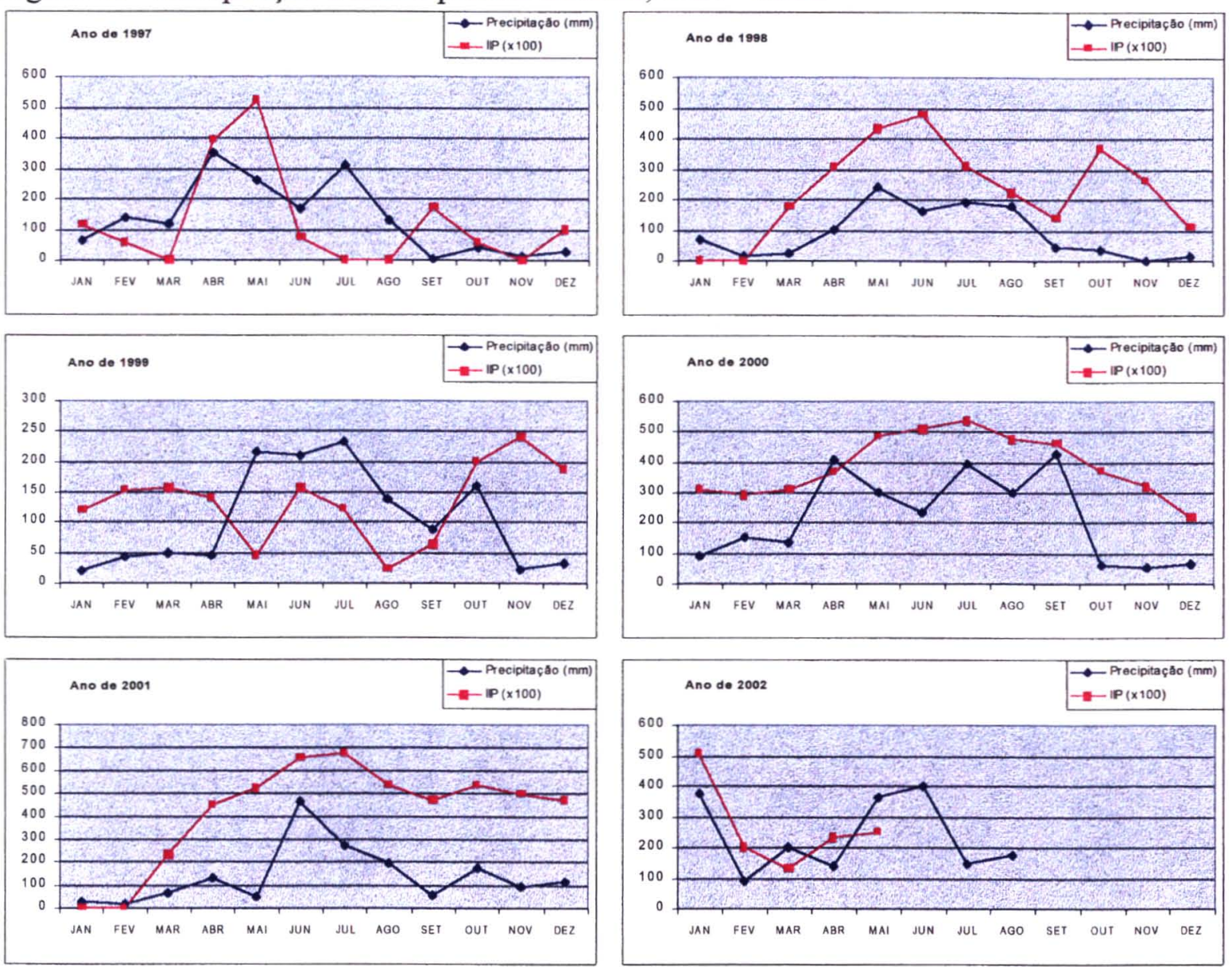

(*) Dados preliminares até maio.

Fonte: INMET - FUNASA - SMS - AL

Tabela 6 - Coeficientes de correlação (r) e valores de (p) para Incidência da Dengue e Índice de infestação Predial (IP) ,comparados à Chuva e Temperatura. Maceió, 19972002.

\begin{tabular}{|c|c|c|c|c|c|c|c|}
\hline VARIÁVEIS & $\begin{array}{l}\text { ESTATÍS } \\
\text { TICAS }\end{array}$ & 1997 & 1998 & 1999 & 2000 & 2001 & 2002 \\
\hline \multicolumn{8}{|l|}{ CHUVA } \\
\hline \multirow{2}{*}{ Incidência Dengue } & $\mathrm{r}$ & 0,3027 & 0,5370 & 0,5292 & 0,6706 & 0,4934 & $-0,0740$ \\
\hline & $\mathrm{p}$ & 0,339 & 0,072 & 0,077 & $0,017^{*}$ & 0,103 & 0,861 \\
\hline \multirow{2}{*}{ IP } & $\mathrm{r}$ & 0,4910 & 0,5963 & $-0,3845$ & 0,7286 & 0,6828 & 0,2989 \\
\hline & $\mathrm{p}$ & 0,105 & $0,041^{*}$ & 0,217 & $0,007 *$ & $0,014 *$ & 0,472 \\
\hline \multicolumn{8}{|l|}{ TEMPERATURA } \\
\hline \multirow{2}{*}{ Incidência Dengue } & $\mathrm{r}$ & $-0,0694$ & 0,1905 & $-0,0798$ & $-0,6153$ & $-0,6710$ & 0,4987 \\
\hline & $\mathrm{p}$ & 0,830 & 0,553 & 0,805 & $0,033^{*}$ & $0,017 *$ & 0,208 \\
\hline \multirow{2}{*}{ IP } & $\mathrm{r}$ & 0,0553 & $-0,4609$ & 0,4404 & $-0,8340$ & $-0,8137$ & $-0,6879$ \\
\hline & $\mathrm{p}$ & 0,864 & 0,132 & 0,152 & $0,001^{*}$ & $0,001^{*}$ & 0,199 \\
\hline
\end{tabular}

* Correlações significantes $(\mathrm{p}<0,05)$ 


\subsection{FATORES CLIMÁTICOS}

A temperatura em Maceió mostrou pouca variabilidade sendo a temperatura média de $28^{\circ} \mathrm{C}$. A pluviosidade envolveu todos os meses do ano, porém as maiores precipitações ocorreram entre os meses de abril e agosto (Anexos 14 e 15). 
5 DISCUSSÃO 


\section{DISCUSSÃO}

Sabe-se que diversos fatores como a intensa urbanização e o aumento do intercâmbio entre diferentes regiões brasileiras e estrangeiras favoreceram a reinfestação e a disseminação do Ae. aegypti no Brasil. Desta forma, criaram-se condições essenciais para ocorrência da dengue em nosso meio, cuja casuística teve inicio a partir de 1982 no Estado de Roraima, sendo ampliada por sucessivos eventos epidêmicos nas cidades mais populosas (Osanai 1984; Marzochi 1994;Trpis e col. 1995; Forattini 1998; Santos e col. 1999; Teixeira e col. 1999; Nogueira e col. 2000).

Os primeiros casos da dengue no Estado de Alagoas ocorreram nos anos de 1986/1987, com registros de 12.625 casos e coeficiente de incidência de 411,2 por 100.000 habitantes, com maior registro da doença em Maceió. Esta epidemia causada pelo DEN-1 foi sucedida pela redução dos casos notificados nos anos seguintes, mas com a entrada do DEN-2 no ano de 1991 este quadro se reverteu resultando na notificação de 1.317 casos e taxa de incidência de 52,6 por 100.000 habitantes. Suspeitou-se que os dois sorotipos circulantes na cidade do Rio de Janeiro tenham se propagado para aquela localidade (Serufo e col. 1993). A partir de 1994, se observa a elevação do número de notificações no mesmo município, doravante resultante da circulação de dois sorotipos. Nesta cidade ainda foram registrados 225 casos em 1996, com taxa de incidência 31,1 por 100.000 habitantes(SESAU/AL 1998 ${ }_{\mathrm{a}}, 1998_{\mathrm{b}}$, 1999).

Neste contexto a análise epidemiológica da doença em Maceió nos anos subsequentes, permitiria conhecer o perfil de sua ocorrência neste município. Para isso, foram selecionadas algumas variáveis que pudesse explicar a distribuição 
temporal e espacial da doença na referida cidade, a partir de dados secundários disponíveis na Secretaria de Estado da Saúde de Alagoas.

A distribuição dos casos segundo a semana epidemiológica, que é um procedimento do Ministério da Saúde, demonstrou que a notificação ocorreu de janeiro a dezembro, porém quando se visualiza a curva epidêmica do ano 2002 se verifica que a partir da semana 5 o número de casos se eleva atingindo pico máximo na semana 11 , sucedido pelo declínio até a semana 36 . Contudo, quando se analisa o período epidêmico de 1998, com menor número de casos, comparativamente a 2002 se observou que $o$ pico de maior incidência se deslocou para a semana 15 (SESAU/AL 2002). Uma epidemia no Estado do Espírito Santo em 2000 evidenciou elevação do número de casos até a semana 27 ( Benincá e Silva 2002). Ainda que o último dado seja de notificações de 20 municípios, a divergência verificada sinaliza para variabilidade da distribuição da dengue por localidade. Souza e col. 1995, observaram que a maior ocorrencia do número de casos da dengue em Fortaleza, aconteceu na semana 23. Epidemia ocorrida em Cuba (Valdés e col. 1997), mostrou que as maiores incidências foram nas semanas epidemiológicas 17 a 30 correspondente aos mêses de maio a agosto, com maior pico na semana 22. Em Rio Branco (Acre), epidemia de dengue ocorrida em 2000, mostrou que os primeiros casos aconteceram na primeira semana de janeiro, com pico nas semanas 30 a32 e 48 a 52 (Lobato e col. 2002). Pereira e col. 2002, em recente trabalho realizado em Porto Velho, mostraram altos índices da dengue na semana 47.

$\mathrm{Na}$ Tabela 2 e Figura 4, são apresentados os coeficientes mensais de incidência, onde observa-se uma grande variabilidade nos valores encontrados, demonstrando que as condições de transmissão se diferenciam por influência dos 
diferentes índices de infestação vetorial e número de pessoas com viremia, tanto em Maceió, como em outras cidades. A tabela 2 demonstra que o coeficiente de incidência é mais expressivo entre os meses de março a junho para 1998 e de fevereiro a junho para 2002. Teixeira e col. 1999, assinalaram que a maior incidência da dengue no Brasil aumenta significativamente nos primeiros meses do ano, cujas taxas mais elevadas ocorrem de março a maio e com diminuição a partir de junho. Benincá e Silva 2002, relataram que a incidência no Espirito Santo passa a ser significativa nos primeiros meses do ano. Informações da FUNASA indicam que a incidência da dengue no Brasil é mais significativa nos meses de março a maio (Ministério da Saúde 2002). Assim sendo, a dengue em Maceió segue a mesma curva de incidência do padrão nacional de transmissão desta doença( Salas-Luévano e Reyes-Villanueva 1994).

Por outro lado, os dados de Maceió evidenciam que o comum para os anos interepidêmicos foi os coeficientes oscilarem entre 1,1 a 10,4 casos por 100.000 habitantes, enquanto que no ano epidêmico de 1998 os coeficientes de incidência estiveram entre 1,7 a 39,0 casos por 100.000 habitantes. Para o ano de 2002 os coeficientes de incidência oscilaram entre 5,4 a 229 casos por 100.000 habitantes(Tabela 2). A discordância entre os níveis epidêmicos mencionados, evidencia-se por conta da variabilidade das taxas registradas, que por sua vez refletem condições adversas de transmissão do vírus existentes entre as localidades (Teixeira e col. 1999).

No caso da epidemia de 2002, quando circulava os sorotipos 1,2 e 3 , com curto intervalo de tempo da entrada do sorotipo 3, foram registrados os mais elevados coeficientes de incidência da dengue ( SESAU/AL 2002). Isto sugere que a 
magnitude da epidemia teve relação direta com a intensa circulação dos três sorotipos, particularmente pela recém entrada do DEN-3 (Nogueira e col. 2001; WHO 2001; Figueiredo e col. 2002; ).

Pelos coeficientes de incidência do ano de 1997, onde o mês de outubro fugiu ao padrão da curva endêmica e epidêmica, pode-se aventar a hipótese de que a epidemia de 1998 possa ter se iniciado a partir daquele mês. Ao contrário, a epidemia de 2002 foi antecedida por período de três anos com incidência de dengue bem reduzida.

Historicamente, as epidemias de dengue têm ocorrido nas estações quentes do ano, estando também associada aos meses chuvosos, porque temperatura e chuva favorecem a proliferação do Ae.aegypti e replicação do vírus (Moore e col. 1978; Gubler 1988; Rebêlo e col.1999; Silva e Silva 1999; Azevedo e col. 2002). Na cidade de Maceió, como em outras cidades da região Nordeste a temperatura é elevada durante todo o ano, justificando assim a transmissão da dengue ao longo dos meses do ano (Dirección de Información y Vigilância Epidemiológica - México 1995; Souza e col. 1995; WHO 2001; Azevedo e col. 2002; Benincá e col. 2002; Lobato e col. 2002; Mourão e col. 2002; Saraiva e col. 2002; Timbó e col. 2002).

No que tange as chuvas em Maceió, a análise de correlação desta com a doença foi estatisticamente significante apenas para o ano 2000 (Tabela 6; Fig. 11). Neste ano, a transmissão foi baixa não se verificando um ano epidêmico. Também se observou que os picos de transmissão das duas epidemias não tiveram uma estreita relação com o período maior de pluviosidade. Partindo do pressuposto de que esta relação seja verdadeira, isto significa que a produção de adultos para a transmissão da doença tenha encontrado maior suporte em recipientes menos sujeitos a ação das 
distribuição mensal dos casos ocorreu de janeiro a maio, sendo que os maiores índices variaram entre poucos meses de cada ano.

Benincá e Silva 2002, chamam atenção para as variações nas freqüências mensais de casos no Estado do Espírito Santo. Portanto, para se predizer o período de maior probabilidade de ocorrência de casos ou exposição humana, torna-se necessário à realização de outros estudos longitudinais, inclusive para o município de Maceió, pela falta de maiores conhecimentos sobre a dinâmica de transmissão da doença (Silveira 1998; Figueiredo 1999; Freire e col. 2000; Santos e Carvalho 2000; Rodrigues e col. 2002).

O homem é o único hospedeiro conhecido para a dengue, motivo pelo qual precisa-se descrever o comportamento da incidência segundo atributos idade e sexo, para o município de Maceió. No geral, se observa que não se tem um padrão único de idade na ocorrência da dengue (Figueiredo e col. 1995; Marquetti e col. 1995; Souza e col. 1995; OPS 1996; Teixeira e col. 1999, 2001), mas por outro lado, tem se verificado uma tendência para elevada ocorrência dos casos em faixas etárias com maior idade. Este aspecto tem sido mais comum quando da entrada de um sorotipo numa área indene. Um fato a ser destacado seria a resposta dada na entrada de um segundo sorotipo. Assim pois, admite-se que a distribuição etária da doença se expande para grupos etários de menor idade quando da entrada de novos sorotipos; discussão sobre este aspecto na literatura, trata da possivel interferência do esgotamento dos suscetíveis no grupo de indivíduos adultos (Figueiredo e col. 1995; OPS 1996; Passos e col. 1998; Teixeira e col. 1999; Valdés e col. 1999; Barrera e col. 2000; WHO 2001; Lobato e col. 2002; Timbó e col. 2002). 
No caso de Maceió a primeira epidemia ocorrida no ano de 1998, predominaram taxas mais elevadas na população acima de 40 anos. Com a entrada do segundo e terceiro sorotipos a epidemia tendeu ainda a ocorrer em adultos, porém com ampliação das faixas etárias destacando-se o grupo de 15 a 49 anos. As taxas ocorridas neste município se assemelham muito a registrada em Tapachule no México, cujas pessoas mais afetadas estavam entre as idades de 15 a 44 e 45 e mais anos (Narro-Robles e Gómez-Dantés, 1995). Noutras localidades do território brasileiro como Ipupiara e Prado, na Bahia, durante a primeira epidemia a dengue foi assinalada em todos os estratos etários, porém com maior prevalência nos indivíduos entre 45-54 anos (Vasconcelos e col. 2000). Na primeira epidemia de dengue no Acre, ano 2000, 70,6\% dos casos atingiram a faixa etária de 15 a 49 anos (Lobato e col. 2002). Com inquéritos sorológicos, o estudo de Fortaleza, após sucessivas epidemias anteriores, demonstrou que não houve diferença estatística significativa entre sexo e idade, concluindo que o risco de se infectar pelo vírus da dengue independe desses dois atributos (Vasconcelos e col. 1998). Na cidade de Belém foi encontrado que sorológicamente as faixas mais afetadas pelos vírus estavam com 55 anos ou mais, embora um número alto também fosse registrado entre 15 e 54 anos (Rosa e col. 2000). Uma avaliação dos casos importados no Estado de São Paulo, revelou que a maior freqüência ocorreu na faixa de 20 a 59 anos (Nascimento, 2001), refletindo o padrão de ocorrência desta doença.

Conhecendo a intensa atividade turística para a região Nordeste e em especial modo para Maceió, pode ser estabelecida uma ponte com eventos epidêmicos transcorridos em outras localidades brasileiras, cuja migração de pessoas com afazeres diversos seria responsável pela introdução do vírus da dengue. Lima e col. 
2002, verificaram que no período de 1998 a 2000 não encontraram significância estatística na relação de idade na cidade do Recife, lembrando que, pelo menos o DEN-1 e DEN-2, circulavam no município. Face a isto, fica explicito que o padrão de ocorrência da dengue segundo a idade, pode sofrer alteração em função do tempo de ocorrência e múltipla circulação viral. Todavia, essas informações sugerem que a igualdade de exposição de todos os grupos etários de uma localidade seja dependente de um tempo de endemicidade da doença, pois parece que na medida que a endemia evolui para uma estabilidade não seria mais possível distinguir este ou aquele grupo etário, exceto quando a doença depender do aparecimento de novos grupos suscetíveis, pois os afetados pelos sorotipos estariam imunes a novas ocorrências (Teixeira e col. 1999). Para Bastos e col. 2002, a soroprevalência em Manaus demonstrou que a faixa etária mais afetada foi de 20 a 29 anos, com $25,5 \%$ de positividade. Neste mesmo período, Mourão e col. 2002, chamou atenção para internações, nas quais $27,3 \%$ eram crianças de até 12 anos e $72,7 \%$ eram adultos. Num perfil clínico-epidemiológico da dengue no Ceará, Timbó e col. 2002, registraram a ocorrrência da doença em $51,2 \%$ na faixa etária de 35 a 64 anos. Por outro lado, Figueiredo e col. 1995, não encontraram diferença significativa entre as faixas etárias pesquisadas.

Quando se analisa os registros da dengue segundo o sexo, depara-se com uma variabilidade pequena sugerindo que o resultado varia conforme o tipo de exposição desses indivíduos ao vírus. Vasconcelos e col. 2000, verificaram diferença significativa entre homem e mulher quando analisaram o resultado de um estudo soroepidemiológico nas cidades de Ipupiara e Prado, Bahia, cujo sexo feminino superou o sexo masculino. No Estado do Acre, não foi tão diferente, pois encontrou- 
se uma proporção de indivíduos do sexo masculino de $43,4 \%$ entre o grupo estudado (Lobato e col. 2002). Além disso, corrobora com o suposto maior envolvimento do sexo feminino na dengue, o inquérito sorológico realizado em Manaus, onde 58,3\% dos casos pertenciam a este sexo (Bastos e col. 2002). Já em Belém as proporções foram de 54,25 para as mulheres e 45,75 para homens (Rosa e col. 2000). Em Maceió, o coeficiente de incidência, para o período estudado, foi sempre maior para sexo feminino. Vasconcelos e col. 1999, não encontrando significância estatística entre sexo, com base na casuística estudada no Maranhão sugeriram que este fato poderia ser explicado pela igual chance de exposição para ambos. A despeito dessas pequenas variabilidades entre sexo masculino e feminino, essas informações reforçam a tendência para a dengue ocorrer independentemente de ser o suscetível homem ou mulher ( DIVE - México 1995; OPS 1996).

A característica de ocorrência espacial da dengue não apresenta uma paisagem uniforme entre seus componentes ambientais. Lima e col. 1999, ao analisar o coeficiente de detecção da dengue em zona urbana do Estado de São Paulo verificou que as taxas segundo os distritos variaram entre $11,0 \%$ a $24,8 \%$, o que não significa necessariamente que a transmissão esteja rigidamente relacionada ao local de moradia da pessoa. Em Maceió, também se constata que houve variabilidade entre os bairros, numa faixa de 0,2 a 249,3 casos por 10.000 habitantes, cujos índices mais elevados estiveram restritos apenas a sete bairros. Se for levada em conta a taxa de incidência entre os anos estudados, mais uma vez a alternância das incidências entre eles fica evidenciada (figuras 7 e anexo 9). Alguns autores tentam explicar o comportamento espacial da incidência considerando as características do ambiente e condição social de seus habitantes. Entretanto, tem-se ora uma maior incidência em bairros com 
elevado padrão econômico e social, ora em ambiente bem degradado ocupado por população pobre (Barrera e col. 2000; Vasconcelos e col. 2000; Lessa e col. 2002). Assim, a diferenciação poderá ser encontrada na condição de maior produtividade do Aedes aegypti.

$\mathrm{O}$ vírus da dengue para circular numa área precisa do Ae. aegypti, portanto o ambientẹ deve oferecer condições ecológicas ao seu desenvolvimento e sua atividade reprodutiva. A condição ecológica para isto reside na oferta de artefatos que acumulem água(Bond e Fay 1969; Marquetti e col. 1995; Chiaravalloti Neto 1997; Barrera e col. 2000; Cunha e col. 2002). A interferência do homem quer restringindo os locais de criação do mosquito, quer estabelecendo barreiras químicas que dificultem o desenvolvimento de seu ciclo vital, determinam a regulação populacional do Ae. aegypti (Reiter e col. 1995). Analisar a distribuição espacial de sua infestação, onde aqueles fatores estão presentes, é uma tarefa difícil. No município de Maceió, existem bairros com indices negativos e outros com valores de $8,3 \%$, comumente ao que se observa em outras localidades. Se for verificado que os indicadores entomológicos apontam resultados que variaram entre os bairros e entre os anos estudados, fica a idéia de que a infestação tem uma mobilidade em função da disponibilidade de recipientes, fruto dos hábitos da comunidade(Alves e col. 1991; Lopes e col. 1993; Suwonkerd e col. 1996; Augusto e col. 1998; Oliveira 1998; Santos e col. 1999; Lenzi e col. 2000; Barata e col. 2001). Na Figura 9 e Anexo 10 se observa a ampla variabilidade do índice de infestação segundo os bairros de Maceió. Nesta se nota ainda a média da positividade dos mesmos se distribuindo irregularmente no período estudado. Este fato ocorreu entre os anos, na seguinte distribuição: 1997 foi de 2,3\%; em 1998 ficou em 2,6\%; 1999 esteve em 1,6\%;2000 
com $3,8 \% ; 2001$ com $4,6 \%$ e 2002 com $2,4 \%$. O bairro Jacintinho se destacou pela constância de índices entomológicos mais altos de 2,6 a $8,3 \%$, enquanto outros que apresentaram índices mais baixos entre 0,0 a $0,6 \%$ foram Trapiche da Barra, Pajuçara, Santo Amaro e Fernão Velho, no ano de 1999 (SESAU/AL 1999; SMS/Mcz 2002).

O estudo da correlação entre o IP e Chuva foi significante nos anos de 1998, 2000 e 2001(Tabela 6), indicando que o índice larvário cresceu com o período de chuvas, o que poderá sugerir que os recipientes a céu aberto contribuíram para a elevação do IP nesses anos. Ao contrário, se os dados obtidos nos anos de 1997, 1999 e 2002, não revelaram igualmente esta diferença, poderia ser admitido que os IP desse periodo tenha contado com a maior participação dos recipientes alimentados com água de abastecimento (Oliveira e Valla 2001; Joshi e col. 1996). Para Maceió, os índices de infestação foram maiores nos meses de março a agosto, quando as chuvas foram mais freqüentes de março a agosto. Por outro lado, na relação de sobreposição da curva de incidência da dengue com a chuva foi demonstrado um padrão similar (SESAU/AL 1999, 2001; SMS/Mcz 2002). Noutras localidades os estudos também demonstraram que a sazonalidade dos casos coincidiu com o ritmo do crescimento da pluviometria (Azevedo e col. 2002; Glasser e Gomes 2002; Lima e col. 2002; Saraiva e col. 2002).

A correlação entre IP e temperatura sendo significativa nos anos de 2000 e 2001, demonstra que a densidade do Ae. aegypti cresceu com a diminuição da temperatura (Tabela 6). Marquetti e col 1995; WHO 2001; Benincá e col. 2002; Glasser e Gomes 2002; Teixeira e col. 1999, 2002, atribuiram o aumento da densidade de Ae. aegypti em virtude do aumento da temperatura. 
6 CONCLUSÕES 


\section{CONCLUSÕES}

1. O padrão sazonal levando-se em conta as semanas epidemiológicas de ocorrência da dengue em Maceió revelou níveis mais elevados nos primeiros meses do ano, similarmente ao padrão de ocorrência nacional.

2. A distribuição etária da incidência foi predominante entre adultos jovens e acima de 50 anos, causados pelos DEN-1, DEN-2 e DEN-3.

3. Na distribuição dos casos da doença em Maceió, sempre predominou o sexo feminino sobre o masculino, independentemente dos períodos epidêmicos e não epidêmicos.

4. A variabilidade dos coeficientes de incidência por bairrro confirma aspecto comum em relação a outras localidades.

5. A história da incidência em períodos epidêmicos e interepidêmicos sugerem uma endemicidade progressiva dos sorotipos virais encontrados.

6. A múltipla circulação de sorotipos numa localidade tende a ampliar o grupo de risco dentro da população exposta.

7. A medida da infestação pelo Índice Predial (IP) revelou uma distribuição não homogênea da infestação de $A e$. aegypti entre os bairros de Maceió.

8. A correlação comprovada entre IP e chuva sugere que a produtividade do vetor se torna mais elevada no período chuvoso que vai de abril a agosto.

9. A correlação comprovada entre IP e temperatura sugere que a infestação vetorial cresce com a diminuição da temperatura. 
10. Os dados analisados indicam a necessidade de mais estudos de comportamento vetorial e como o vírus se dissemina, além da exposição do homem aos dois fatores, com a finalidade de subsidiar estratégias de controle da dengue em Maceió. 
7 RECOMENDAÇÕES 


\section{RECOMENDAÇÕES}

1. Para prevenção da doença é necessário a integração do controle vetorial à Vigilância Epidemiológica.

2. Manter o banco de dados da dengue disponível para consulta de técnicos e pesquisadores.

3. Analisar rotineiramente os dados para divulgação contínua a fim de gerar motivação da comunidade no controle da doença.

4. No controle da doença é indispensável o monitoramente mensal dos indices de infestação vetorial.

5. Recomenda-se a elaboração de um programa de combate ao vetor sustentado nos conhecimentos da sua biologia, distribuição e comportamento.

6. Estudos incluindo a avaliação dos níveis de densidade larvária e outros indicadores de abundância do vetor nos várias bairros da cidade, nos ambientes intra e extradomiciliares, bem como na identificação e produtividade dos criadouros preferenciais, serão de elevada importância para elaboração de estratégias de prevenção e controle da dengue.

7. Melhorar o suprimento e armazenamento de água, tratamento dos resíduos sólidos, modificações dos criadouros (destruição, alteração, eliminação ou reciclagem de recipientes descartáveis).

8. Projetos de educação, instrução sanitária e participação da comunidade nos. programas de controle do vetor. 
8 REFERÊNCIAS 


\section{REFERÊNCIAS}

Albuquerque CMR, Melo-Santos MAV, Bezerra MAS, Barbosa RMR, Silva DF, Silva E. Primeiro registro de Aedes albopictus em área da Mata Atlântica, Recife, PE, Brasil. Rev Saúde Pública 2000; 34:314-5.

Alves MCGP, Gurgel SM, Almeida MCRR. Plano amostral para cálculo de densidade larvária de Aedes aegypti e Aedes albopictus no Estado de São Paulo, Brasil. Rev Saúde Pública 1991; 25:251-6.

Alves MCGP, Silva NN. Simplificação do método de estimação da densidade larvária de Aedes aegypti no Estado de São Paulo. Rev Saúde Pública 2001; 35:467-73.

Andrade CS, Cáceres AG, Vaquerizo A, Ibañez-Bernal S, Cachay LS. Reappearence of Aedes aegypti (Diptera: Culicidade) in Lima, Peru. Mem Inst Oswaldo Cruz 2001; 96:657-8.

Augusto LGS, Novaes TCP, Abrahão CEC, Pavão CA, Souza CA. Avaliação crítica do programa de erradicação do Aedes aegypti: contribuições técnicas para medidas de controle. Rev IMIP 2000; 14:90-7.

Augusto LGS, Torres JPM, Costa AM, Pontes C, Novaes TCP. Programa de erradicação do Aedes aegypti: inócuo e perigoso (e ainda perdulário). Cad Saúde Pública 1998; 14:876-7.

Avilés G, Rangeón G, Vorndam V, Briones A, Baroni P, Enria D, Sabatini MS. Dengue reemergente in Argentina. Emerg Infect Dis 1999; 5:575-8.

Azevedo RSS, Souza MRS. Rosa EST da, Rodrigues SG, Vasconcelos HB, Nunes MRT et al. Epidemia de dengue na Grande Belém. Análise dos casos confirmados entre 1998 e 2000. In: Anais do $28^{\circ}$ Congresso da Sociedade Brasileira de Medicina Tropical; 2002 fev 24-28; Foz do Iguaçu, Brasil. Foz do Iguaçu: Sociedade Brasileira de Medicina Tropical; 2002, p. 95. 
Barata EAM de Freitas, Costa AIP da, Chiaravalloti Neto F, Glasser CM, Barata JMS, Natal D. População de Aedes aegypti (L.) em área endêmica de dengue, Sudeste do Brasil. Rev Saúde Pública 2001; 35:237-42.

Barrera R, Avila J, Gonzalez-Telles S. Unreliable supply of potable water and elevated Aedes aegypti larval indices: a causal relationship? J Am Mosq Control Assoc 1993; 2:189-95.

Barrera R, Delgado N, Jiménez M, Villalobos I, Romero I. Estratificación de una ciudad hiperendémica en dengue hemorrágico. Rev Panam Salud Publica 2000; 8:225-33.

Barrera R, Navarro JC, Mora-Rodriguez, JD, Dominguez D, Gonzalez-Garcia JE. Deficiencia en servicios públicos y cría de Aedes aegypti en Venezuela. Bol Oficina Sanit Panam 1995; 118:410-23.

Bastos MS, Figueiredo RMP, Lima MJL, Almeida TMC, Sandoval JJF. Estudo sorológico do dengue no Estado do Amazonas no ano de 2001. In: Anais do $\mathbf{2 8}^{\mathbf{0}}$ Congresso da Sociedade Brasileira de Medicina Tropical; 2002 fev 24-28; Foz do Iguaçu, Brasil. Foz do Iguaçu: Sociedade Brasileira de Medicina Tropical; 2002, p. 98.

Benincá ARB, Silva TCC. Dengue: análise epidemiológica da doença no Espírito Santo no período de 1995 a 2001. In: Anais do $28^{\circ}$ Congresso da Sociedade Brasileira de Medicina Tropical; 2002 fev 24-28; Foz do Iguaçu, Brasil. Foz do Iguaçu: Sociedade Brasileira de Medicina Tropical; 2002, p. 91.

Bond HA, Fay RW. Factors influencing Aedes aegypti occurrence in containers. Mosq News 1969:13-21.

Calado DC, Silva MAN. Avaliação da influência da temperatura sobre o desenvolvimento de Aedes albopictus. Rev Saúde Pública 2002; 36:173-9.

Campos J, Andrade CFS. Susceptibilidade larval de duas populações de Aedes aegypti a inseticidas quimicos. Rev Saúde Pública 2001; 35:232-6. 
Cardoso Júnior RP, Scandar SAS, Mello NV, Ernandes S, Botti MV, NascimentoEMM. Detecção de Aedes aegypti e Aedes albopictus, na zona urbana do Município de Catanduva-SP, após controle de epidemia de dengue. Rev Soc Bras Med Trop 1997; 30:37-40.

[CDC]Centers for Disease Control and Prevention. Dengue outbreak associated with multiple serotypes-Puerto Rico, 1998. MMWR Morb Mortal Wkl Rep 1998; 47:952-6.

Chadee DD. Métodos de evaluación de la problación de Aedes aegypti y tratamientos com inseticidas en una población de Trinidad, Antillas. Bol Oficina Sanit Panam 1990;109:350-9.

Chadee DD. Size of emerging and host-seeking Aedes aegypti and the relationship to containers and blood-feeding success in Trinidad, West Indies. Bull Soc Vector Ecol 1993;18:105-8.

Chadee DD. Factors influencing the duration of blood-feeding by laboratory-reared and wild Aedes aegypti (Diptera: Culicidae) from Trinidad, West Indies. Ann Trop Med Parasitol 1997; 91:199-207.

Chan YC, Chan KL, Ho BC. Aedes aegypti (L.) and Aedes albopictus (Skuse) in Singapore City: distribution and density. Bull World Health Organ 1971; 44:61727.

Chiaravalloti Neto F. Aedes aegypti na região de São José do Rio Preto, Estado de São Paulo. São Paulo; 1993. [Dissertação de Mestrado - Faculdade de Saúde Pública da USP].

Chiaravalloti Neto F, Costa AIP, Soares MRD, Scandar SAS, Cardoso Júnior RP. Descrição da colonização de Aedes albopictus (Diptera: Culicidae) na região de São José do Rio Preto, SP, 1991-1994. Rev Soc Bras Med Trop 1996: 29:543-8.

Chiaravalloti Neto F. Conhecimento da população sobre dengue, seus vetores e medidas de controle em São José do Rio Preto, São Paulo. Cad Saúde Pública $1997 \mathrm{a} ; 13: 447-53$. 
Chiaravalloti Neto F. Descrição da colonização de Aedes aegypti na região de São José do Rio Preto, São Paulo. Rev Soc Bras Med Trop 1997b; 30:279-85.

Chiaravalloti Neto F. Epidemiologia da dengue nas regiões de São José do Rio Preto e Araçatuba, São Paulo, 1990 a 1996. São Paulo; 1999. [Tese de Doutorado Faculdade de Saúde Pública da USP].

Clark GG. Dengue and dengue hemorrhagic fever. J Florida Mosq Control Assoc 1992; 63:48-53.

Clark GG. Situación epidemiológica del dengue en América: desafios para su vigilancia y control. Salud Publica Mex 1995; 37 Suppl:S5-S11.

Conceição e col. Dengue Hemorrágico- Casuistica do seviço de doenças infecciosas e parasitárias do Hospital Universitário Clementino Fraga Filho - UFRJ(2000-2001). In: Anais do $28^{\circ}$ Congresso da Sociedade Brasileira de Medicina Tropical; 2002 fev 24-28; Foz do Iguaçu, Brasil. Foz do Iguaçu: Sociedade Brasileira de Medicina Tropical; 2002, p. 92.

Costa AIP. Identificação de unidades ambientais urbanas como condicionantes da ocorrência de Aedes aegypti (Diptera: Culicidae) e de dengue na cidade de São José do Rio Preto, SP, em 1995. São Paulo; 1996. [Dissertação de Mestrado Faculdade de Saúde Pública da USP].

Costa AIP, Natal D. Distribuição espacial da dengue e determinantes socioeconômicos em localidade urbana no Sudeste do Brasil. Rev Saúde Pública $1998 ; 32: 232-6$.

Cunha RV, Schatzmayr HG, Miagostovich MP, Barbosa AMA, Paiva FG, Miranda RMO et al. Dengue epidemic in the State of Rio Grande do Norte, Brazil, in 1997. Trans R Soc Trop Med Hyg 1999; 93:247-9.

Cunha SP, Alves JRC, Lima MM, Duarte JR, Barros LCV, Silva JL et al. Presença de Aedes aegypti em Bromeliaceae e depósitos com plantas no Município do Rio de Janeiro, RJ. Rev Saúde Pública 2002; 36:244-5. 
Dal Fabbro AL. Estudo epidemiológico do dengue em Ribeirão Preto no período 1990-1997. Ribeirão Preto; 1997. [Pró-forma da Tese de Doutorado - Faculdade de Medicina de Ribeirão Preto da USP].

Dégallier N, Vilarinhos PTR, Carvalho MSL, Knox MB, Caetano Jr J. People's knowledge and practice about dengue, its vectors and control means in Brasília (DF), Brazil: its relevance with entomological factors. J Am Mosq Control Assoc 2000; 16:114-27.

Dirección de Información y Vigilancia Epidemiológica. Dirección General de Epidemiologia. Panorama epidemiológico del dengue y dengue hemorrágico en México. Salud Publica México1995; 37 Supl: S11-S13

Donalisio MRC. $O$ enfrentamento de epidemias: as estratégias e perspectivas do controle do dengue. Campinas; 1995. [Tese de Doutorado - Faculdade de Ciências Médicas da UNICAMP].

Donalisio MR. O dengue no espaço habitado. São Paulo: Hucitec; 1999.

Edman J, Kittayapong P, Linthicum K, Scott T. Attractant resting boxes for rapid collection and surveillance of Aedes aegypti (L.) inside houses. J Am Mosq Control Assoc 1997;13:24-7.

Edman JD, Scott TW, Costero A, Morrison AC, Harrington LC, Clark GG. Aedes aegypti (Diptera: Culicidae) movement influence by availability of oviposition sites. $\mathbf{J}$ Med Entomol 1998; 34:578-83.

Espinoza Gomez F, Hernandez Suarez CM, Coll Cárdenas R. Factores que modifican los indices larvarios de Aedes aegypti em Colima, México. Rev Panam Salud Publica 2000; 10:6-2.

Figueiredo LTM, Cavalcante SMB, Simões MC. Encuesta serológica sobre el dengue entre escolares de Rio de Janeiro, Brasil; 1986 y 1987. Bol Oficina Sanit 1991; 111:525-32. 
Figueiredo LTM. Estudos sobre o dengue em Ribeirão Preto, no período 1990 a 1993. São Paulo; 1993. [Tese de Doutorado - Faculdade de Medicina de Ribeirão Preto da USP].

Figueiredo LTM, Owa MA, Carlucci RH, Dal Fabbro AL, Melo NV, Capuano DM et al. Dengue serologic survey in Ribeirão Preto, São Paulo, Brazil. Bull Pan Am Health Organ 1995; 29:59-69.

Figueiredo LTM. Patogenia das infecções pelos vírus do dengue. Medicina (Ribeirão Preto) 1999; 32:15-20.

Figueiredo e col. Dinâmica da sorologia e isolamento viral na epidemia de dengue em Manaus(1998-2001). In: Anais do $\mathbf{2 8}^{\circ}$ Congresso da Sociedade Brasileira de Medicina Tropical; 2002 fev 24-28; Foz do Iguaçu, Brasil. Foz do Iguaçu: Sociedade Brasileira de Medicina Tropical; 2002, p. 94.

Focks DA, Daniels E, Haile DG, Keesling JE. A simulation model of the epidemiology of urban dengue fever: literature analysis, model development, preliminary validation and samples of simulation results. Am J Trop Med Hyg 1995; $53: 489-506$.

Focks DA, Chadee DD. Pupal survey: an epidemiologically significant surveillance method for Aedes aegypti: an example using data from Trinidad. Am J Trop Med Hyg 1997; 56:159-67.

Forattini OP, Kakitani I, Sallum MAM, Rezende L. Produtividade de criadouro de Aedes albopictus em ambiente urbano. Rev Saúde Pública 1997;31: 545-55.

Forattini OP. Mosquitos Culicidae como vetores emergentes de infecções. Rev Saúde Pública 1998; 32:497-502.

Forattini OP, Kakitani I, Ueno HM. Emergência de Aedes albopictus em recipientes artificiais. Rev Saúde Pública 2001; 25:456-60.

Fouque F, Reynes JM, Moreau JP. Dengue en la Guayana Francesa, 1965-1993. Bol Oficina Sanit Panam 1995; 119:140-8. 
Freimuth V, Linnan HW, Potter P. Communicating the threat of emerging infections to the public. Emerg Infect Dis 2000; 6:337-47.

Freire PSM, Gimenez EA, Nishimura WE, Caseiro MM. Dengue Hemorrágica. RBM- Rev Bras Med 2000; 57:16-31.

Gadelha DP, Toda AT. Biologia e comportamento do Aedes aegypti. Rev Bras Malariol Doenças Trop 1985; 37:29-36.

Gesler W. The uses spatial analysis in medical geography: a review. Soc Sci Med 1986; 23:963-73.

Glasser CM, Gomes AC. Clima e sobreposição de Aedes aegypti e Aedes albopictus na infestação do Estado de São Paulo. Rev Saúde Pública 2002; 36:166-72.

Gomes A de C. Medidas dos níveis de infestação urbana para Aedes (Stegomyia) aegypti e Aedes (Stegomyia) albopictus em programa de vigilância entomológica. Inf Epidemiol SUS 1998; 7:49-57.

Gubler DJ. Dengue. In: Monath TP, editor. The arboviruses: epidemiology and ecology. v.2. Boca Raton, Florida: CRC Press Inc; 1988. p. 223-60.

Gubler DJ, Costa-Valez A. Programa de prevención del dengue epidémico y el dengue hemorrágico en Puerto Rico y las Islas Vírgenes Estadounidenses. Bol Oficina Sanit Panam 1992; 113:109-19.

Gubler DJ, Clark GG. Community-based integrated control of Aedes aegypti: a brief overview of current programs. Am J Trop Med Hyg 1994; 50(6 Suppl):50-60.

Gubler DJ, Clark GG. Community involvement in the control of Aedes aegypti. Acta Tropica 1996; 61:169-79.

Guzmám MG, Vázquez S. Martínez E, Álvarez M, Rodríguez R, Kouri G et al. Dengue in Nicaragua, 1994: reintroduction of serotype 3 in America. Rev Panam Salud Publica 1997; 1:193-9. 
Honório NA, Oliveira RL. Freqüência de larvas e pupas de Aedes aegypti e Aedes albopictus em armadilhas, Brasil. Rev Saúde Pública 2001; 35:385-91.

Hornby JA, Moore DE, Miller Jr TW. Aedes albopictus distribution abundance and colonization in Lee Country, Florida and its effect on Aedes aegypti. J Am Mosq Control Assoc 1994; 10:397-402.

Ibañez-Bernal S, Briseño B, Mutebi JP, Argot E, Rodriguez G, Martínez-Campos C et al. First record in America of Aedes albopictus naturally infected with dengue virus during the 1995 outbreak at Reynosa, Mexico. Med Vet Entomol 1997; 11:305-9.

Jetten TH, Focks DA. Potential changes in the distribution of dengue transmission under climate warning. Am J Trop Med Hyg 1997; 57:285-97.

Joshi V, Mathur ML, Dixit AK, Singhi M. Entomological studies in a dengue endemic area, Jalore Rajasthan. Indian J Med Res 1996; 104:161-5.

Kaul SM, Sharma RS, Sharma SN, Panigrahi N, Phukan PK, Lal S. Preventing dengue/dengue haemorrhagic fever outbreaks in the National Capital Territory of Delhi -the role of entomological surveillance. J Commun Dis 1998; 30:187-92.

Knudsen $\mathrm{AB}$, Slooff $\mathrm{R}$. Vector-borne disease problems in rapid urbanization: new approaches to vector control. Bull World Health Organ 1992; 70:1-6.

Ko YC, Chen MJ, Yeh SM. The predisposing and protective factors against dengue virus transmission by mosquito vector. Am J Epidemiol 1992; 136:214-20.

Kuno G. Review of the factors modulating dengue transmission. Epidemiol Rev 1995; 17:321-35.

Lenzi MF, Camillo-Coura L, Grault CE, Val MB do. Estudo do dengue em área favelizada do Rio de Janeiro: consideraçoes iniciais. Cad Saúde Pública 2000;16:851-6. 
Leontsini E, Gil E, Kendall D, Clark GG. Effect of a community based Aedes aegypti control programme on mosquito larval production sites in El Progreso, Honduras. Trans R Soc Trop Med Hyg 1993; 87:267-71.

Lessa E, Lima ICAR de, Farias MMC de, Pinto AMV, Aráujo EJ, Oliveira ENDE. Estudo epidemiológico do dengue no Recife/Pernambuco, no período de 1995 à 1998. In: Anais do $28^{\circ}$ Congresso da Sociedade Brasileira de Medicina Tropical; 2002 fev 24-28; Foz do Iguaçu, Brasil. Foz do Iguaçu: Sociedade Brasileira de Medicina Tropical; 2002, p. 96.

Lifson AR. Mosquitoes, models and dengue. Lancet 1996; 347:1201-2.

Lima ICAR de; Lessa E; Farias MMC de, Pinto AMV, Araujo EJ. Diagnóstico epidemiológico do dengue em Recife, Pernambuco no período de 1998 a 2000. In: Anais do $28^{\circ}$ Congresso da Sociedade Brasileira de Medicina Tropical; 2002 fev 24-28; Foz do Iguaçu, Brasil. Foz do Iguaçu: Sociedade Brasileira de Medicina Tropical; 2002, p. 94.

Lima VLC, Figueiredo LTM, Correa FHR, Leite OF, Rangel O, Vido AA et al. Dengue: inquérito sorológico pós-epidemico em zona urbana do Estado de São Paulo (Brasil). Rev Saúde Pública 1999; 33:566-74.

Lloyd LS, Winch P, Ortega-Canto J, Kendall C. The design of a community-based health education intervention for the control of Aedes aegypti. Am J Trop Med Hyg $1994 ; 50: 401-11$.

Lobato C, Moraes M, Zacarias A, Moraes MA, Lima F, Costa R. Aspectos epidemiológicos e entomológicos da dengue no Estado do Acre - 2000 e 2001. In: Anais do $28^{\circ}$ Congresso da Sociedade Brasileira de Medicina Tropical; 2002 fev 24-28; Foz do Iguaçu, Brasil. Foz do Iguaçu: Sociedade Brasileira de Medicina Tropical; 2002, p. 87.

Lopes J, Lozovei AL. Ecologia de mosquitos (Diptera: Culicidae) em criadouros naturais e artificiais de área rural do norte do Paraná, Brasil. II coletas com isca humana. Rev Bras Zool 1996; 44:585-95. 
Lopes J, Silva MAN da, Borsato AM, Oliveira VDRB de, Oliveira FJA Aedes (stegomyia) aegypti L. e a culicideofauna associada em área urbana da região sul, Brasil. Rev Saúde Pública 1993; 27:326-33.

Loroño-Picco MA, Cropp CB, Farfän JA, Vorndan AV, Rodríguez-Angelo EM, Rasado-Paredes EP et al. Common occurrence of concurrent infection by multiple dengue virus serotypes. Am J Trop Med Hyg 1999; 61:725-30.

Löwenberg-Neto P, Navarro-Silva MA. Primeiro registro de Aedes albopictus no Estado de Santa Catarina, Brasil. Rev Saúde Pública 2002; 36:246-7.

Macoris MLG, Mazine CAB, Andrighetti MTM, Yasumaro S, Silva ME, Nelson MJ, Winch PJ. Factors favouring houseplant container infestation with Aedes aegypti larvae in Marilia, Brazil. Rev Panam Salud Publica 1997; 1:280-6.

MapInfo Corporation. Manual de Referencia . Troy, New York, 2000.

Marquetti MC, Carus F, Aguilera L, Navarro A. Influencia de factores abióticos sobre la incidencia de Aedes aegypti en el Município 10 de Octubre de Ciudade de la Habana, 1982-1992. Rev Cubana Med Trop 1995; 47:88-92.

Marzochi KBF. Dengue in Brazil - situation, transmission and control: a proposal for ecological control. Mem Inst Oswaldo Cruz 1994; 89:235-45.

Mazine CAB, Macoris MLG, Andrighetti MTM, Yasumaro S, Silva ME, Nelson MJ et al. Disposable containers as larval habitats for Aedes aegypti in a city with regular refuse collection: a study in Marilia, São Paulo State, Brazil. Acta Trop 1996; 62:113.

Mazzari MB, Mora JD, Godoy BO, Sequeda MG. Situación del dengue y el Programa de Control de Aedes aegypti en Venezuela: 1998. Bol Dir Malariol San Amb 1998; 38:137-44.

Medronho RA. A geografia do dengue no Município do Rio de Janeiro: uma análise por geoprocessamento. Rio de Janeiro; 1993. [Dissertação de MestradoEscola Nacional de Saúde Pública da Fiocruz]. 
Miagostovich MP, Nogueira RMR, Cavalcanti SMB, Marzochi KBF, Schatzmayr HG. Dengue epidemic in the State of Rio de Janeiro, Brazil: virological and epidemiological aspects. Rev Inst Med Trop São Paulo 1993; 35:149-54.

Milby MM, Reisen WK. Estimation of vectorial capacity: vector survivorship. Bull Soc Vector Ecol 1989; 14:47-54.

Ministério da Saúde. Fundação Nacional de Saúde. Departamento de Operações. Coordenação de Controle de Doenças Transmitidas por Vetores. Manual de dengue: vigilância epidemiológica e atenção ao doente. $2^{2}$ ed. Brasilia: DEOPE; 1996.

Ministério da Saúde. Fundação Nacional de Saúde. Secretaria Estadual de Saúde. Conselho de Secretários Municipais de Saúde. Plano de erradicação do Aedes aegypti em Alagoas. Alagoas; 1996/1997.

Ministério da Saúde. Fundação Nacional de Saúde. Secretaria Executiva do Plano Diretor de Erradicação do Aedes aegypti do Brasil - PEAa. Instruções para o pessoal de combate ao vetor: manual de normas técnicas. $2^{\mathrm{a}}$ ed.rev. Brasilia (DF); 1998.

Ministério da Saúde. Fundação Nacional de Saúde. Centro Nacional de Epidemiologia. Evolução temporal das doenças de notificação compulsória no Brasil de 1980 a 1998. Bol Epidemiol 1999; 3.

Ministério da Saúde. Fundação Nacional de Saúde. Secretaria Executiva do Plano Diretor de Erradicação do Aedes aegypti do Brasil - PEAa. Instruções para o pessoal de combate ao vetor: manual de normas técnicas. $3^{\mathrm{a}}$ ed.rev. Brasilia (DF); 2001.

Ministério da Saúde. Fundação Nacional de Saúde. Centro Nacional de Epidemiologia. Programa nacional de controle da dengue. Brasilia (DF); 2002.

Montesano-Castellanos R, Ruiz-Matus C. Vigilancia epidemiológica del dengue en México. Salud Publica Mex 1995;37 Supl:64-74.

Moore CG, Cline BL, Ruiz-Tibén E, Lee D, Romney-Joseph H, Rivera-Correa E. Aedes aegypti in Puerto Rico: environmental determinants of larval abundance and relation to dengue virus transmission. Am J Trop Med Hyg 1978; 27:1225-31. 
Moore CG. The future vector born disease control: needs and directions. Bull Soc Vector Ecol 1990; 15:1-4.

Morrison AC, Getis A, Santiago M, Rigau-Perez JG, Reiter P. Exploratory space-time analysis of reported dengue cases during an outbreak in Florida, Puerto Rico 19911992. Am J Trop Med Hyg 1998; 58:287-98.

Mourão e col. Epidemia de Febre Hemorrágica do dengue em Manaus: estratégias de controle da letalidade. In: Anais do $28^{\circ}$ Congresso da Sociedade Brasileira de Medicina Tropical; 2002 fev. 24-28; Foz do Iguaçú, Brasil. Foz do Iguaçu: Sociedade Brasileira de Medicina Tropical; 2002, p. 82.

Narro-Robles J, Gómez-Dantés H. El dengue en Mexico: um problema prioritario de Salud Publica. Salud Publica Mexico 1995; 37 Supl:12-20.

Nathan MB, Knudsen AB. Aedes aegypti infestation characteristics in several Caribbean countries and implication for integrated community-based control. J Am Mosq Control Assoc 19; 7:400-4.

Nobre A, Antezana D, Tauil PL. Febre amarela e dengue no Brasil: epidemiologia e controle. Rev Soc Bras Med Trop 1994; 27 Supl 3:59-66.

Nogueira RMR, Miagostovich MP, Filippis AMB de, Pereira MAS, Schtzmayr HG. Dengue virus type 3 in Rio de Janeiro, Brazil. Mem Inst Oswaldo Cruz 2001; 96:925-6.

Nogueira RMR, Miagostovich MP, Lampe E, Schatzmayr HG. Isolation of dengue virus type 2 in Rio de Janeiro. Mem Inst Oswaldo Cruz 1990; 253.

Nogueira RMR, Miagostovich MP, Lampe E, Souza RW, Zagne SMO, Schatzmayr HG. Dengue epidemic in the State of Rio de Janeiro, Brazil 1990-1: co-circulation of dengue 1 and dengue 2 serotypes. Epidemiol Infect 1993;111: 163-70.

Nogueira RMR, Miagostovich MP, Schatzmayr HG, Moraes GC, Cardoso FMA, Ferreira J. et al. Dengue type 2 outbreak in the South of the State of Bahia, Brazil; 
laboratorial and epidemiological studies. Rev Inst Med Trop São Paulo 1995;37: 507-10.

Nogueira RMR, Miagostovich MP, Schatzmayr HG. Molecular epidemiology of dengue viruses in Brazil. Cad Saúde Pública 2000;16:205-11.

Oliveira RM de. A dengue no Rio de Janeiro: repensando a participação popular em saúde. Cad Saúde Pública 1998;14 Supl 2:69-78.

Oliveira RM de, Valla VV. As condições e as experiências de vida de grupos populares no Rio de Janeiro: repensando a mobilização popular no controle do dengue. Cad Saúde Pública 2001:17 Supl: 77-88.

O'Meara GF, Evans Jr LF, Gettman AD, Cuda JP. Spread of Aedes albopictus and decline of Aedes aegypt (Diptera: Culicidae) in Florida. J Med Entomol 1995; 32:554-62.

[OPS] Organización Panamericana de la Salud. La Batalla contra Aedes aegypti. Bol Oficina Sanit Panam 1992;113:462-5.

[OPS] Organización Panamericana de la Salud. Prevención y controle del dengue clásico y hemorrágico en centroamérica. Bol Oficina Sanit Panam 1996; 121:36872.

[OPS] Organización Panamerican de la Salud. Boletin Epidemiológico. Washington (DC) $1997 ; 18(2)$.

Osanai CH. A epidemia de dengue em Boa Vista, Território Federal de Roraima, 1981-1982. Rio de Janeiro; 1984. [Dissertação de Mestrado-Escola Nacional de Saúde Pública da Fiocruz].

[PAHO] Pan American Health Organizacion. Dengue and dengue hemorrhagic fever in the Americas: guidelines for prevention and control. Washington (DC): PAHO; 1994. (Scientific Publication, 548). 
[PAHO] Pan American Health Organization. Feasibility of eradicating Aedes aegypti in the Americas. Washington (DC). Rev Panam Salud Publica 1997; 1:68-72.

Passos ADC, Rodrigues EMS, Dal Fabbro AL. Dengue control in Ribeirão Preto, São Paulo, Brazil. Cad Saúde Pública 1998; 14 Supl 2:123-8.

Pereira M. Recipientes artificiais utilizados como criadouro por Aedes aegypti na região de Araçatuba. São Paulo; 1996. [Dissertação de Mestrado - Faculdade de Saúde Pública da USP].

Pereira M. Insetos urbanos. Biológico (São Paulo) 1997; 59:11-4.

Pereira M. Produtividade e habitats larvarios de Aedes aegypti em Santos, Estado de São Paulo. São Paulo; 2001. [Tese de Doutorado-Faculdade de Saúde Pública da USP].

Pereira MG. Epidemiologia: teoria e prática. Rio de Janeiro: Guanabara-Koogan; 1995.

Pereira e col. Controle do Aedes aegypti em Porto Velho frente a epidemia de dengue. In: Anais do $28^{\circ}$ Congresso da Sociedade Brasileira de Medicina Tropical; 2002 fev 24-28; Foz do Iguaçu, Brasil. Foz do Iguaçu: Sociedade Brasileira de Medicina Tropical; 2002, p.90.

Perez Diaz R, Fuentes Gonzalez O. Analisis del sistema de vigilancia por larvitrampas en el Município Mariel (1984-1987). Rev Cubana Med Trop 1990; 42:254-60.

Perich MJ, Davila G. Turner A, Garcia A, Nelson M. Behavior of rasting Aedes aegypti (Culicidade:diptera) and Its relation to ultra-low volume adulticidade efficacy in Panama City, Panama. J Med Entomol 2000; 37:541-6.

Phillips I, Need J, Escamilla J, Colán E, Sanchéz S, Rodriguez M et al. Primer brote de dengue documentado en la región Amazónica del Perú. Bol Oficina Sanit Panam $1993 ; 114: 513-9$. 
Platt KB, Linthicum KJ, Myint KSA, Innis BL, Lerdthusnee K, Vaughn DW. Impact of dengue virus infection on feeding behavior of Aedes aegypti. Am J Trop Med Hyg 1997; 57:119-25.

Pontes RJS, Dal Fabbro AL, Rocha GM , Santiago RC, Figueiredo LTM, Silva AAMCC et al. Epidemia de dengue em Ribeirão Preto, São Paulo, Brasil: nota prévia. Rev Saúde Pública 1991; 25:325-7.

Pontes RJS. Estudo da epidemia de dengue no Município de Ribeirão Preto, 1990-1991. Ribeirão Preto; 1992. [Tese de Doutorado - Faculdade de Medicina de Ribeirão Preto da USP].

Pontes RJS, Ruffino-Netto A. Dengue em localidade urbana da Região Sudeste do Brasil: aspectos epidemiológicos. Rev Saúde Pública 1994; 28:218-27.

Pontes RJS, Ruffino Netto A. Vigilância e busca ativa de casos suspeitos de dengue hemorrágico em Ribeirão Preto, São Paulo. Rev Panam Salud Publica 1997; 1:18692.

Prata A, Rosa APAT da, Teixeira G, Coelho ICB, Tavares-Neto J, Dias J et al. Condutas terapêticas e de suporte no paciente com dengue hemorrágico. Inf Epidemiol SUS 1997; 5-33.

Putnam JL, Scott TW. Blood-feeding behavior of dengue-2 virus-infected Aedes aegypti. Am J Trop Med Hyg 1995; 52:225-7.

Rawlins SC. Spatial distribution of insectiside resistance in Caribbean populations of Aedes aegypti in its significance. Rev Panam Salud Publica 1998; 4:243-51.

Rawlins SC. Emerging and re-emerging vector borne diseases in the Caribbean region. West India Med J 1999; 48:252-3.

Rebêlo JMM, Costa JML, Silva FS, Pereira YNO, Silva JM da. Distribuição de Aedes aegypti e do dengue no Estado do Maranhão, Brasil. Cad Saúde Pública 1999;15: 477-86. 
Reisen WK. Estimation of vectorial capacity: introduction. Bull Soc Vector Ecol $1989 ; 14: 39-40$.

Reiter P, Amador MA, Anderson RA, Clark GG. Short report: dispersal of Aedes aegypti in an urban área blood feeding as demonstrated by rubidium-marked eggs. Am J Trop Med Hyg 1995; 52:177-9.

Rocco IM, Ferreira IB, Katz G, Souza LTM de, Souza DM, Kimura-Gushiken EK et al. Ocorrência de dengue em Ribeirão Preto, SP, Brasil de 1986 a 1996. Rev Inst Adolfo Lutz 1998; 57:7-12.

Rodrigues EMS, Dal Fabbro AL, Salomão R, Ferreira IB, Rocco IM, Fonseca BAL. Epidemiologia da infecção pela dengue em Ribeirão Preto, SP, Brasil. Rev Saúde Pública 2002; 36:160-5.

Rodriguez-Figueiroa L, Rigau-Perez JG, Suarez EL, Reiter P. Risk factors for dengue infecction during an outbreak in Yanes, Puerto Rico in 1991. Am J Trop Med Hyg $1995 ; 52: 496-502$.

Rosa APAT da, Vasconcelos PFC, Rosa EST da, Rodrigues SG, Mondet B, Cruz ACR et al. Dengue epidemic in Belém, Pará, Brazil, 1996-97. Emerging Infectious Diseases 2000; 6(3): 298-301.

Rouquayrol MZ, Almeida Filho $\mathrm{N}$ de. Epidemiologia e saúde. $5^{\mathrm{a} e d . ~ R i o ~ d e ~ J a n e i r o: ~}$ Medsi; 1999.

Salas-Luévano MA, Reyes-Villanueva F. Variación estacional de las poblaciones de Aedes aegypti en Monterrey, México. Salud Publica 1994; 36:385-92.

Santos AH, Camargo MF, Silva EA, Abrão N, Alves RBN, Isac E. Controle de criadouros dos vetores de dengue e da febre amarela urbana na cidade de Goiânia com participação popular. Rev Patol Trop 1999; 28:233-41.

Santos RS, Carvalho MS. Análise da distribuição espacial de larvas de Aedes aegypti na Ilha do Governador, Rio de Janeiro, Brasil. Cad Saúde Pública 2000; 16:31-42. 
Santos RS. Caracterização e análise da distribuição espacial de criadouros de Aedes aegypti na Ilha do Governador, Rio de Janeiro. Rio de Janeiro, 2000. [Tese de Doutorado - Escola Nacional de Saúde Pública da Fiocruz].

Santos RS. Fatores associados á ocorrência de formas imaturas de Aedes aegypti na Ilha do Governador, Rio de Janeiro, Brasil. Rev Soc Bras Med Trop 1999; 32:37382.

Saraiva e col. A descentralização do atendimento de dengue em Manaus-AM. In: Anais do $2^{\circ}$ Congresso da Sociedade Brasileira de Medicina Tropical; 2002 fev. 24-28; Foz do Iguaçu, Brasil. Foz do Iguaçu: Sociedade Brasileira de Medicina Tropical; 2002, p. 86.

Savage HM, Smith GC. Aedes albopictus y Aedes aegypti en las Américas: implicaciones para la transmisión de arbovirus e identificación de hembras adultas dañadas. Bol Oficina Sanit Panam 1995; 118:473-8.

Schatzmayr HG. Viroses emergentes e reermegentes. Cad Saúde Pública 2001;17 Supl:209-13.

Schtzmayr HG, Nogueira RMR, Rosa APAT da. An outbreak of dengue vírus at Rio de Janeiro-1986. Mem Inst Oswaldo Cruz 1986; 81:245-6.

Scott TW, Naksathit A, Day JF, Kittayapong P, Edman JD. A fitness advantage for Aedes aegypti and the viruses it transmites when females feed only on human blood. Am J Trop Med Hyg 1997; 57:235-9.

Secretaria de Estado da Saúde. Departamento de Vigilância à Saúde. Programa de Erradicação do Aedes aegypti PEAa. O PEAa Alagoas situação atual e perspectivas: relatório. Maceió; $1998_{a}$

Secretaria de Estado da Saúde. Departamento de Vigilância à Saúde. Programa de Erradicação do Aedes aegypti PEAa. Relatório de avaliação das atividades desenvolvidas pelo PEAa no período de 1997 a 1998. Maceió; 1998b. 
Secretaria de Estado da Saúde. Departamento de Vigilância à Saúde. Programa de Erradicação do Aedes aegypti PEAa. Descentralização da gestão do PEAa em Alagoas: experiência e resultados. Maceió; 1999.

Secretaria de Estado da Saúde. Núcleo de Vigilância Epidemiológica. Programa de Erradicação do Aedes aegypti - PEAa. Plano estadual de intensificação das ações de controle do dengue: versão preliminar. Alagoas; 2001.

Secretaria de Estado da Saúde. Projeto de Vigilância Epidemiológica. Relatório da situação atual do dengue em Alagoas. Maceió; 2002.

Secretaria Municipal de Saúde (SMS). Departamento de Defesa à Saúde. Programa de erradicação do Aedes aegypti - PEAa: plano operacional 1999/2000. Maceió (Mcz) 2000, 2002.

Seng CM, Jute N. Breeding of Aedes aegypti (L.) and Aedes albopictus (Skuse) in urban housing of Sibu Town, Sarawak. Southeast Asian J Trop Med Public Health $1994 ; 25: 543-8$.

Serufo JC, Souza AM, Tavares VA, Jammal MC, Silva JG. Dengue in the Southeastern region of Brazil: historical analysis and epidemiology. Rev Saúde Pública 1993; 27: 157-67.

Service MW. Importance of ecology in Aedes aegypti control. Southeast Asian J Trop Med Public Health 1992; 23:681-90.

Sherman C, Fernandez EA, Chan AS, Lozano RC, Leontsini E, Winch PJ. La untadita: a procedure for maintaining washbasins and drums free of Aedes aegypti based on modification of existing practices. Am J Trop Med Hyg 1998; 58:257-62.

Silva HHG, Silva IG. Influência do período de quiescência dos ovos sobre o ciclo de vida de Aedes aegypti (Linnaeus, 1762) (Diptera: Culicidae) em condições de laboratório. Rev Soc Bras Med Trop 1999; 32:349-55.

Silveira AC. Dengue: aspectos epidemiológicos e de controle. Rev Soc Bras Med Trop 1998; 31 Supl. 2:5-14. 
Souza RV, Cunha RV da, Miagostovich MP, Timbó MJ, Montenegro F, Pessoa ETFP, Nogueira RMR, Schatzmayr HG. An outbreak of dengue in the state of Ceará, Brazil. Mem Inst Oswaldo Cruz 1995; 90:345-6.

Statsoft Incorporation. Statistica for Windows 5.0 [ computer program]. Tulsa; 1995.

Sulaiman S, Pawanchee A, Arifin Z, Wahab A. Relationship between Breteau and house indices and cases of dengue/dengue hemorrhagic fever in Kuala Lumpur, Malaysia. J Am Mosq Control Assoc 1996; 12:494-6.

Suleman M, Arshad M, Khan K. Yellowfever mosquito (Diptera:culicidae) introduced into Landi Kotal, Pakistan by Tire importation. J Med Entomol 1996; 33:689-93.

Suwonkerd W, Tsuda Y, Takagi M, Wada Y. Seasonal occurrence of Aedes aegypti and Aedes albopictus in use Tires in 1992-1994, Chiangmai, Thailand. Trop Med 1996; 38:101-5.

Tandon N, Ray S. Breeding habitats and larval indices of Aedes aegypti and aedes albopictus in the Residential areas of Calcuta City. J Commun Dis 2000; 32:180-4.

Tauil PL. Urbanização e ecologia do dengue. Cad Saúde Pública 2001;179 Supl:99102.

Teixeira MG, Barreto ML, Guerra Z. Epidemiologia e medidas de prevenção do dengue. Inf Epidemiol SUS 1999; 8:5-33.

Teixeira MG, Costa MCN, Barreto ML, Barreto FR. Epidemiologia do dengue em Salvador-Bahia, 1995-1999. Rev Soc Bras Med Trop 2001;34: 269-74.

Thavara U, Tawatsin A, Phan-Urai P, Ngamsuk W, Chansang C, Liu M et al. Dengue vector mosquitos at a tourist attraction, Ko Samui, in 1995. Southeast Asian J Trop Med Public Health 1996; 27:160-3. 
Thu HM, Aye KM, Thein S. The effect of temperature and humidity on dengue virus propagation in Aedes aegypti mosquitos. Southeast Asian J Trop Med Public Health 1998; 29:280-4.

Timbó e col. Perfil clínico e epidemiológico do dengue hemorrágico no Ceará, Ano 2001. In: Anais do $28^{\circ}$ Congresso da Sociedade Brasileira de Medicina Tropical; 2002 fev 24-28; Foz do Iguaçu, Brasil. Foz do Iguaçu: Sociedade Brasileira de Medicina Tropical; 2002, p. 103.

Trpis M, Häusumann W, Craig Jr GB. Estimates of population size, dispersal and longevity of domestic Aedes aegypti (Diptera: Culicidade) by mark-release-recapture in the Village of Shauri Moyo in Easten Kenya. J Med Entomol 1995; 32:27-33.

Tun-Lin W, Kay BH, Barnes A. The premisse condition index: a tool for streamling surveys of Aedes aegypti. Am J Trop Med Hyg 1995a; 53:591-4.

Tun-Lin W, Kay BH, Barnes A. Understanding productivity, a key to Aedes aegypti surveillance. Am J Trop Med Hyg 1995b; 53:595-601.

Tun-Lin W, Maung-Maung-Mya, Sein-Maung-Than, Tin-Maung-Maung. Rapid and efficient removal of inimature Aedes aegypti in metal drum by sweep net and modified sweepring method. Southeast Asian J Trop Med Public Health 1995; 26:754-9

Tun-Lin W, Kay BH, Barnes A. Forsyth S. Critical examination of Aedes aegypti indices: correlations with abundance. Am J Trop Med Hyg 1996; 54:543-7.

Valdés L, Guzmán MG, Kouri G, Delgado J, Carbonell I, Cabreta MV et al. La epidemiologia del dengue y del dengue hemorrágico en Santiago de Cuba, 1997. Rev Panam Salud Publica 1999; 6:16-24.

Vasconcelos PFC, Menezes DB, Melo LP, Pessoa ETFP, Rodrigues SG, Rosa EST et al. A large epidemic of dengue fever with dengue hemorrhagic cases in Ceará Sate, Brazil, 1994. Rev Inst Med Trop São Paulo 1995; 37:253-5. 
Vasconcelos PFC, Lima JWO, Rosa APAT, Timbó MJ, Rosa EST, Lima HR, Rodrigues SG, Rosa JFST. Epidemia de dengue em Fortaleza, Ceará: inquérito soroepidemiológico aleatório. Rev Saúde Pública 1998; 32:447-54.

Vasconcelos PFC, Lima JWO, Raposo ML, Rodrigues SG, Rosa JFST et al. Inquérito soro-epidemiológico na Ilha de São Luis durante epidemia de dengue no Maranhão. Rev Soc Bras Med Trop 1999; 32:171-9.

Vasconcelos PFC, Mota K, Straatmann A, Santos-Torres S, Rosa APAT, Tavares Neto J. Epidemia de dengue em Ipupiara e Prado, Bahia. Inquérito soroepidemiológico. Rev Soc Bras Med Trop São Paulo 2000; 33:61-7.

Vezzani D, Velázquez SM, Soto S, Schweigmann NJ. Environmental characteristics of the cemeteries of Buenos Aires City (Argentina) and infestation levels of Aedes aegypti (Diptera: Culicidade). Mem Inst Oswaldo Cruz 2001; 96:3227-34.

Winch P. Social and cultural responses to emerging vector-borne diseases. J Vector Ecol 1998; 23:47-53.

Winch PJ, Barrientos-Sanchez G, Puigserver-Castro E, Manzano-Cabrera L, Lloyd LS, Mendez-Galvan JF et al. Variation in Aedes aegypti larval indices an one year period in a neighborhood of Mérida, Yucatán, México. J Am Mosq Control Assoc 1992: 193-5.

[WHO] World Health Organization. Dengue. Wkly Epidemiol Rec 1998; 73:185-92.

[WHO] World Health Organization. Dengue/dengue haemorrhagic fever. Wkly Epidemiol Rec 2000; 75:193-200.

[WHO] World Health Organization. Dengue hemorrágica: diagnóstico, tratamento, prevenção e controle. $2^{\mathrm{a} e d .}$ Geneva: WHO/São Paulo: Editora Santos; 2001.

[WHO] World Health Organization. Dengue prevention and control. Wkly Epidemiol Rec 2002: 77:41-8. 
Yasumano S, Silva ML, Andrighetti MTM, Macoris ML, Mazine CAB, Winch PJ. Community involvement in a dengue prevention project in Marilia, São Paulo, State, Brazil. Human Org 1998; 57:209-14.

Zagne SMO, Alves VGF, Nogueira RMR, Miagostovich MP, Lampe E, Tavares W. Dengue haemorrhagic fever in the state of Rio de Janeiro, Brazil: a study of 56 confirmed cases. Trans R Soc Trop Med Hyg 1994; 88:677-9. 
ANEXOS 


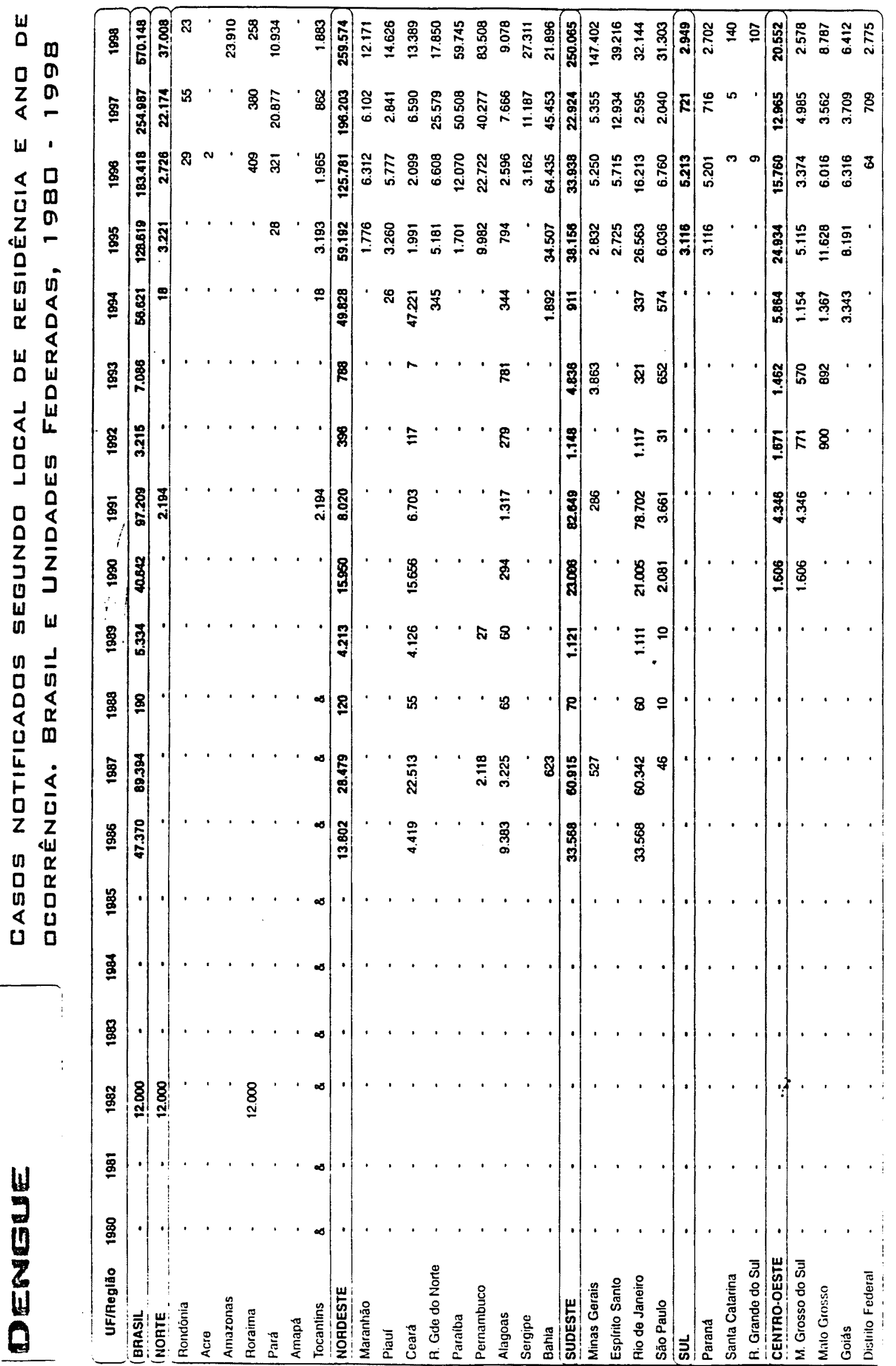

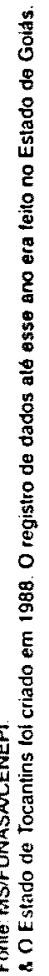




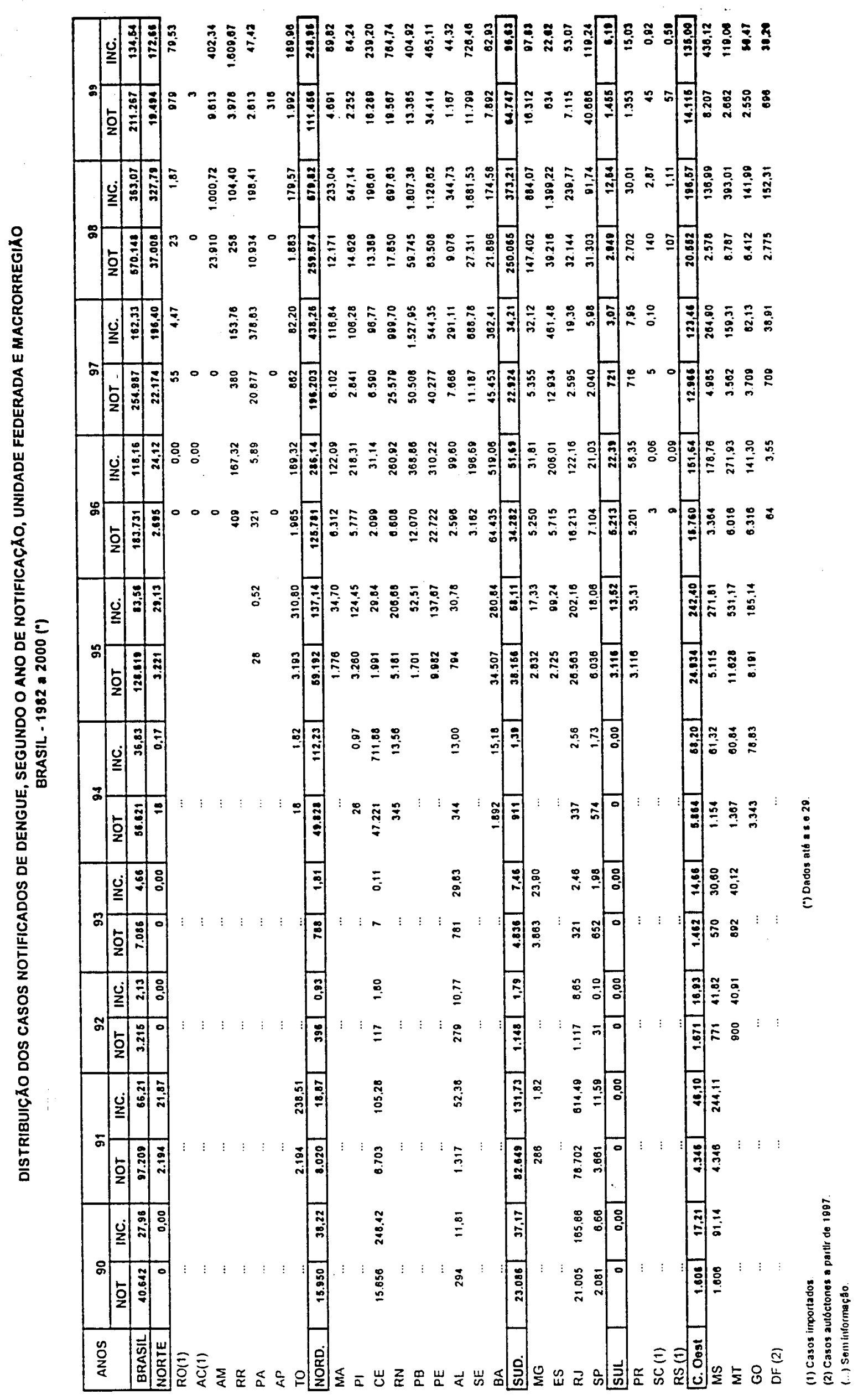


MSIFUNASACENEPUCGVEPICOVEV

DENGUE: TOTAL DE CASOS NOTIFICADOS POR MES E POR UNIDADE FEDERADA, BRASIL- $2000^{\prime \prime}$

\begin{tabular}{|c|c|c|c|c|c|c|c|c|c|c|c|c|c|c|}
\hline REGIUF & JAN & FEV & MAR & ABR & MN & JUN & JUL & AGO & SET & out & HOV & OEZ & MLgn_(2) & TOTAL \\
\hline BRASIL & 23.556 & 35.650 & 45.460 & 42.813 & 34.519 & 15.733 & 9.758 & $7 A 74$ & 4.594 & 5.151 & 7813 & 6.449 & 900 & 239.870 \\
\hline NORTE & 3.202 & 4.518 & 3.727 & 2.213 & 1.931 & 1.447 & 1.670 & 1.702 & 1.042 & 1.864 & 3.802 & 3.638 & 92 & 30.848 \\
\hline RO & 37 & 25 & 23 & 32 & 35 & 13 & 30 & 27 & 74 & 893 & 1.727 & 715 & 4 & 3.635 \\
\hline$A C(3)$ & 22 & 24 & 38 & 45 & 93 & 223 & 333 & 264 & 170 & 199 & 316 & 589 & & 2.316 \\
\hline$A M$ & 920 & 1.386 & 1.129 & 473 & 434 & 211 & 122 & 155 & 107 & 161 & 328 & 985 & & 6.411 \\
\hline$R R$ & 367 & 697 & 1.042 & 807 & 735 & 559 & 861 & 817 & 377 & 172 & 362 & 499 & & 7.295 \\
\hline PA & 1.426 & 1.951 & 1.112 & 594 & 447 & 306 & 260 & 354 & 245 & 280 & 604 & 564 & 75 & 8.218 \\
\hline$A P(4)$ & 5 & 20 & 6 & 6 & 5 & 1 & 0 & 1 & 1 & 0 & 5 & 0 & & 50 \\
\hline TO & 425 & 415 & 377 & 256 & 182 & 134 & 64 & 84 & 68 & 159 & 460 & 286 & 13 & 2.923 \\
\hline NORD. & 10.357 & 14.214 & 21.614 & 21.604 & 22.144 & 10.663 & 6.739 & 4.749 & 2.680 & 2.254 & 2.877 & 1.371 & 229 & 121,495 \\
\hline MA & 870 & 784 & 844 & 270 & 336 & 319 & 202 & 259 & 119 & 148 & 156 & 57 & 5 & 4.339 \\
\hline $\mathrm{Pl}$ & 414 & 476 & 470 & 564 & 1.325 & 1.476 & 875 & 676 & 385 & 338 & 274 & 63 & & 7.336 \\
\hline$C E$ & 1.274 & 1.920 & 2.743 & 2.375 & 4.740 & 2.636 & 1.552 & 1.366 & 743 & 520 & 714 & 321 & & 20.904 \\
\hline RN & 657 & 2.049 & 3.582 & 3.877 & 2.014 & 1.290 & 1.388 & 819 & 511 & 347 & 389 & 187 & 11 & 17.121 \\
\hline PB & 981 & 1.937 & 4.113 & 5.785 & 5.491 & $2.1 \pm 1$ & 1.016 & 362 & 456 & 275 & 168 & 54 & 55 & 22.804 \\
\hline$P E$ & 2.241 & 3.517 & 5.879 & 5.511 & 5.765 & 1.888 & 1.038 & 802 & 242 & 339 & 517 & 210 & & 27.949 \\
\hline AL & 45 & 109 & 360 & 385 & 238 & 75 & 38 & 29 & 15 & 8 & 14 & 11 & 140 & 1.467 \\
\hline SE & 1.914 & 1.732 & 1.354 & 1.037 & 1.195 & 429 & 360 & 288 & 121 & 76 & 111 & 59 & & 8.676 \\
\hline BA & 1.961 & 1.690 & 2.269 & 1.800 & 1.040 & 439 & 270 & 148 & 88 & 233 & 534 & 409 & 18 & 10.899 \\
\hline SUD. & 6.488 & 13.342 & 15.153 & 14.120 & 8.472 & 2.864 & 1.087 & 776 & 653 & 751 & 715 & 1.064 & 85 & 65.570 \\
\hline MG & 3.884 & 9.313 & 6.812 & 4.289 & 1.313 & 309 & 91 & 42 & 42 & 35 & 18 & 131 & 82 & 26.361 \\
\hline ES & 1.037 & 2.613 & 5.514 & 4.905 & 3.375 & 1.009 & 387 & 177 & 88 & 96 & 102 & 180 & & 19.483 \\
\hline RJ & 289 & 318 & 612 & 923 & 1.003 & 392 & 199 & 150 & 102 & 95 & 96 & 102 & & 4.281 \\
\hline $\mathrm{SP}$ & 1.278 & 1.098 & 2.215 & 4.003 & 2.781 & 1.154 & 410 & 407 & 421 & 525 & 499 & 651 & 3 & 15.445 \\
\hline SUL & 164 & 502 & 1.693 & 1,496 & 415 & 164 & 45 & 65 & 58 & 47 & 71 & 40 & 0 & 4.760 \\
\hline PR & 148 & 489 & 1.682 & 1.482 & 410 & 161 & 40 & 62 & 52 & 46 & 67 & 37 & & 4.676 \\
\hline $\operatorname{SC}(4)$ & 7 & 6 & 4 & 7 & 4 & 3 & 4 & 1 & 4 & 1 & 0 & 0 & & 41 \\
\hline RS (4) & 9 & 7 & 7 & 7 & 1 & 0 & 1 & 2 & 2 & 0 & 4 & 3 & & 43 \\
\hline C. OEST. & 3.345 & 3.074 & 3.273 & 3.380 & 1.557 & 595 & 217 & 182 & 161 & 235 & 348 & 336 & 494 & 17.197 \\
\hline $\mathrm{MS}$ & 1.105 & 856 & 1.446 & 1.870 & 803 & 313 & 101 & 96 & 59 & 57 & 82 & 45 & & 6.833 \\
\hline MT & 1.711 & 1.780 & 1.261 & 1.048 & 503 & 140 & 40 & 12 & 9 & 9 & 82 & 142 & & 6.737 \\
\hline Go & 428 & 336 & 459 & 390 & 212 & 108 & 49 & 54 & 82 & 153 & 178 & 148 & & 2.597 \\
\hline$D F(5)$ & 101 & 102 & 107 & 72 & 39 & 34 & 27 & 20 & 11 & 16 & 6 & 1 & 494 & 1.030 \\
\hline
\end{tabular}

Forde: FNS E SES.
"Dados provisórios ate a s.e 52.
(3) Foram confirmados 55 casos autoctones.
(5) Foram registrados 27 casos autbctores (2) Més ignorado

(4) Casos importados

CASOS CONFRMADOS DE FEBRE HEMORRAGICA DO DENGUE (FHD) - 2000

\begin{tabular}{|c|c|c|c|}
\hline Estados & Casos & Obitos & \\
\hline Ceará & 2 & 1 & \\
\hline Goiás & 3 & 1 & . \\
\hline Minas Gerais & 2 & 1 & \\
\hline Mato Grosso & $\mathfrak{1}$ & 1 & . \\
\hline Pernambuco & 33 & 0 & \\
\hline Rio de Janeiro & 13 & 0 & \\
\hline Rio Grande do Norte & 6 & 0 & \\
\hline Săo Paulo & 2 & 1 & \\
\hline Total & 62 & 5 & \\
\hline
\end{tabular}

- Ultimo caso registrado na semana epidemrobgica ro 42. 
DENGUE: TOTAL DE CASOS NOTIFICADOS POR MÊS E POR UNIDADE FEDERADA,

BRASIL - 2001 ${ }^{\text {(1) }}$

\begin{tabular}{|c|c|c|c|c|c|c|c|c|c|c|c|c|c|c|c|}
\hline REG/UF & JAN & FEV & MAR & ABR & MAI & JUN & JUL & AGO & SET & OUT & NOV & DEZ & M.Ign.(2) & TOTAL & Soro- \\
\hline BRASIL & 34.804 & 48.470 & 73.073 & 84.153 & 78.713 & 39.237 & 17.257 & 10.531 & 7.994 & 8.903 & 10.022 & 9.447 & 5.513 & 428.117 & \\
\hline NORTE & 14.806 & 10.318 & 5.978 & 3.750 & 2.877 & 2.005 & 1.778 & 1.516 & 1.680 & 1.890 & 2.416 & 2.099 & 2.933 & 54.046 & \\
\hline RO & 713 & 313 & 190 & 89 & 113 & 55 & 22 & 27 & 5 & 41 & 56 & 28 & & 1.652 & 1 \\
\hline$A C$ & 1.539 & 347 & 157 & 98 & 34 & 49 & 18 & 13 & 5 & 14 & 176 & 51 & & 2.501 & 1 e 2 \\
\hline$A M$ & 8.378 & 6.127 & 2.584 & 1.158 & 838 & 300 & 128 & 64 & 37 & 37 & 27 & 149 & & 19.827 & te 2 \\
\hline RR & 1.135 & 627 & 237 & 228 & 208 & 103 & 254 & 234 & 312 & 787 & 718 & 485 & & 5.328 & $1 \mathrm{e} 3$ \\
\hline$P A$ & 1.564 & 1.731 & 1.519 & 1.028 & 467 & 331 & 169 & 106 & 273 & 367 & 562 & 313 & 2.933 & 11.363 & 1 e 2 \\
\hline$A P$ & 25 & 43 & 250 & 402 & 601 & 849 & 980 & 903 & 953 & 430 & 143 & 51 & & 5.630 & 1 \\
\hline TO & 1.452 & 1.130 & 1.041 & 747 & 616 & 318 & 207 & $169^{\circ}$ & 95 & 214 & 734 & 1.022 & & 7.745 & te 2 \\
\hline NORD. & 10.442 & 17.390 & 27.100 & 28.797 & 30.113 & 19.072 & 10.568 & 6.929 & 4.696 & 4.686 & 3.970 & 2.524 & 1.544 & 167.831 & \\
\hline MA & 1.347 & 1.129 & 1.381 & 947 & 1.047 & 461 & 242 & 135 & 96 & 97 & 108 & 80 & & 7.070 & $1 \in 2$ \\
\hline PI & 474 & 1.045 & 1.496 & 1.954 & 2.106 & 1.652 & 759 & 656 & 300 & 255 & 211 & 220 & & 11.128 & 1 e 2 \\
\hline $\mathrm{CE}$ & 2.934 & 4.371 & 7.476 & 7.303 & 8.416 & 6.869 & 4.022 & 2.373 & 1.654 & 2.173 & 1.444 & 764 & & 49.799 & $1 \in 2$ \\
\hline RN & 1.630 & 3.867 & 6.654 & 4.892 & 4.857 & 3.712 & 1.802 & 1.382 & 953 & 536 & 467 & 401 & 1.539 & 32.692 & $1 e 2$ \\
\hline PB & 33 & 266 & 629 & 3.156 & 4.199 & 1.576 & 398 & 57 & 143 & 229 & 215 & 187 & & 11.088 & 1 e 2 \\
\hline$P E$ & 873 & 1.414 & 1.625 & 2.313 & 2.834 & 1.903 & 1.526 & 1.222 & 619 & 530 & 599 & 323 & & 15.781 & $t \in 2$ \\
\hline AL. & 137 & 158 & 359 & 827 & 170 & 103 & 98 & 80 & 89 & 59 & 57 & 27 & & 2.164 & 1 e 2 \\
\hline SE & 263 & 331 & 422 & 585 & 862 & 619 & 531 & 244 & 176 & 193 & 88 & 54 & & 4.368 & ie 2 \\
\hline $\mathrm{BA}$ & 2.751 & 4.809 & 7.058 & 6.820 & 5.622 & 2.177 & 1.190 & 780 & 666 & 614 & 781 & 468 & 5 & 33.741 & te 2 \\
\hline SUD. & 7.121 & 16.809 & 33.220 & 44.674 & 40.165 & 16.662 & 3.996 & 1.454 & 973 & 1.032 & 1.198 & 1.752 & 1.036 & 170.092 & \\
\hline$M G$ & 2.595 & 5.059 & 9.868 & 9.688 & 6.953 & 1.895 & 702 & 339 & 288 & 396 & 610 & 774 & & 39.167 & i e 2 \\
\hline ES & 922 & 1.910 & 3.053 & 2.013 & 1.297 & 785 & 495 & 107 & 100 & 48 & 37 & 50 & & 10.817 & 1 \\
\hline RJ & 2.893 & 7.548 & 11.722 & 17.483 & 15.797 & 7.689 & 2.044 & 864 & 533 & 574 & 532 & 756 & 3 & 68.438 & $1,2 \mathrm{e} 3$ \\
\hline SP (6) & 711 & 2.292 & 8.577 & 15.490 & 16.118 & 6.293 & 755 & 144 & 52 & 14 & 19 & 172 & 1.033 & 51.670 & 1 e 2 \\
\hline SUL & 206 & 567 & 1.217 & 967 & 388 & 113 & 106 & 84 & 73 & 128 & 103 & 153 & 0 & 4.105 & \\
\hline PR & 187 & 536 & 1.188 & 934 & 354 & 93 & 86 & 71 & 63 & 118 & 98 & 141 & & 3.869 & 2 \\
\hline$S C(3)$ & 8 & 17 & 18 & 19 & 21 & 8 & 7 & 5 & 8 & 9 & 5 & 7 & & 132 & \\
\hline RS (3) & 11 & 14 & 11 & 14 & 13 & 12 & 13 & 8 & 2 & 1 & 0 & 5 & & 104 & \\
\hline C. OEST. & 2.229 & 3.386 & 5.558 & 5.965 & 5.170 & 1.385 & 809 & 548 & 572 & 1.167 & 2.335 & 2.919 & 0 & 32.043 & \\
\hline MS & 217 & 644 & 1.712 & 3.070 & 3.178 & 428 & 151 & 118 & 91 & 178 & 359 & 781 & & 10.927 & 1 e 2 \\
\hline MT & 227 & 337 & 464 & 458 & 486 & 224 & 104 & 117 & 86 & 447 & 758 & 823 & & 4.531 & $1 \mathrm{e} 2$ \\
\hline GO & 1.153 & 1.939 & 2.895 & 2.076 & 1.192 & 579 & 371 & 234 & 330 & 466 & 1.145 & 1.310 & & 13.690 & 1 e 2 \\
\hline DF (4) & 632 & 466 & 487 & 361 & 314 & 154 & 183 & 79 & 65 & 76 & 73 & 5 & & 2.895 & te 2 \\
\hline
\end{tabular}

Fonte: FUNASA E SES.

"Dados até a semana 52. Sujeitos à atteraçăo
(2) Més ignorado
(4) Confirmados 203 casos autóctones
(3) Casos imporados
(5) Casos autbctones
(6) Casos autoctones contímados

CASOS CONFIRMADOS DE FEBRE HEMORRÁGICA DO DENGUE (FHD) - 2001*

\begin{tabular}{|c|c|c|}
\hline Estados & Casos & Obitos \\
\hline Bahia & 1 & 0 \\
\hline Ceará & 74 & 7 \\
\hline Goiás & 24 & 1 \\
\hline Pemambuco & 13 & 1 \\
\hline Piaui & 4 & 0 \\
\hline Rio de Janeiro & 425 & 12 \\
\hline São Paulo & 5 & 1 \\
\hline Sergipe & 2 & 0 \\
\hline Tocantins & 2 & 1 \\
\hline Total & 682 & 29 \\
\hline
\end{tabular}

- Útimo caso registrado na semana epidemiologica nº 49 . 
Repüblica Federativa do Brasil Minlstério da Saúde
SINAN

SISTEMA NACIONAL DE AGRAVOS DE NOTIFICACĀO FICHA DE NOTIFICACÃO

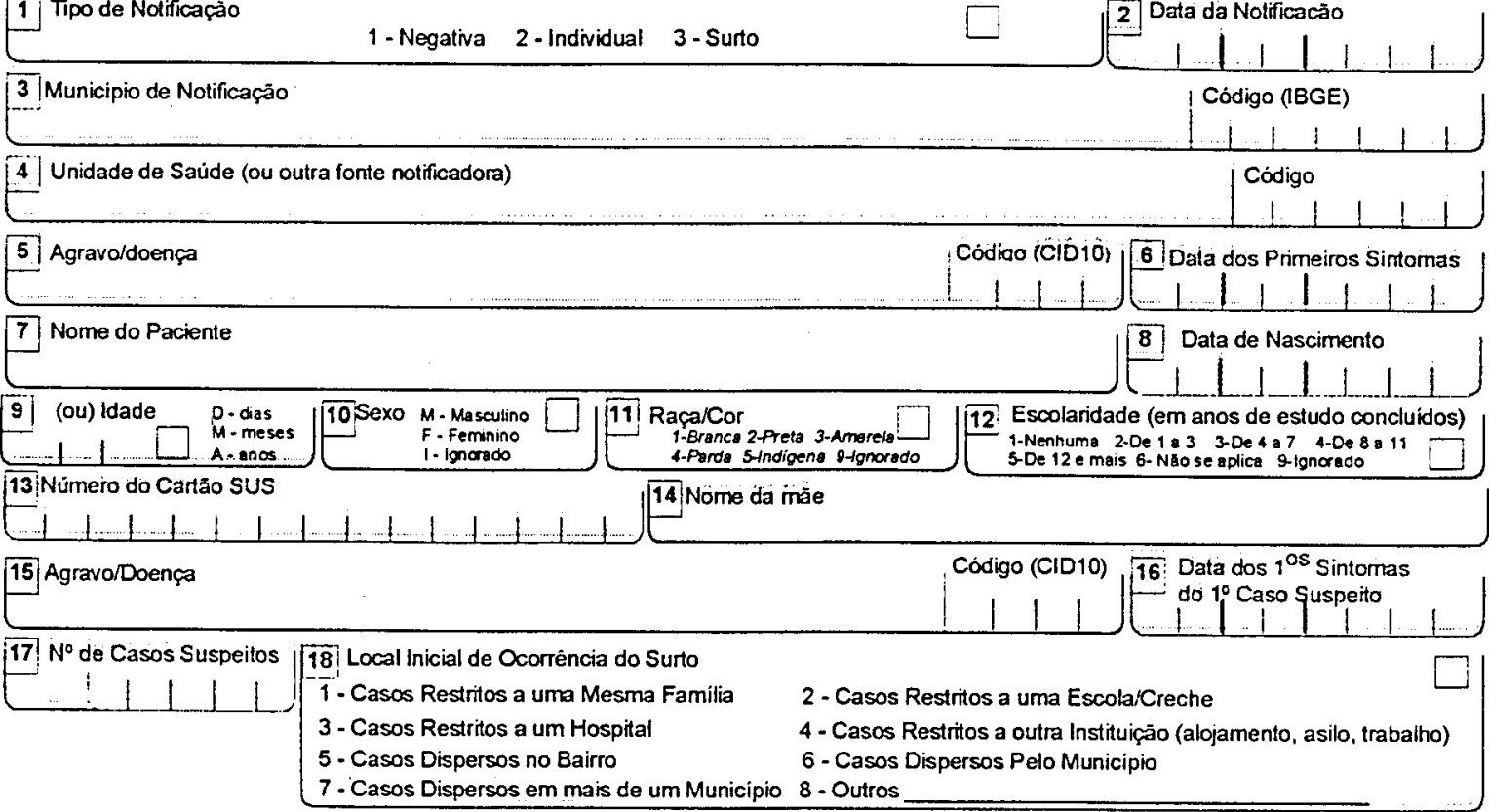

19 Logradouro (rua, avenida

7 - Casos Dispersos em mais de um Municipio 8 - Outros

...)

25 Baimo 
República Federativa do Brasil Ministério da Saúde
SINAN

SISTEMA DE INFORMAGAO DE AGPAVOS DE NOTIFICACAO FICHA DEINVESTIGAGio
$\mathrm{N}^{\circ}$

OENGUE

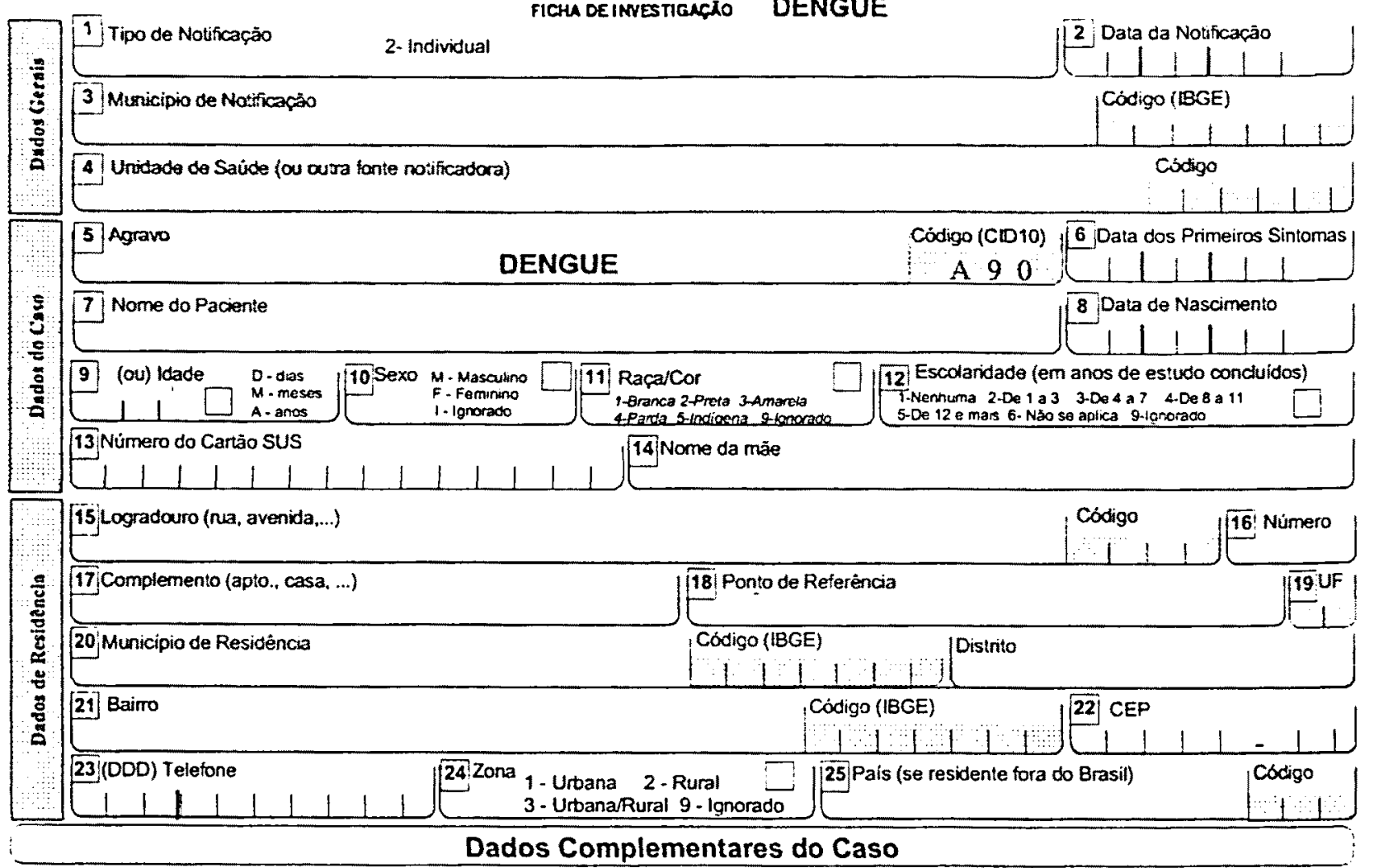

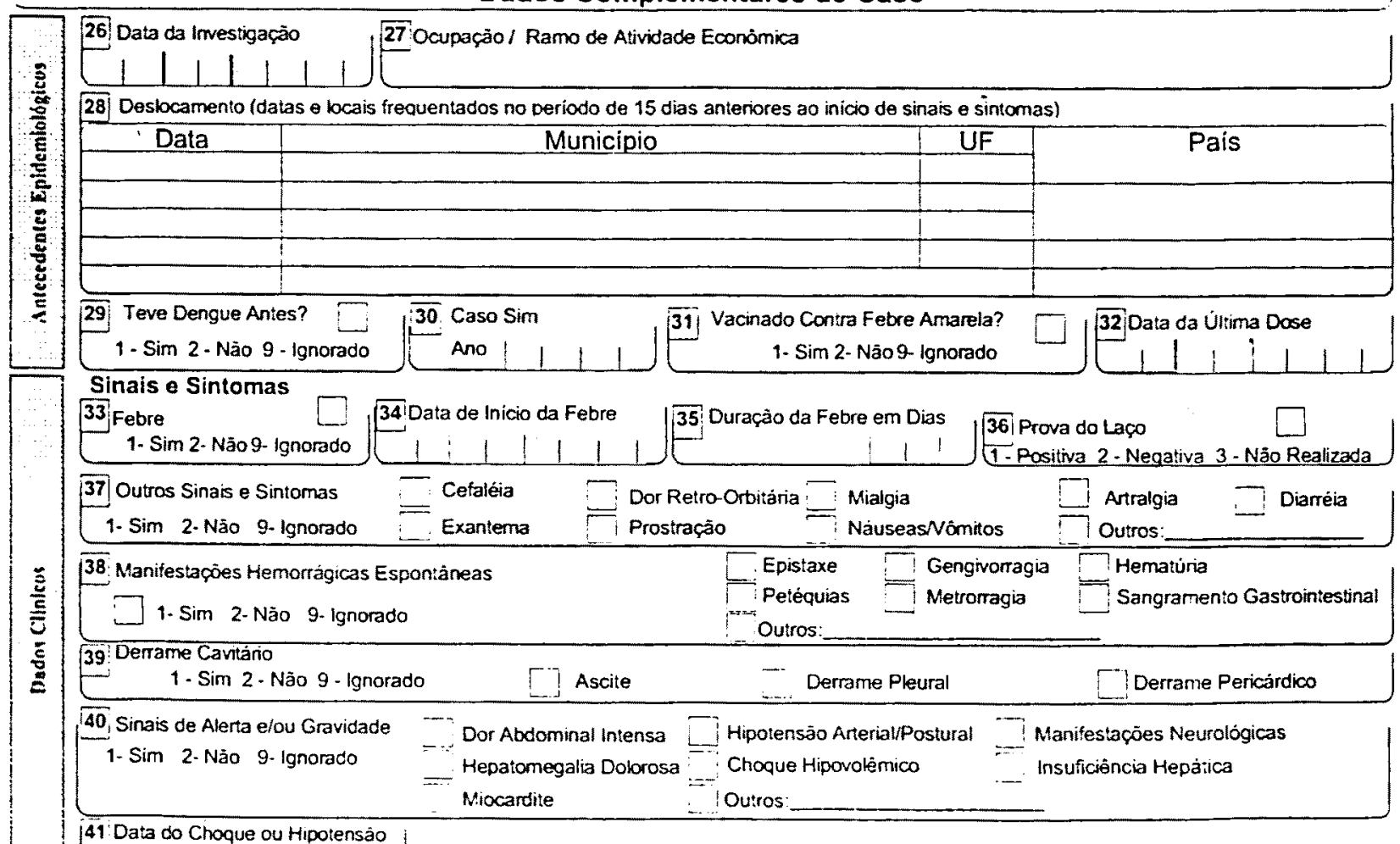




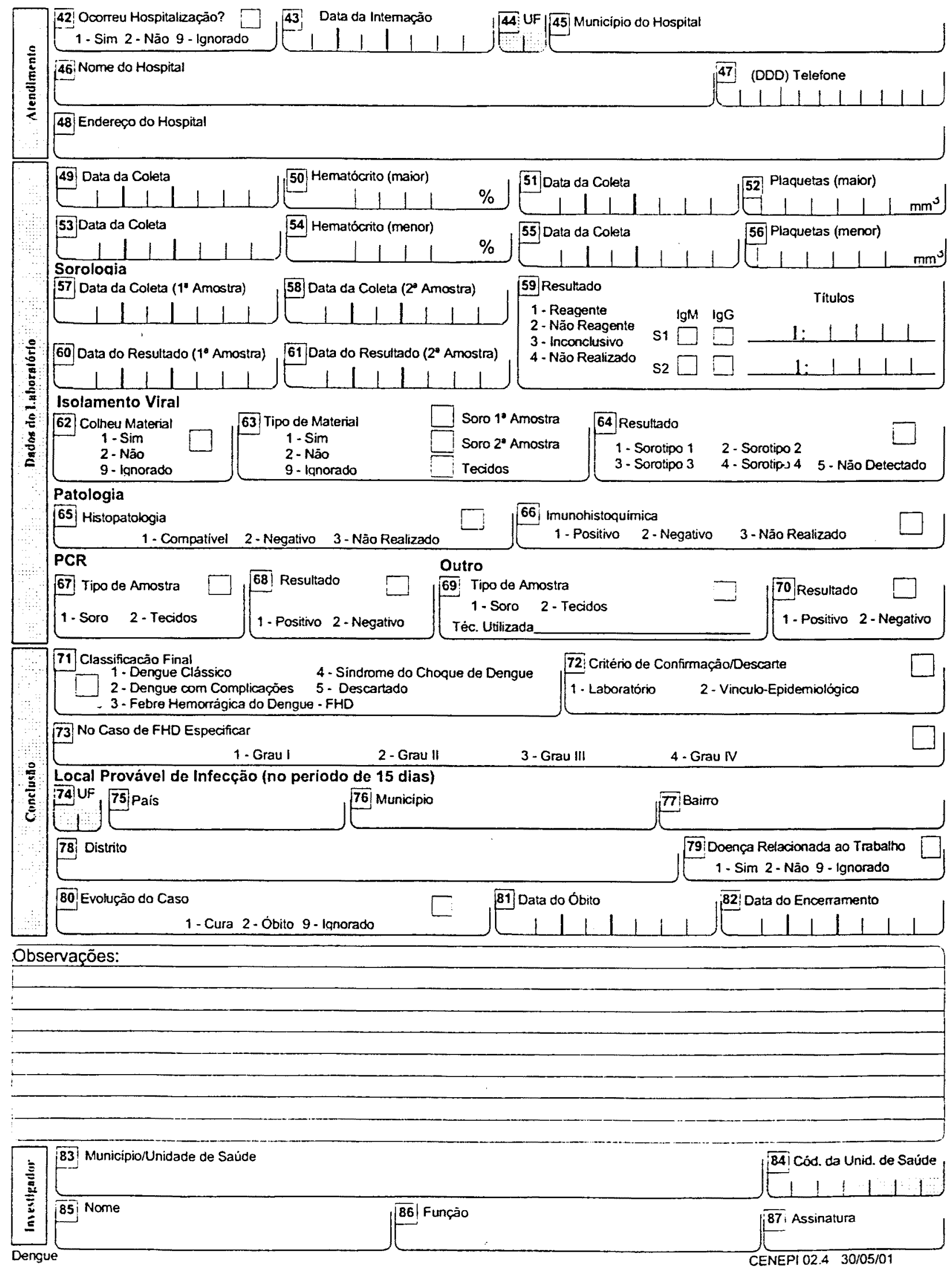


Anexo 7 - Coeficientes de incidência da dengue (casos notificados por 100.000 habs.) por semana epidemiológica. Maceió, 1997 - 2002*

\begin{tabular}{|c|c|c|c|c|c|c|}
\hline $\begin{array}{l}\text { Sem } \\
\text { Epid }\end{array}$ & 1997 & 1998 & 1999 & 2000 & 2001 & 2002 \\
\hline 1 & & 1,043707877 & 0,637009 & 0,250991 & 0,245566 & 0,360033 \\
\hline 2 & 1,740973 & 0,782780907 & 0,509607 & 0,250991 & 0,368349 & 0,960088 \\
\hline 3 & 1,740973 & 3,13112363 & 0,382206 & 0,250991 & 0,491133 & 1,080099 \\
\hline 4 & 0,937447 & 2,870196661 & 0,764411 & 0,250991 & 0,613916 & 2,880264 \\
\hline 5 & 0,267842 & 1,304634846 & 1,146617 & 0,627477 & 0,982265 & 7,680704 \\
\hline 6 & 0,669605 & 2,348342722 & 0,254804 & 0,250991 & 0,736699 & 10,08092 \\
\hline 7 & 0,133921 & 2,348342722 & 0,382206 & 0,125495 & 0,491133 & 5,640517 \\
\hline 8 & 0,267842 & 1,43509833 & 1,146617 & 0,376486 & 0,491133 & 17,28158 \\
\hline 9 & 1,473131 & 1,043707877 & 0,509607 & 1,129459 & - & 30,6028 \\
\hline 10 & 1,607052 & 1,696025299 & 0,637009 & 0,250991 & 0,245566 & 36,24332 \\
\hline 11 & 1,071368 & 2,870196661 & 0,637009 & 0,627477 & 0,736699 & 54,36498 \\
\hline 12 & 1,205289 & 5,479466352 & 0,764411 & 0,501982 & 0,122783 & 46,80429 \\
\hline 13 & 0,937447 & 5,740393321 & 0,509607 & 0,878468 & 0,736699 & 37,44343 \\
\hline 14 & 0,803526 & 10,43707877 & 0,891813 & 0,627477 & 0,491133 & 36,96339 \\
\hline 15 & 1,473131 & 13,69866588 & 1,911028 & 1,003963 & 1,227832 & 36,0033 \\
\hline 16 & 1,205289 & 7,436418621 & 0,637009 & 0,501982 & 0,613916 & 36,12331 \\
\hline 17 & 0,937447 & 6,392710744 & 0,764411 & 1,505945 & 1,105048 & 33,36306 \\
\hline 18 & 0,937447 & 10,04568831 & 0,891813 & 1,003963 & 0,982265 & 27,12248 \\
\hline 19 & 1,071368 & 6,26224726 & 1,146617 & 1,129459 & 1,350615 & 23,28213 \\
\hline 20 & 1,473131 & 10,04568831 & 1,656224 & 0,125495 & 1,596181 & 27,72254 \\
\hline 21 & 1,874894 & 10,04568831 & 2,930242 & 0,752972 & 1,96453 & 28,68263 \\
\hline 22 & 1,740973 & 13,43773891 & 1,911028 & 1,129459 & 0,736699 & 20,88191 \\
\hline 23 & 0,937447 & 6,00132029 & 0,891813 & 0,376486 & 1,718964 & 23,64217 \\
\hline 24 & 0,267842 & 6,784101198 & 0,891813 & 1,003963 & 2,087314 & 17,5216 \\
\hline 25 & 0,267842 & 2,217879238 & 0,637009 & 1,129459 & 1,350615 & 13,32122 \\
\hline 26 & 0,401763 & 2,348342722 & 0,382206 & 1,505945 & 1,227832 & 8,880813 \\
\hline 27 & 0,535684 & 3,13112363 & 0,509607 & 1,129459 & 1,96453 & 11,16102 \\
\hline 28 & 1,071368 & 2,739733176 & 0,891813 & 0,627477 & 0,368349 & 12,36113 \\
\hline 29 & 1,071368 & 1,565561815 & 0,764411 & 1,254954 & 0,982265 & 10,08092 \\
\hline 30 & 1,740973 & 1,174171361 & 0,891813 & 1,254954 & 0,491133 & 9,120835 \\
\hline 31 & 0,937447 & 0,782780907 & 1,019215 & 0,501982 & 1,96453 & 5,640517 \\
\hline 32 & 3,214103 & 0,652317423 & 0,891813 & 2,007926 & 0,982265 & 6,840627 \\
\hline 33 & 2,410578 & 1,043707877 & 0,637009 & 0,627477 & 1,473398 & 5,160473 \\
\hline 34 & 0,669605 & 0,391390454 & 0,509607 & 1,003963 & 1,105048 & 4,320396 \\
\hline 35 & 0,803526 & 0,260926969 & 0,764411 & 0,250991 & 0,982265 & 3,480319 \\
\hline 36 & 1,874894 & $=$ & 0,509607 & 0,501982 & 1,841747 & 1,32012 \\
\hline 37 & 0,937447 & 0,521853938 & 0,764411 & 0,752972 & 1,350615 & \\
\hline 38 & 0,937447 & 0,521853938 & 0,509607 & 0,878468 & 1,473398 & \\
\hline 39 & 1,473131 & 0,521853938 & 0,764411 & 0,376486 & 1,105048 & \\
\hline 40 & 2,008815 & 0,391390454 & 0,509607 & 0,878468 & 0,859482 & \\
\hline 41 & 2,946262 & 0,391390454 & 0,254804 & 0,125495 & 0,613916 & \\
\hline 42 & 2,67842 & 0,260926969 & 0,764411 & 0,627477 & 0,859482 & \\
\hline 43 & 2,812341 & 0,652317423 & 0,254804 & 0,125495 & 0,736699 & \\
\hline 44 & 1,607052 & - & 0,254804 & 0,376486 & 0,368349 & \\
\hline 45 & 2,008815 & 0,652317423 & 1,146617 & 0,501982 & 0,982265 & \\
\hline 46 & 1,205289 & 0,782780907 & 0,254804 & 0,376486 & 1,105048 & \\
\hline
\end{tabular}




\begin{tabular}{lllllll}
\hline 47 & 0,937447 & 0,260926969 & 0,637009 & 0,376486 & 0,122783 & - \\
48 & 0,535684 & 0,782780907 & 0,254804 & - & 0,368349 & - \\
49 & 0,937447 & 1,043707877 & 0,509607 & 0,376486 & 0,245566 & - \\
50 & 0,669605 & 0,260926969 & 0,254804 & 0,125495 & 1,105048 & - \\
51 & 1,071368 & - & 0,127402 & 0,125495 & 1,105048 & - \\
52 & 0,669605 & 0,130463485 & 0,637009 & 0,501982 & 0,491133 & - \\
\hline
\end{tabular}

(*) Dados preliminares até a semana 36. Fonte: SINAN/PROVEP/SESAU-AL 


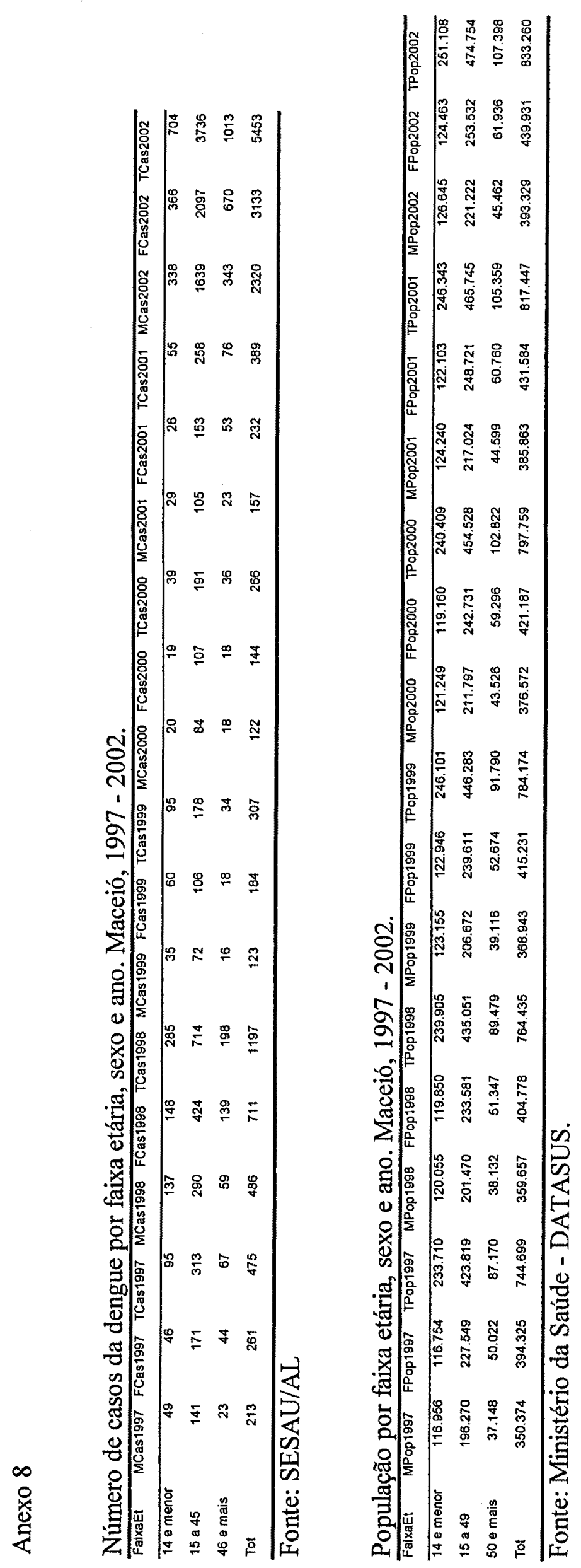




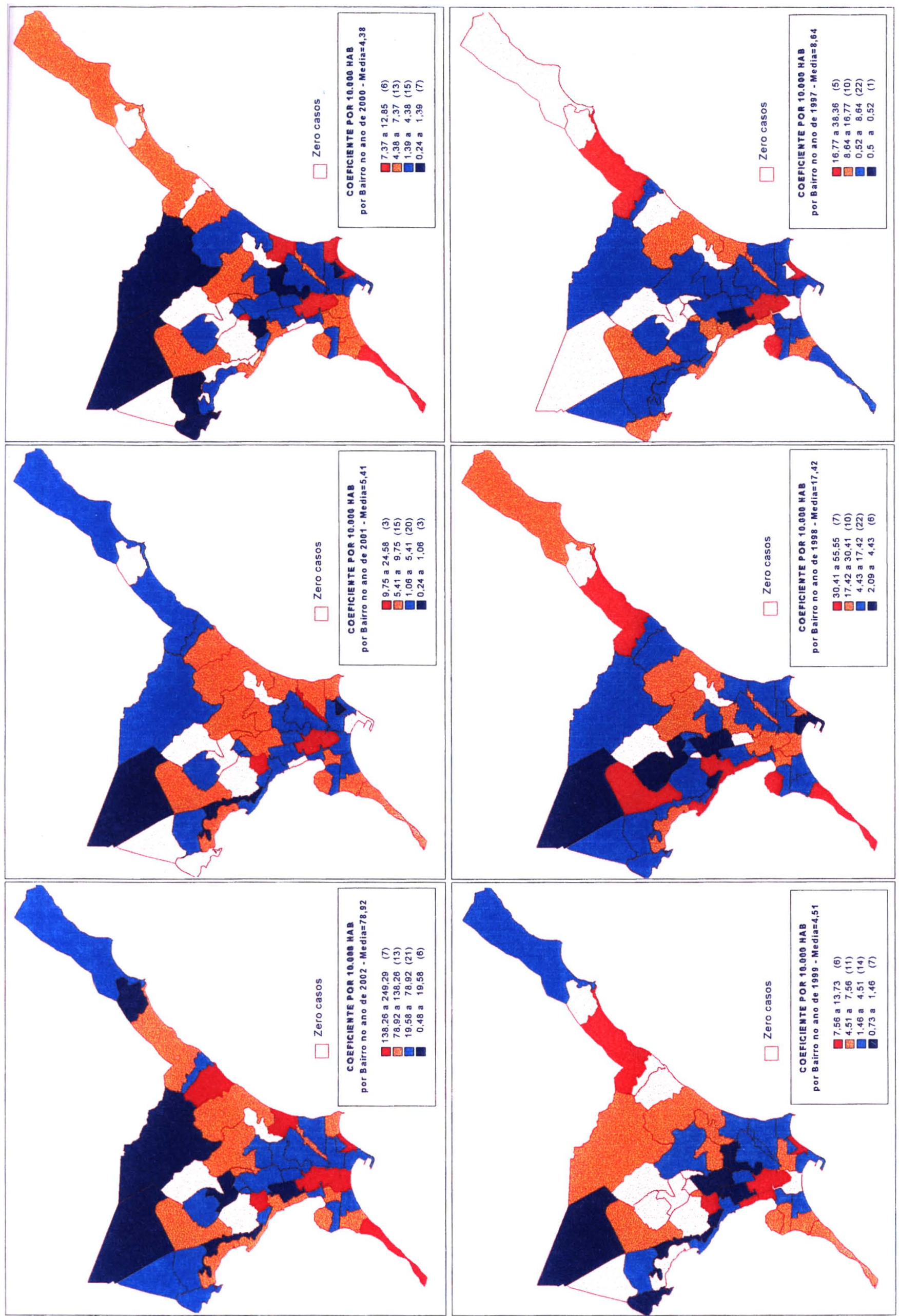




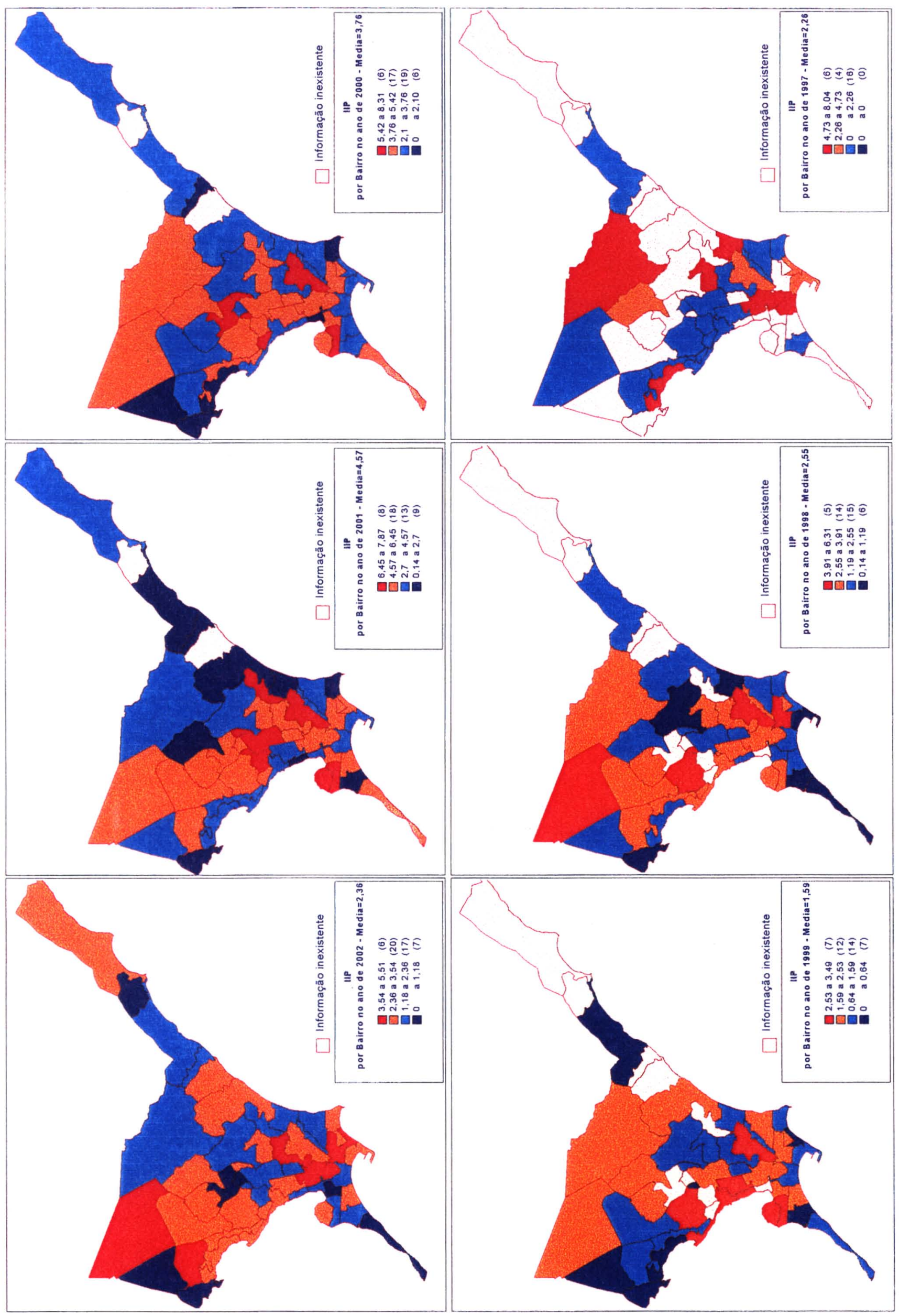


Anexo 11

Coeficientes de incidência da dengue (por 10.000 habs.) por ano. Maceió, 1997 - 2002*

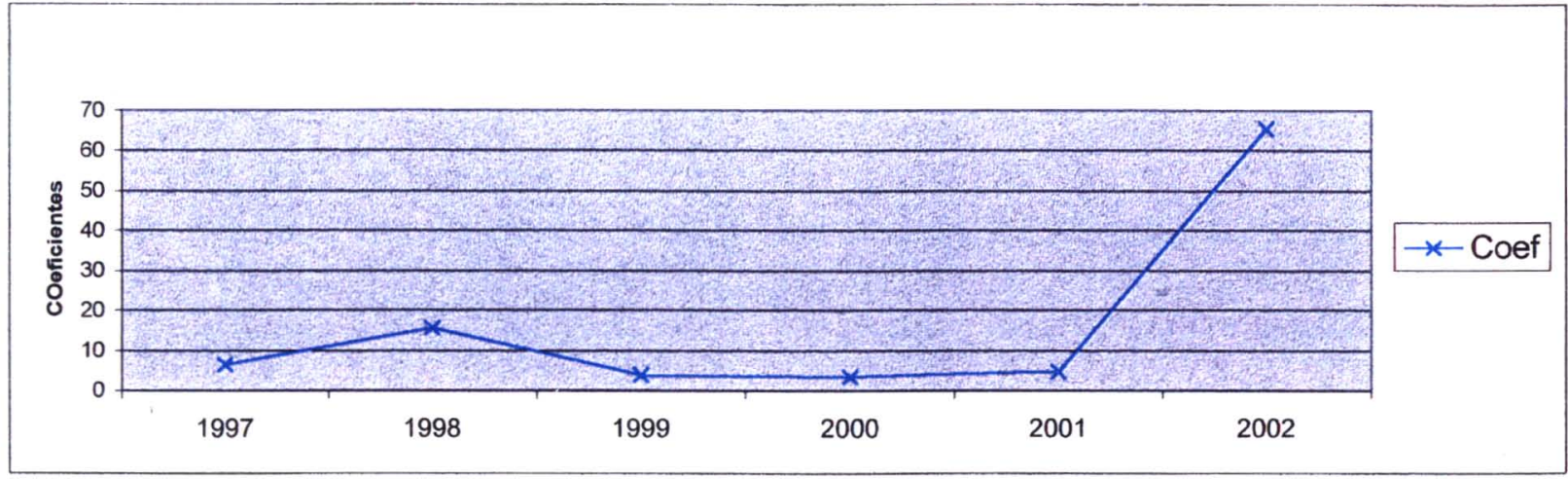

(*) Dados preliminares ate a semana 36 Fonte: SINAN/PROVEP/SESAU-AL 
Anexo 12

Coeficientes de incidência da Dengue (por 1.000.000 habs.) por mês e ano. Maceió, 1997 - 2002*

\begin{tabular}{lrrrrrr}
\hline \multicolumn{1}{r}{$\mathbf{1 9 9 7}$} & $\mathbf{1 9 9 8}$ & $\mathbf{1 9 9 9}$ & $\mathbf{2 0 0 0}$ & $\mathbf{2 0 0 1}$ & $\mathbf{2 0 0 2}$ \\
\hline JAN & $\mathbf{4 4 , 1 9 3 9 2}$ & 80,35259 & 24,10578 & 10,71368 & 18,74894 & 58,92523 \\
FEV & 13,3921 & 76,33496 & 30,80183 & 14,73131 & 29,46262 & 453,9921 \\
MAR & 62,94286 & 172,7581 & 32,14103 & 36,15866 & 20,08815 & 2292,727 \\
ABR & 44,19392 & 389,71 & 44,19392 & 38,83708 & 37,49787 & 1589,642 \\
MAI & 53,56839 & 373,6395 & 69,63891 & 32,14103 & 64,28207 & 1191,897 \\
JUN & 36,15866 & 316,0535 & 49,55076 & 54,9076 & 77,67417 & 940,1253 \\
JUL & 44,19392 & 88,38785 & 32,14103 & 45,53313 & 41,5155 & 476,7587 \\
AGO & 72,31733 & 29,46262 & 32,14103 & 44,19392 & 60,26444 & 245,0754 \\
SET & 60,26444 & 18,74894 & 34,81945 & 29,46262 & 73,65654 & 53,56839 \\
OUT & 104,4584 & 17,40973 & 18,74894 & 18,74894 & 33,48024 & \\
NOV & 57,58602 & 17,40973 & 24,10578 & 17,40973 & 28,12341 & \\
DEZ & 38,83708 & 22,76657 & 18,74894 & 12,05289 & 36,15866 & \\
\hline
\end{tabular}

(*) Dados preliminares até o mês de setembro.

Fonte: SINAN/PROVEP/SESAU-AL 
Anexo 13

Índice de Infestação Predial (x 100) de Aedes aegypti por mês e ano. Maceió, 1997 - 2002*

\begin{tabular}{lrrrrrr}
\hline & $\mathbf{1 9 9 7}$ & $\mathbf{1 9 9 8}$ & $\mathbf{1 9 9 9}$ & $\mathbf{2 0 0 0}$ & $\mathbf{2 0 0 1}$ & $\mathbf{2 0 0 2}$ \\
\hline JAN & 113,00 & 0,00 & 119,00 & 309,00 & 0,00 & 507,00 \\
FEV & 56,00 & 0,00 & 153,00 & 291,00 & 0,00 & 202,00 \\
MAR & 0,00 & 175,00 & 156,00 & 307,00 & 235,00 & 129,00 \\
ABR & 391,00 & 306,00 & 140,00 & 366,00 & 448,00 & 232,00 \\
MAI & 522,00 & 433,00 & 45,00 & 486,00 & 523,00 & 248,00 \\
JUN & 74,00 & 479,00 & 157,00 & 508,00 & 655,00 & \\
JUL & 0,00 & 311,00 & 121,00 & 539,00 & 677,00 & \\
AGO & 0,00 & 224,00 & 22,00 & 478,00 & 534,00 & \\
SET & 170,00 & 140,00 & 63,00 & 461,00 & 467,00 & \\
OUT & 56,00 & 368,00 & 200,00 & 370,00 & 533,00 & \\
NOV & 0,00 & 261,00 & 241,00 & 321,00 & 496,00 & \\
DEZ & 102,00 & 112,00 & 187,00 & 218,00 & 469,00 & \\
\hline
\end{tabular}

(*) Dados preliminares até o mês de maio.

Fonte: FUNASA/SMS-AL 
Anexo 14

Temperatura por mês e ano. Maceió 1997 - 2002*

\begin{tabular}{lrrrrrr}
\hline & 1997 & 1998 & 1999 & 2000 & 2001 & 2002 \\
\hline JAN & 26,2 & 26,9 & 26,5 & 25,6 & 25,7 & 24,4 \\
FEV & 25,4 & 26,7 & 26,2 & 25,7 & 26,1 & 25,4 \\
MAR & 25,9 & 27,3 & 26,3 & 25,6 & 26 & 25,3 \\
ABR & 25,5 & 26,8 & 26,4 & 25,3 & 25,1 & 25,1 \\
MAI & 24,6 & 25,7 & 25,2 & 24,6 & 25,1 & 24,3 \\
JUN & 24,2 & 24,7 & 24,5 & 23,7 & 23,5 & 23,2 \\
JUL & 23,1 & 24 & 23,8 & 23,1 & 23,3 & 23,4 \\
AGO & 23,3 & 23,9 & 23,6 & 23,4 & 23,2 & 23 \\
SET & 24,6 & 24,5 & 23,7 & 23,5 & 24,3 & \\
OUT & 25,5 & 25,1 & 24,4 & 24,2 & 24,7 & \\
NOV & 25,9 & 26,1 & 25,7 & 25,1 & 25 & \\
DEZ & 26,5 & 26,6 & 25,8 & 25 & 24,8 & \\
\hline
\end{tabular}

(*) Dados preliminares até o mês de agosto.

Fonte: INMET - AL 
Anexo 15

Precipitação por mês e ano. Maceió, 1997 - 2002*

\begin{tabular}{lrrrrrr}
\hline & 1997 & 1998 & 1999 & 2000 & 2001 & 2002 \\
\hline JAN & 66,5 & 71,3 & 21,3 & 90,5 & 27,6 & 376,1 \\
FEV & 139,1 & 17,6 & 42,2 & 151 & 16,5 & 91,7 \\
MAR & 116,9 & 23,8 & 49,4 & 136 & 64,4 & 201,7 \\
ABR & 349,8 & 101,3 & 44,9 & 406,2 & 128,8 & 136,9 \\
MAI & 261,2 & 241 & 216,6 & 300,3 & 49,9 & 365 \\
JUN & 168,7 & 162,2 & 208,9 & 235,4 & 460,2 & 401,6 \\
JUL & 309,4 & 193,1 & 232,6 & 394,1 & 271,2 & 146,3 \\
AGO & 128,6 & 181,5 & 137,7 & 300,2 & 195,8 & 176,9 \\
SET & 2,3 & 44,4 & 89,2 & 426,9 & 52 & \\
OUT & 39,7 & 36,6 & 160,1 & 63,4 & 171,8 & \\
NOV & 12,7 & 0,7 & 21,6 & 55,2 & 93,9 & \\
DEZ & 29,6 & 16,3 & 33 & 66 & 115,9 & \\
\hline
\end{tabular}

(*) Dados preliminares até o mês de agosto.

Fonte: INMET - AL 